\title{
Rupture Process of Large Earthquakes in the Northern Mexico Subduction Zone
}

\author{
LARry J. RufF ${ }^{1}$ and Angus D. Miller ${ }^{1,2}$
}

\begin{abstract}
The Cocos plate subducts beneath North America at the Mexico trench. The northernmost segment of this trench, between the Orozco and Rivera fracture zones, has ruptured in a sequence of five large earthquakes from 1973 to 1985: the Jan. 30, 1973 Colima event $\left(M_{s} 7.5\right)$ at the northern end of the segment near Rivera fracture zone; the Mar. 14, 1979 Petatlan event $\left(M_{s} 7.6\right)$ at the southern end of the segment on the Orozco fracture zone; the Oct. 25, 1981 Playa Azul event $\left(M_{s} 7.3\right)$ in the middle of the Michoacan "gap"; the Sept. 19, 1985 Michoacan mainshock $\left(M_{s} 8.1\right)$; and the Sept. 21, 1985 Michoacan aftershock $\left(M_{s} 7.6\right)$ that reruptured part of the Petatlan zone. Body wave inversion for the rupture process of these earthquakes finds the best: earthquake depth; focal mechanism; overall source time function; and seismic moment, for each earthquake. In addition, we have determined spatial concentrations of seismic moment release for the Colima earthquake, and the Michoacan mainshock and aftershock. These spatial concentrations of slip are interpreted as asperities; and the resultant asperity distribution for Mexico is compared to other subduction zones. The body wave inversion technique also determines the Moment Tensor Rate Functions; but there is no evidence for statistically significant changes in the moment tensor during rupture for any of the five earthquakes. An appendix describes the Moment Tensor Rate Functions methodology in detail.

The systematic bias between global and regional determinations of epicentral locations in Mexico must be resolved to enable plotting of asperities with aftershocks and geographic features. We have spatially "shifted" all of our results to regional determinations of epicenters. The best point source depths for the five earthquakes are all above $30 \mathrm{~km}$, consistent with the idea that the down-dip edge of the seismogenic plate interface in Mexico is shallow compared to other subduction zones. Consideration of uncertainties in the focal mechanisms allows us to state that all five earthquakes occurred on fault planes with the same strike (N65 ${ }^{\circ} \mathrm{W}$ to $\mathrm{N} 70^{\circ} \mathrm{W}$ ) and dip $\left(15 \pm 3^{\circ}\right)$, except for the smaller Playa Azul event at the down-dip edge which has a steeper dip angle of 20 to $25^{\circ}$. However, the Petatlan earthquake does "prefer" a fault plane that is rotated to a more east-west orientation-one explanation may be that this earthquake is located near the crest of the subducting Orozco fracture zone. The slip vectors of all five earthquakes are similar and generally consistent with the NUVEL-predicted Cocos-North America convergence direction of $\mathrm{N}^{\circ} 3^{\circ} \mathrm{E}$ for this segment. The most important deviation is the more northerly slip direction for the Petatlan earthquake. Also, the slip vectors from the Harvard CMT solutions for large and small events in this segment prefer an overall convergence direction of about $\mathrm{N} 20^{\circ} \mathrm{E}$ to $\mathrm{N} 25^{\circ} \mathrm{E}$.

All five earthquakes share a common feature in the rupture process: each earthquake has a small initial precursory arrival followed by a large pulse of moment release with a distinct onset. The delay time varies from $4 \mathrm{~s}$ for the Playa Azul event to $8 \mathrm{~s}$ for the Colima event. While there is some evidence of spatial concentration of moment release for each event, our overall asperity distribution for the northern Mexico segment consists of one clear asperity, in the epicentral region of the 1973 Colima earthquake, and then a scattering of diffuse and overlapping regions of high moment release for the
\end{abstract}

\footnotetext{
${ }^{1}$ Department of Geological Sciences, University of Michigan, Ann Arbor, MI 48109, U.S.A.

${ }^{2}$ Now at: The University of Durham, Durham, England.
} 
remainder of the segment. This character is directly displayed in the overlapping of rupture zones between the 1979 Petatlan event and the 1985 Michoacan aftershock. This character of the asperity distribution is in contrast to the widely spaced distinct asperities in the northern Japan-Kuriles Islands subduction zone, but is somewhat similar to the asperity distributions found in the central Peru and Santa Cruz Islands subduction zones. Subduction of the Orozco fracture zone may strongly affect the seismogenic character as the overlapping rupture zones are located on the crest of the subducted fracture zone. There is also a distinct change in the physiography of the upper plate that coincides with the subducting fracture zone, and the Guerrero seismic gap to the south of the Petatlan earthquake is in the "wake" of the Orozco fracture zone. At the northern end, the Rivera fracture zone in the subducting plate and the Colima graben in the upper plate coincide with the northernmost extent of the Colima rupture zone.

Key words: Earthquake rupture process, asperities, moment tensor rate functions.

\section{Introduction}

\subsection{Large Earthquakes and Tectonics along the Mexico Subduction Zone}

The Cocos plate subducts beneath North America at the Mexico subduction zone. While this subduction zone has most of the features expected for subduction beneath a continent, it also has several unusual characteristics. There is a high level of shallow seismicity along the entire $1,000 \mathrm{~km}$ length of the zone, but a deep Wadati-Benioff zone is not present as the subducted plate apparently underplates the Mexico lithosphere. The associated volcanic arc is somewhat unusual as the trench-volcano distance varies from $200 \mathrm{~km}$ at the northern end of the subduction zone to more than $300 \mathrm{~km}$ toward the southern end of the Cocos-North America subduction zone. Subduction is characterized by the occurrence of large to great underthrusting earthquakes ( $M_{s}$ of 7 to 8 ), with a relatively short recurrence time of 30 years (RIKITAKE, 1976; MCNALly and MinsTER, 1981). On a global basis, the characteristic largest earthquakes in Mexico of about magnitude 8 are smaller than "expected" (see RUFF and KANAMORI, 1983a). Compared to other subduction zones that subduct young lithosphere with a fast convergence rate, the plate contact interface in Mexico is apparently segmented into shorter rupture lengths. RUFF (1989a) speculated that a trench environment relatively devoid of sediments, such as the Mexico trench, might result in shorter along-trench seismic segments. BYRNE $e t$ al. (1988) emphasize the role of sediments in determining the up-dip edge of the seismogenic plate interface. Perhaps the lack of sediments in Mexico may allow the coupled zone to extend close to the trench axis. TichelaAR and RUFF (1993) recently completed a global survey of the depth of the down-dip edge of the seismogenic plate interface in subduction zones. They show that the Mexico subduction zone is anomalous: while the depth of coupling in most subduction zones is about $40 \pm 5 \mathrm{~km}$, the down-dip edge of coupling in Mexico is just $25 \pm 5 \mathrm{~km}$. Although TICHELAAR and RUFF (1993) note that the shallow coupling 
depth may be related to the "small" size of Mexico earthquakes, there is no clear reason why depth extent of coupled interface would determine the along-trench seismic segmentation.

Although the Mexican earthquakes may be smaller than "expected," earthquakes such as the recent Michoacan earthquake of Sept. 19, $1985\left(M_{s} 8.1\right)$ still represent terrible natural catastrophes. The Michoacan earthquake has undergone many studies, including detailed modern rupture process studies. In contrast, many of the earlier Mexico events have not undergone modern rupture studies. Figure 1 shows the northern segment of the Mexico subduction zone between the CocosNorth America-Rivera plates triple junction to the north, and the Orozco Fracture Zone and the Guerrero seismic gap to the south (see SINGH and MORTERA, 1991). Five large earthquakes have ruptured this subduction zone segment since 1973. All five earthquakes have focal mechanisms determined from long-period surface waves. Chael and Stewart (1982) determined a time function of the 1979 event by forward modeling of body waves. SiNGH and MorTera (1991) show time functions for all five events as part of their study to examine the older pre-1963 events. Harvard CMTs (see DzIEWONSKI and WoOdHouse, 1983) are available for four of the five events. As mentioned above, the 1985 mainshock received several rupture process studies (e.g., see Ekström, 1989; MendozA and Hartzell, 1989; MeNDEZ and ANDERson, 1991; YomogidA, 1988). However, the large aftershock of the Michoacan event, on Sept. 21, 1985 has not received as much attention (MENDOZA, 1993). One curious feature is that the 1985 aftershock is similar in size

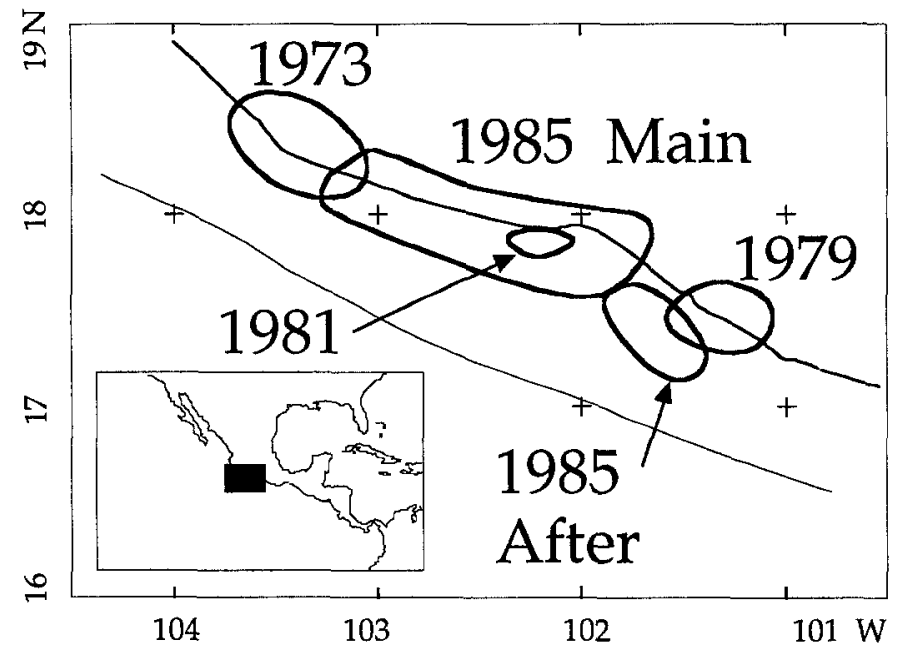

Figure 1

Base map of the northern Mexico subduction zone segment. Aftershock areas of the five large earthquakes (from UNAM, 1986), are shown with years of occurrence. Cocos plate subducts to the northeast beneath North America; the trench axis is plotted to the southwest of the rupture zones. The Mexico coastline is also shown. These basic features are plotted for reference in the following maps. 
to the 1979 Petatlan event, but is apparently located up-dip of the 1979 event. Similar to other large events along the Mexico subduction zone, the 1979 event had an extensive foreshock sequence (GETTRUST et al., 1981). VALDES et al. (1982) show the detailed aftershock distribution of the 1979 event. REYES et al. (1979) conducted a special study of the 1973 Colima earthquake and associated seismicity. Given the basic interpretation that the Colima event is a subduction event, it is odd that the fault plane of their focal mechanism has a very steep dip of $30^{\circ}$, and the strike is $330^{\circ}$, more northerly than the trench strike. Even more strange is the fact that CHAEL and STEWART (1982) used the surface wave data from REYES et al. (1979), but they found a fault plane with an EW strike of $266^{\circ}$. Since the 1973 Colima earthquake is the northernmost large earthquake of the Cocos-North America plate interaction, an EW fault plane would have had major tectonic implications. Thus, it is important to reexamine the focal mechanism for the 1973 Colima earthquake. Of the five large events that we will consider, the 1981 Playa Azul earthquake has the smallest magnitude $\left(M_{s} 7.3\right)$ and aftershock area (HASKOV et al., 1983). However, it is an interesting event because it occurred in the middle of the Michoacan gap four years before the 1985 event. Most rupture process studies of the 1985 mainshock conclude that the 1981 event ruptured the zone between two dominant asperities of the 1985 mainshock.

Earthquake slip vectors in subduction zones are used to determine relative plate motions. The NUVEL model (DEMETs et al., 1990) is the most recent global plate tectonic model, and the NUVEL data set includes many slip vectors from Harvard CMT solutions (see DzIEwONSKI and WoodHOUSE, 1983, for a description of the method, and the ISC bulletins for specific solutions). Overall, the Harvard CMTs are quite reliable; thus it is a curious observation that the Harvard CMT slip vectors for large earthquakes in northern Mexico seem to be systematically biased with respect to the NUVEL-predicted convergence direction. This observation motivates a reexamination of the moment tensors and focal mechanisms of the large events in Mexico.

The Orozco fracture zone subducts within the northern Mexico segment. The rupture zone of the 1985 Michoacan mainshock appears to straddle the down-dip extension of this fracture zone. Thus, another motivation to study these earthquakes is to see the effects of fracture zone subduction. The overall strike of the northern Mexico trench axis is about $295^{\circ}\left(\mathrm{N} 65^{\circ} \mathrm{W}\right)$, but there is a subtle change from $290^{\circ}$ to the south of the Orozco fracture zone to about $300^{\circ}$ to the north. We will look for variations in the fault geometry that may be associated with the Orozco fracture zone.

\subsection{Asperity Distributions}

Rupture process studies of large and great earthquakes have either speculated or concluded that the "asperity distribution" along the plate interface controls the size of earthquakes (e.g., LAY et al., 1982: RUFF and KANAMORI, 1983b; SCHWARTZ 
and RufF, 1987; RuFF, 1989a; BeCK and RufF, 1989; BECK and Christensen, 1991; RUFF, 1992a). Many other rupture process studies of individual earthquakes have also referred to subregions of higher moment release as asperities. In the observational perspective of the above work, "asperities" are subregions of the rupture area that slip more than the average slip of the largest earthquake to break the plate boundary. In some rare cases, some arguments can be made that the "asperities" remained locked since the previous large earthquake (see BECK and RUFF, 1985). In a theoretical study, MADARIAGA (1977) showed that the simple mechanical interpretation of asperities as locked zones surrounded by freely slipping zones could result in coseismic moment release similar to some of the above observational results. KANAMORI (1981) provided a simple mechanical definition of asperities as regions of higher failure strength that he related to some aspects of seismicity during the seismic cycle. The above "asperity model" has evolved to become the asperity/barrier model (see BECK and RUFF, 1985; RUFF 1989a) where allowance is made for "geometric barriers" in the plane interface that can significantly affect the details of seismic wave radiation (see discussions of barrier model in DAS and AKI, 1977; AKI, 1979). The asperity/barrier model is most commonly described as the asperities having a higher failure stress level than the surrounding weaker regions, and it also assumed that there is an associated slip deficit at the asperities before the large earthquake (e.g., RUFF, 1989a). Since most subduction zones must have some fraction of aseismic slip in the plate interface, perhaps the most precise statement that can be made about the "weaker" regions is that aseismic slip is concentrated there over the seismic cycle. Unfortunately, various descriptions of the asperity model have not been completely self-consistent, nor have they been completely precise on the mechanical behavior of the plate interface. Scholz (1990) offers a connection between the "asperity model" and theoretical concepts of the mechanical behavior of the plate interface. To return to the practical perspective of rupture process studies, we still define "asperities" as those subregions with larger coseismic slip in the largest earthquake. Many tests of the asperity model require determination of adjacent asperities along the subduction zone, i.e. the asperity distribution (e.g. RUFF, 1992a). To find the asperities, several large adjacent earthquakes must occur in the recent few decades to allow rupture process studies. The sequence of recent large earthquakes in the northern segment of the Mexico subduction zone (Fig. 1) provides the opportunity to add one more example to the global "catalog" of asperity distributions along subduction zone segments.

The scientific goals for this study can be summarized as follows: a systematic study of the rupture processes of the earthquakes; a detailed comparison of the slip vectors of these large Mexican earthquakes and the predicted slip directions from the NUVEL model (DEMETS et al., 1990); a teleseismic "view" of moment release and asperity distribution along the Mexico subduction zone; is there anything unusual about the 1981 event to indicate that it was an intra-asperity precursor; and, a seismotectonic comparison of the asperity distribution. 


\section{Body-wave Inversion for Earthquake Source Process}

Progress in our understanding of earthquakes follows from the systematic determination of source parameters. While everyone acknowledges the complexity of earthquakes, only certain integral properties of the earthquake source can be reliably determined. The progression in source parameter determination has recently included the moment tensor (e.g., DzIEWONSKI and WoODHOUSE, 1983; SIPKIN, 1986a). The moment tensor gives the overall integral measure of earthquake size and faulting geometry. Moment tensors for earthquakes larger than magnitude 5 or so are now routinely listed in the NEIC and ISC global catalogs.

To return to the issue of earthquake complexity, rupture process studies seek to determine some spatial-temporal features of the moment release on the fault plane. Rupture process studies require special effort because resolution of spatial variations in moment release is quite difficult. For most earthquakes that occur in the world, the most detailed study of the source process can only determine the various "point source" parameters. Use of point source parameters does not mean that the earthquake is a point source, it means that we are describing the earthquake by integrals over the spatial variations in moment release. An example of a point source parameter is the moment tensor. Another example is the overall source time function, i.e., moment rate function, which can be deconvolved from body wave seismograms if the moment tensor is known.

Moment Tensor Rate Functions (MTRFs) are the most general description of a seismic source with no explicit spatial variations in moment release. The MTRFs include the moment tensor and source time function as specializations. The MTRF description of an earthquake allows the moment tensor to vary arbitrarily as a function of time. This variability could represent changes in faulting geometry during the rupture process. Alternatively, it could represent the simultaneous rupture of two or more different faulting geometries. Since there is a linear connection between seismograms and the MTRFs, the determination of the MTRFs is a linear inverse problem. Several investigators have taken advantage of this desirable characteristic (e.g., STUMP and JoHnson, 1977; SIPKIN, 1986b; VASCO, 1989; RUFF and TICHELAAR, 1990). The primary problem with MTRFs is what to do with them after finding them. Most seismologists, while acknowledging the complexity of each earthquake, take the reasonable scientific approach that we should seek to determine the fewest number of earthquake parameters that will still provide an adequate explanation of the data. Thus, we should try to represent an earthquake by just one moment tensor and one time function, if possible. The full MTRF description should be kept only if the data "demand" a time-varying focal mechanism. The quantitative implementation of the above idea is tricky because extraction of a moment tensor and time function from the MTRFs is perceived to be a nonlinear inverse problem. Furthermore, due to errors and incompatibilities in the observed seismograms, inversion for the MTRFs always produces a time-vary- 
ing moment tensor, thus some statistical test must be applied to the results to determine if the focal mechanism variations are significant. Thus, given the MTRFs, there are two questions to be answered: (1) how to extract the "best" moment tensor and time function from the MTRFs, and (2) how to assess whether a single moment tensor and time function are a statistically adequate representation of the earthquake? This paper answers the above two questions with a technique that may be systematically applied to earthquakes with magnitudes from 6 to 7.5 or so. The details are given in the appendix, here we only need to consider a single statistical parameter, $\zeta$ or the "MTRF parameter," that tells us if the MTRFs can be replaced by a single moment tensor and time function. If $\zeta$ is close to or less than 1 , then the earthquake can be represented by a single moment tensor during the rupture process. Applications shown in this paper are for important and interesting earthquakes in the Mexico subduction zone.

The following sections give a brief overview of the body-wave inversion techniques that we use to find: the MTRFs (Moment Tensor Rate Functions); the best focal mechanism and time function; an image of the rupture process; calculation of radiated wave energy; and relative location of epicenters and rupture process features. Most of the details can be found in other papers, with the exception of the MTRF inversion and subsequent extraction of the best moment tensor and time function. These details are given in the Appendix.

\subsection{Overview}

Seismic source theory and elastodynamics provide a complete description of any internal source that generates seismic waves (see AKI and RICHARDS, 1980). The displacement along the $i$ th direction observed at some location, denoted by $\Omega$, is a convolution of the Green's functions with the source functions, over all components of the moment tensor, and integrated over the entire source volume:

$$
u_{i}(t, \Omega)=\iiint_{V} G_{i j, k}(t, \Omega, V) * m_{j k}(t, V) d V
$$

where $G_{i j}$ are the Green's functions that depend on time $(t)$, receiver location $(\Omega)$, and position within the source volume $(V) ; *$ denotes convolution with respect to time; and the seismic source is described by $m_{j k}(t, V)$, the moment tensor density functions that vary in time and space across the source volume. A key property of seismic source theory is that there is a linear connection between the source description and the observed wave displacements, hence the inverse is linear. Equation (1) is the most general description - several reductions must be made before we have an expression useful for applications. Also, seismologists have discovered that the Green's functions for certain parts of the seismograms can be reliably constructed. For example, teleseismic body waves have fairly simple 
Green's functions that offer minimal distortion of the source time history. Let us make the first specialization of Eq. (1) by assuming that $u_{i}(t, \Omega)$ will be a teleseismic $P$ - or $S$-wave seismogram, now denoted by $s_{i}(t, \Omega)$,

$$
s_{i}(t, \Omega)=\iiint_{V} g_{i j, k}(t, \Omega, V) * \dot{m}_{j k}(t, V) d V
$$

where $g_{i j}$ are modified versions of $G_{i j}$ that now include the seismographic instrument response and attenuation effects, plus reflected phases for shallow earthquakes; and $\dot{m}_{j k}(t, V)$ are now the moment tensor rate density functions. A completely general source description is retained in Eq. (2). However, unless the source region is quite large, the observed seismograms will be unable to resolve any spatial variation in the moment release. As discussed by many previous investigators (e.g, AKI and RICHARDS, 1980; RUFF, 1987), resolution of spatial variations in moment release depends on the combination of good distribution of stations about the source and precise temporal resolution of coherent features across the stations. An approximate measure of horizontal spatial resolution is $T / p$, where $p$ is the ray parameter in s/ $\mathrm{km}$ for $P$ or $S$ waves, and $T$ is the shortest period of temporal coherence across seismograms. Optimistic values of $p$ and $T$ would be $p=0.10 \mathrm{~s} / \mathrm{km}$ and $T=1 \mathrm{~s}$, while pessimistic values might be $p=0.05 \mathrm{~s} / \mathrm{km}$ and $t=3 \mathrm{~s}$. Consequently, for earthquakes with fault zones that are smaller than 10 to $60 \mathrm{~km}$, teleseismic waves can only resolve fault-averaged source properties. The above fault dimensions translate into earthquake magnitudes as large as 7 to 7.5 for underthrusting subduction events. Thus for certain circumstances, even large subduction earthquakes may be "seen" as a point source by teleseismic waves. It may sometimes be desirable to treat an earthquake as a point source even if spatial resolution is available in the recorded seismograms. This is easily accomplished by filtering the seismograms to remove the higher frequencies. When the seismograms consist of wave periods substantially longer than the directivity time shifts, then the earthquake can be modeled as a point source.

Directivity time shifts appear in the seismograms due to the travel-time shifts in $g_{i j}$ across the fault zone (see AKI and RICHARDS, 1980; or RUFF, 1983). When these directivity time shifts cannot be resolved in the recorded seismograms, then the Green's functions can be taken outside the integral over the source region. Thus, we rewrite $g_{i j}(t, \Omega, V)$ as $g_{i j}\left(t, \Omega, V_{0}\right)$, where $V_{0}$ implies that we evaluate $g_{i j}$ at a specified fixed location within the source region. Two reasonable choices are the hypocenter or centroid locations. To retain a completely linear formulation, the hypocentral location is used. Thus, Eq. (2) becomes

$$
s_{i}(t, \Omega)=g_{i j, k}\left(t, \Omega, V_{0}\right) * \iiint_{V} \dot{m}_{j k}(t, V) d V .
$$

We now see that the seismograms can only see the spatial integration of $\dot{m}_{j k}$. Define 
the Moment Tensor Rate Functions (MTRFs) as this integral

$$
\dot{M}_{j k}(t)=\iiint_{V} \dot{m}_{j k}(t, V) d V .
$$

Equation (3) then becomes

$$
s_{i}(t, \Omega)=g_{i j, k}\left(t, \Omega, V_{0}\right) * \dot{M}_{j k}(t) .
$$

The basic units of $\dot{M}_{j k}$ are moment rate, each function gives the time history of moment rate of a particular moment tensor component. The above development shows that the MTRFs represent the spatial integration of moment release throughout the source volume, which could even contain a network of faults. Since the only restriction to go from Eq. (2) to Eq. (5) is the lack of resolution of spatial variations, the MTRFs are the most general "point source" description of an earthquake. They allow the source to display arbitrary changes in the moment tensor as a function of time. Of course, there is still a direct linear connection between the seismograms and the MTRFs, thus the inverse problem allows full use of linear inverse methodology, including calculation of the model covariance matrix.

\subsection{A priori Reduction to Moment Tensor and Time Function}

Most seismological investigators have further reduced Eq. (5). Recall that the MTRFs contain both faulting geometry and time history information, hence the reductions typically emphasize one source aspect or the other. If we use wave periods that are longer than the source duration, then we cannot distinguish the time history of the source. For this case, we can characterize the time history of all MTRFs by a single source time function, $f(t)$, and the MTRFs are reduced to

$$
\dot{M}_{j k}(t) \Rightarrow M_{j k} f(t)
$$

where $f(t)$ has units of $1 /$ time, such that $\int f(t) d t=1$. The simplest a priori choice for $f(t)$ is the delta function, though one could use a more complicated time function, if desired. Substitute (6) into (5) to find:

$$
s_{i}(t, \Omega)=\left[g_{i j, k}\left(t, \Omega, V_{0}\right) * f(t)\right] M_{j k}
$$

where the functions in the bracket are specified a priori. We see from Eq. (7) that when the coherent wave periods are longer than the total source duration, the moment tensor is the remaining source characteristic.

Suppose that we have a good estimate of $M_{j k}$ from long-period surface waves; then we can estimate $f(t)$ from body waves. In this case, Eq. (7) becomes

$$
s_{i}(t, \Omega)=\left[g_{i j, k}\left(t, \Omega, V_{0}\right) M_{j k}\right] * f(t)
$$

where the function in the bracket is specified a priori. Based on Eq. (8), we can deconvolve the source time function from a single seismogram, or simultaneously 
from several seismograms. In some cases, seismologists wish to determine both the moment tensor and the source time function from Eq. (7). Unfortunately, the reparameterization of the source description from $\dot{M}_{j k}(t)$ to $\left(M_{j k} f(t)\right)$ now makes the simultaneous estimation of $M_{j k}$ and $f(t)$ a nonlinear inverse problem. One can assume an initial simple $f(t)$ and then linearly invert for $M_{j k}$. Then one can seek changes to $f(t)$ and $M_{j k}$ that reduce the error between observed and synthetic seismograms (e.g., BARKER and LANGSTON, 1981; NABELEK, 1984). Recall that the source description is fundamentally a linear inverse problem; the above nonlinear problems result from the reparameterization of the source description to reduce the five functions of MTRFs to the product of five numbers and one function. The number of unknowns is less, but the inverse problem is more burdensome, and formal error estimates are not possible. The methodology that we follow employs linear inversion to obtain the MTRFs, and then tests whether or not the MTRFs can be reduced to a single moment tensor and time function (see Appendix).

\subsection{Inversion for Spatial Variations in Moment Release}

If we think that we can resolve information about the spatial distribution of moment release from our collection of seismograms, then we must return to Eq. (2). If one is willing to invert an underdetermined linear system, then the integral of Eq. (2) can be discretized, and various methods will give some results for the space and time variable moment tensor rate density functions. On the other hand, any a priori information that we can incorporate into the problem would allow us to reduce the number of unknowns and solve a better posed inverse problem. One of the most useful reductions is to assume that we know the focal mechanism of the earthquake. While there are many examples of changes in focal mechanism during earthquakes, it is typically assumed that large subduction earthquakes rupture with a nearly constant focal mechanism. With this assumption, we need not invert for the five components of the moment tensor at each space-time grid point, we only need to invert for the displacement rate. Thus, Eq. (2) becomes

$$
s_{i}(t, \Omega)=\iiint_{V}\left[M_{j k} g_{i j, k}(t, \Omega, V)\right] * \dot{m}(t, V) d V .
$$

The next most useful simplification is to realize that the waveshape of Green's functions for teleseismic waves does not vary significantly in the horizontal direction across the fault plane, except for the relative travel time $\left(T(V)-T_{0}\right)$. Since underthrusting earthquakes are characterized by fault planes with small dips, the change in hypocentral depth across the rupture area is small for many earthquakes. Thus, under these conditions (see AKI and RichARDS, 1980; RUFF, 1983, 1987; for details) we can rewrite Eq. (9) as

$$
s_{i}(t, \Omega)=\left[M_{j k} g_{i j, k}\left(t-T_{0}, \Omega, V_{0}\right)\right] * \iiint_{V} \dot{m}\left(t-\left(T(V)-T_{0}\right), V\right) d V .
$$


If we further assume that the moment release is concentrated along one direction, say the $x$ direction with its directivity parameter $\Gamma$, then Eq. (10) can be reduced to

$$
s_{i}(t, \Omega)=\left[M_{j k} g_{i j, k}\left(t-T_{0}, \Omega, x_{0}\right)\right] * \int_{x_{\min }}^{x_{\max }} \dot{m}(t-\Gamma x, x) d x .
$$

The above approximation is quite useful for strike-slip earthquakes, and can be used for large underthrusting events that have an elongated rupture area. To invert Eq. (11) for the moment release, we use the iterative "tomographic imaging" technique as discussed in RUFF (1987) and applied in SCHELL and RUFF (1989) and BECK and RUFF (1989). For underthrusting events, we can determine the best overall rupture directions by pointing the $x$ axis in all possible directions. Also, to further reduce the effective number of unknown parameters, we use the a priori notion that most of the moment release occurs close to a rupture front. Thus, we can try all possible rupture azimuths and rupture velocities and choose the "best" model from one that best fits the data. The iterative solution to the tomographic imaging problem uses a variant of the conjugate gradients technique. This method guarantees convergence, and in practice only a small number of iterations, typically less than 10 , is required to achieve convergence. The tomographic imaging technique used here parallels that used by SCHELL and RUFF (1989), except for the "preprocessing" of the input time functions. SCHELL and RUFF (1989) studied the 1972 Sitka $\left(M_{w} 7.6\right)$ strike-slip earthquake, and there was an abundance of on-scale $P$-wave seismograms before the shadow zone. In the case of large underthrusting events, we typically will use some seismograms from the shadow zone, thus their absolute amplitudes are diminished. We found that the best method for preprocessing the resultant time functions was: (1) first normalize the time functions to zero moment by subtraction of half-sine function of the duration of the time function; and (2) rescale the peak amplitudes of all the time functions to the peak amplitudes from the nondiffracted stations. We invert these rescaled time functions to find the best rupture direction and velocity. To produce a final estimate of the moment release along this rupture direction, we add a third step to the above scheme: (3) the seismic moment is added to the time functions with a half-sine function of the same duration as the time functions. Also, in contrast to SCHELL and RUFF (1989), we find a single best time function for a group of stations in the same azimuthal sector by multistation inversion for the time function with an assumed focal mechanism (method of RuFF, 1989b). Thus, there are fewer time functions that are used in the tomographic imaging, but each time function is less "noisy," and there is a better balance between different azimuths than in the original azimuthal distribution of stations.

\subsection{Radiated Wave Energy}

Earthquake energy is a fundamental characteristic of earthquakes, but it is quite difficult to reliably measure. Most estimates of earthquake energy use empirical 
formulas that relate magnitude to energy (i.e., GUTENBERG and RICHTER, 1956; KANAMORI, 1977). The formula from KANAMORI (1977) can be written as the ratio of energy to moment is a constant, that is, $E / M_{0}=5 \times 10^{-5}$. It is possible to determine the radiated wave energy, a lower bound on total earthquake energy, by two methods: (1) directly summing the wave energy in many seismograms that completely sample the focal sphere; or (2) determine the rupture process as the space-time history of moment release, and then use the computer to "radiate" the $P$ and $S$ waves in all directions and integrate the wave energy. For large earthquakes, teleseismic rupture process studies should image all of the significant wave energy. KIKUCHI and FUKAO (1988) applied method \#2 to several great and large earthquakes, and they found that the "observed" wave energy is about one-tenth the amount expected from the Kanamori energy-moment formula.

The energy calculation is fairly straightforward and is based on established procedures. The basic relation for radiated wave energy from HASKELL (1964) is

$$
\begin{aligned}
& E_{P}=\frac{1}{16 \pi^{2} \rho \alpha^{5}} \iiint R_{P}^{2}[\ddot{M}(t, \theta, \phi)]^{2} d t \sin \theta d \theta d \phi \\
& E_{S}=\frac{1}{16 \pi^{2} \rho \beta^{5}} \iiint\left[R_{S H}^{2}+R_{S V}^{2}\right][\ddot{M}(t, \theta, \phi)]^{2} d t \sin \theta d \phi d \theta
\end{aligned}
$$

where $E_{P}$ and $E_{S}$ are the $P$ - and $S$-wave energies; $\rho, \alpha$, and $\beta$ are the density, $P$ wave and $S$ wave velocities; $R_{P}, R_{S H}$, and $R_{S V}$, are the radiation pattern factors for $P, S H$, and $S V$ waves; $\theta$ and $\phi$ are the spherical coordinates; and $\ddot{M}$ is the second derivative, with respect to time, of the moment accumulation as seen from all directions around the focal sphere. Henceforth, we will just explicitly write the $S$-wave energy equation. Our tomographic imaging method idealizes the moment release to occur just along one direction, i.e., a line source. Thus, the moment rate function, $\dot{M}$, depends only on time and the directivity parameter, $\Gamma_{S}=\cos (\theta) / \beta$, as follows

$$
\dot{M}\left(t, \Gamma_{S}\right)=\int_{x_{\min }}^{x_{\max }} \dot{m}\left(t-\Gamma_{S} x, x\right) d x
$$

where $\dot{m}$ is the moment rate density function, and the faulting extends from $x_{\min }$ to $x_{\max }$ along the $x$ direction, $\theta=0^{\circ}$. Note that $\dot{M}\left(t, \Gamma_{S}\right)$ does not depend on $\phi$. Substitute the above specialization of $\dot{M}$ into the basic energy equation (12), integrate over $\phi$, and change the integration variable to $\chi=\cos (\theta)$ to find the radiated $S$-wave energy

$$
E_{S}=\frac{1}{16 \rho \beta^{5}}\left\{\int_{-1}^{1} R(\chi)\left[\int_{0}^{\infty} \ddot{M}\left(t, \Gamma_{S}(\chi)\right) d t\right] d \chi\right\}
$$

where $R(\chi)=\left(4 \chi^{4}-3 \chi^{2}+1\right)$ for fault slip parallel to the $x$ direction, and $R(\chi)=\left(1-\chi^{4}\right)$ for slip perpendicular to the $x$ direction. Given our tomographic 
inversion for $\dot{m}(t, x)$, the above double integral is numerically evaluated by generating $\ddot{M}\left(t, \Gamma_{s}\right)$ for the full range of $\chi$, i.e., the entire focal sphere. Unfortunately, we have discovered that the energy estimate is sensitive to various parameters of the source imaging that are poorly determined; in particular, the assumed rupture velocity can exert a strong influence on the energy estimate. Thus, we will show a range of energy estimates that correspond to rupture velocities from the lower bound up to the $S$-wave velocity.

\subsection{Epicentral Relocations and "Hand-picked" Directivity Analysis}

We have tested various epicentral locations by using linearized relative epicentral relocation. This simple technique is well-known and has been used by many seismologists; we briefly describe it here for the sake of completeness. Suppose we want to locate event " $A$ " with respect to event " $O$ " based on the observed time delays, $\Delta t$, at various stations. From the observational perspective, the time delay at the $i$ th station is: $\Delta t_{i}=t_{A i}-t_{o i}$, where $t_{A i}$ and $t_{o i}$ are the arrival times of events " $A$ " and " $o$ ". The event-to-station azimuth (counterclockwise from East) and ray parameter of the wave from event " $o$ " to the $i$ th station are $\phi_{i}$ and $p_{i}$. We place an $(x, y)$ coordinate system at the fixed epicentral location of event " $o$ ", with $+x$ pointed East and $+y$ pointed North. For the teleseismic case, any hypocentral depth difference between events " $O$ " and " $A$ " is absorbed into the origin time shift, $T_{A}$. The linearized expansion of the travel-time function then produces the theoretical connection between the origin time shift and epicental perturbations $\left(T_{A}, x_{A}\right.$, and $y_{A}$ ) of event " $A$ " with respect to event " $o$ " and the observed travel-time delays as follows

$$
\Delta t_{i}=T_{A}-\left(p_{i} \cos \phi_{i}\right) x_{A}-\left(p_{i} \sin \phi_{i}\right) y_{A} .
$$

With a total number of observed travel-time delays of $N$, we seek the least-squares solution of the $N$ equations for the three unknowns: $T_{A}, x_{A}$, and $y_{A}$. Error estimates are important for relocation assessment, thus we use the resultant $r m s$ misfit between observed and best-fit time delays, together with the model covariance matrix, to calculate the $(x, y)$ error ellipse about $x_{A}$ and $y_{A}$. Note that this relocation procedure gives only the relative location of event " $A$ " with respect to event " $o$ "- we must assume the absolute location of event " $O$ ". Also, this procedure uses only the common stations - this restriction makes the procedure quite simple and yet it implicitly corrects for any station effects. We have used this relocation procedure to test the mainshock locations with respect to the ISC catalog locations, and also to relocate mainshocks with respect to each other.

The above procedure is also used to study the rupture process of large earthquakes. From an observational perspective, we "pick" the arrival times at each station of an easily identified feature in the source time functions. This feature, event " $A$ ", is relocated with respect to event " $O$ " which is typically the point of 
rupture initiation, i.e., the epicenter. Thus, this "hand-picked" directivity analysis is simply a relative epicentral location problem, and possesses the advantage over other techniques of rupture imaging in that we obtain statistical estimates of the reliability of the feature location. It is desirable to use this "hand-picked" directivity whenever possible, and it is especially useful for multiple-event rupture processes where we can clearly pick the beginning of each subevent (e.g., BECK and RUFF, 1987). This simple and reliable method can be used for any coherent feature in the time functions. The usefulness of the solution depends on whether: (1) the origin of the observed feature is spatially concentrated within the rupture zone, and (2) the seismologist can "pick" the same feature in all seismograms. Fortunately, any departure from ideal circumstances should be seen in the calculation of the error ellipse.

\section{Results of Seismological Analysis}

Teleseismic rupture process studies can locate moment release with respect to a reference point, typically the epicenter. To compare results from adjacent earthquakes, the relative epicentral locations must be correct. To compare moment release to tectonic features, then the absolute locations should also be reliable. Seismicity in Mexico presents some special problems. Given the lack of numerous large aftershocks, the rupture zones of large earthquakes are mostly based on the small aftershocks located by local and regional networks. Thus epicentral locations must be consistent with the local aftershock locations. SINGH and LERMo (1985) document a strong systematic bias in the ISC and PDE/NEIC epicenters with respect to the local epicenters. We shall use epicentral locations determined by various local networks, and thus the teleseismic rupture process studies will be referenced to these locations. While the epicentral locations based on local networks are the best estimates, the depths and origin times from the local network may not be compatible with the global data set. Teleseismic waveform modeling can find the "best" depth for the overall moment release, for an average velocity between the surface and hypocenter. Given this "best" depth, we can recalculate the origin time such that the teleseismic arrival times are well-predicted. Since the spatial location of moment release is sensitive to the start times of the body waves, these start times will be listed for all body-wave phases used in the inversions for all events. In addition, we shall also list the seismogram scale factors that result from the omnilinear inversion of the seismograms. An additional special problem exists for the 1985 Michoacan mainshock since local acceleragrams have been used to determine the rupture process - these records do contain information on the absolute location of the moment release. Hence, we must use a compatible epicenter to mix teleseismic and local records in rupture process studies. 


\subsection{The 1973 Colima Earthquake}

\subsubsection{Epicenter and aftershock area}

REYES et al. (1979) presented a detailed study of the 1973 Colima earthquake and its aftershocks. They deployed a temporary seismic network within days after the mainshock, and thus recorded the large Feb. 10, 1973 (M 6.2) aftershock. The epicenter for this aftershock is probably the most reliable absolute location in the Colima region of an event large enough to be teleseismically recorded. This large aftershock is near the northwestern end of the aftershock zone of REYES et al. (1979). The main cluster of aftershocks is located at the southeastern end of the aftershock zone, about $55 \mathrm{~km}$ to the southeast of the Feb. 10 event. REYEs et al. (1979) also show a location for the 1973 mainshock that is displaced about $30 \mathrm{~km}$ to the southwest from the ISC and PDE epicenters. This systematic shift is documented for other large Mexico earthquakes in SINGH and LERMO (1985). Thus, the REYES et al. (1979) mainshock location is more reliable than the ISC or PDE location, but their epicenter is still down-dip of the main aftershock cluster.

We locate the mainshock epicenter with respect to the Feb. 10 aftershock by using the $P$-wave arrivals at 18 common stations that range in epicentral distance from $13.9^{\circ}$ to $48.9^{\circ}$. The azimuthal range of the stations covers only the eastern sector from $322^{\circ}$ around to $149^{\circ}$. The relocation places the mainshock epicenter $80 \mathrm{~km}$ along an azimuth of $117^{\circ}$ from the Feb. 10 event, with an error estimate of about $11 \mathrm{~km}$. This azimuth of $117^{\circ}$ coincides with the local trend of the coastline and also points towards the southeastern aftershock cluster, but the $80 \mathrm{~km}$ distance places the mainshock epicenter beyond the southeastern aftershock cluster. If the mainshock epicenter of REYEs et al. (1979) is shifted by $15 \mathrm{~km}$ further to the southwest, then it falls on the $117^{\circ}$ azimuth from the Feb. 10 event, and also is at the center of the aftershock cluster. We use this mainshock epicenter as our compromise location; the geographic coordinates are: $18.20^{\circ} \mathrm{N}, 103.18^{\circ} \mathrm{W}$.

\subsubsection{MTRF inversion for focal mechanism and depth}

As noted by CHAEL and STEWART (1982), the $P$ waves for the Colima earthquake show a "complication" of an emergent arrival. While CHAEL and STEWART (1982) were unable to find a time function with their forward modeling technique, there is no difficulty with a deconvolution or inverse method. On the other hand, finding the proper start time of the $P$ waves can be difficult for an emergent arrival for seismograms at large epicentral distance. After careful comparison of seismograms, we have used the arrival times listed in Table 1. We have used the naturally rotated $S H$ wave at AKU in the MTRF inversion. Usually, it is not possible to use $S H$ at a distance of $72^{\circ}$ for a large earthquake because the $S c S$ arrival interferes with $S$. However, we noticed that both the $S$ and $S c S$ are essentially nodal on the AKU $S H$ record - this special case allows the use of this record. 
Table 1

Station data and some results for the 1973 Colima earthquake

\begin{tabular}{|c|c|c|c|c|c|c|c|c|c|c|c|}
\hline \multirow[b]{2}{*}{ Sta } & \multirow[b]{2}{*}{ Net } & \multirow[b]{2}{*}{ Comp } & \multirow[b]{2}{*}{ Phase } & \multicolumn{2}{|c|}{$\begin{array}{l}\text { Epicentral } \\
\text { params }\end{array}$} & \multirow{2}{*}{$\begin{array}{c}\text { Start } \\
\text { time } \\
21 \mathrm{hrs}+\end{array}$} & \multirow{2}{*}{$\begin{array}{l}\text { obs- } \\
\text { pre }\end{array}$} & \multirow{2}{*}{$\begin{array}{c}a \\
\text { factor }\end{array}$} & \multirow{2}{*}{\multicolumn{2}{|c|}{$\begin{array}{l}\text { direct. } \Delta t, \mathrm{~s} \\
\text { peak duration }\end{array}$}} & \multirow[t]{2}{*}{$M_{0}$} \\
\hline & & & & $\Delta_{q}^{\circ}$ & $A z,{ }^{\circ}$ & & & & & & \\
\hline KBS & W & Z & $P$ & 76.9 & 10 & 13: 1.3 & -2.2 & $0.93]$ & & & \\
\hline KTG & $\mathrm{W}$ & Z & $P$ & 70.0 & 21 & $12: 20.4$ & -2.9 & 1.27 & & & \\
\hline NUR & W & $\mathrm{Z}$ & $P$ & 91.1 & 23 & $14: 11.9$ & -3.4 & 1.54 & 13 & 31 & 0.9 \\
\hline $\mathrm{AKU}$ & W & Z & $P$ & 71.6 & 26 & $12: 30.7$ & -1.7 & 1.27 & & & \\
\hline ESK & W & Z & $P$ & 80.8 & 35 & $13: 22.0$ & -2.4 & 1.007 & & & \\
\hline STU & W & Z & $P$ & 90.4 & 38 & 14: 9.6 & -2.4 & 1.62 & & & \\
\hline VAL & W & $E$ & $P$ & 77.7 & 39 & 13: 4.9 & -2.8 & 0.94 & 15 & 32 & 0.8 \\
\hline TOL & W & Z & $P$ & 85.3 & 50 & $13: 46.2$ & -1.4 & $1.24]$ & & & \\
\hline NAT & W & Z & $P$ & 71.0 & 102 & $12: 26.4$ & -3.0 & 0.98 & 15 & 35 & 0.6 \\
\hline ARE & W & Z & $P$ & 46.5 & 136 & $9: 37.8$ & -0.6 & 0.917 & & & \\
\hline SOM & W & Z & $P$ & 76.6 & 160 & 13: 2.0 & +0.5 & 0.13 & 17 & 31 & 0.6 \\
\hline WEL & W & Z & $P$ & 96.0 & 229 & $14: 42.1$ & +4.2 & $\left.1.65^{*}\right]$ & & & \\
\hline RAR & W & Z & $P$ & 67.9 & 237 & $12: 13.3$ & +3.4 & 1.88 & 13 & 27 & 0.5 \\
\hline $\mathrm{AFI}$ & W & Z & $P$ & 74.8 & 250 & $12: 52.7$ & +1.4 & 1.24 & & & \\
\hline KIP & W & Z & $P$ & 51.5 & 283 & $10: 17.8$ & +0.8 & 0.24 & 13 & 26 & \\
\hline MAT & W & $\mathrm{Z}$ & $P$ & 100.5 & 314 & $14: 57.1$ & -1.0 & $2.17^{*}$ & 13 & 31 & \\
\hline AKI & W & $\mathbf{N}$ & $\begin{array}{c}S H \\
\text { back az. }\end{array}$ & 71.6 & $\begin{array}{c}26 \\
(273)\end{array}$ & $21: 41.2$ & -8.0 & 1.01 & & & \\
\hline
\end{tabular}

"Net" code: W, WWSSN. "Comp": Z, vertical; $N$, north; E, east. "Phase": $P$ wave. "Epicentral params": distance and azimuth. "Start time": onset of observed waves, 21 hours plus the listed minutes:seconds. "obs--pre": arrival time residual. " $a$ factor": the seismogram scale factors from omnilinear analysis, based on MTRF inversion with AKU SH and at the best depth of $25 \mathrm{~km}$, * diffracted $P$ waves. "direct. $\Delta t$ ": times of features in source time functions, in $\mathrm{s}$, "peak" is the first peak in moment release of the time functions, "duration" is duration of the pulse. " $M_{0}$ ": seismic moment of the source time functions, in $10^{20} \mathrm{Nm}$.

For the initial body wave inversions, the seismograms are filtered such that the MTRF inversion can be used to find the overall best depth and focal mechanism. We use a "zero-phase yet-causal" time domain symmetric triangle filter with $10 \mathrm{~s}$ duration. Using different combinations of stations, allowing a variable or fixed focal mechanism, and with different damping values, the overall best point source depth is 20 to $25 \mathrm{~km}$. To show a particular example, using $17 P$ waves and the AKU $S H$ wave, with $70 \mathrm{~s}$ duration, we invert for MTRFs of $60 \mathrm{~s}$ duration with a $4 \mathrm{~s}$ sampling, a damping of 0.10 , and at a depth of $25 \mathrm{~km}$ (Figure 2). The MTRFs are plotted in the left column, and the observed (solid) and synthetic (dashed) seismograms are plotted in the right column. Two of the $P$-wave phases are diffracted, so the final value of seismic moment uses only the nondiffracted station amplitudes. In Figure 2, the time functions from the reduction to the major double 


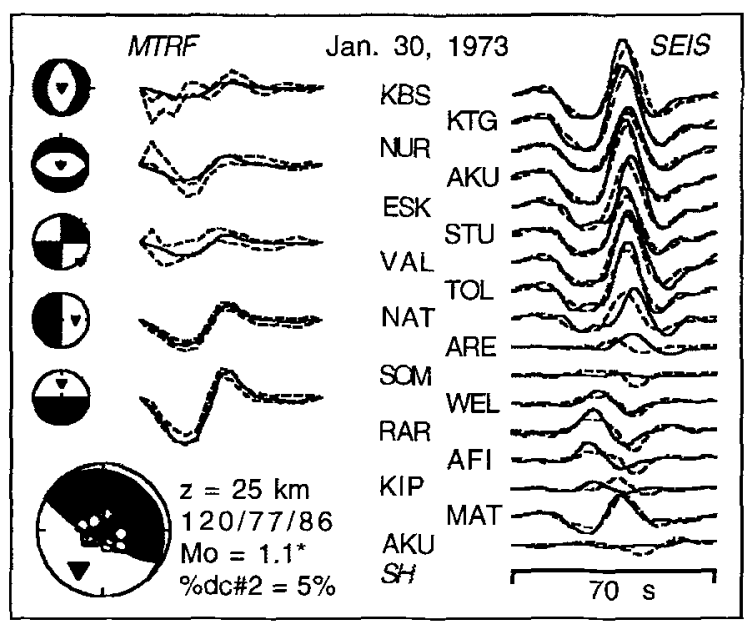

Figure 2

Inversion of seismograms for MTRFs for the 1973 Colima earthquake. The five MTRFs are shown on the left, while the observed (solid) and synthetic (dashed) seismograms are shown to the right. The inversion is for a source depth of $25 \mathrm{~km}$. Each MTRF is identified by its equivalent double-couple focal mechanism. The dashed traces show the \pm uncertainty of the individual MTRFs obtained by omnilinear inversion. A single source time function and double-couple focal mechanism are extracted from the MTRFs (see Appendix for details). The solid traces are the source time function rescaled by the moment tensor components corresponding to the double-couple mechanism shown below. The focal mechanism parameters are listed as: strike of $120^{\circ}$, dip of $77^{\circ}$, and rake angle of $86^{\circ}$. The seismic moment is 1.1 , in units of $10^{20} \mathrm{Nm}$, The second double couple is $5 \%$ of the size of the major double couple. The synthetic seismograms are calculated for the final model of one time function and one double couple. Station distribution is plotted on the focal sphere, and the time scale is the same for both the MTRFs and seismograms.

couple are plotted with the error bounds about the original MTRFs. Visual inspection of Figure 2 shows that the individual MTRFs are consistent with a single moment tensor and double couple, but the MTRF parameter is the best overall quantitative measure of the adequacy of reduction. The left side of Figure 3 shows the fit between the synthetic and observed seismograms as a function of assumed point-source depth. We find the best point-source depth to be $25 \mathrm{~km}$, but with low resolution, expected for a large event (see TichelaAR et al., 1992). The minimum in the MTRF parameter gives an indication of the "best" solution. Figure 3 also shows the statistical parameters for MTRF inversion without the $S H$ seismogram; the best fit for a double couple and time function is now at a depth of $15 \mathrm{~km}$. For the inversion with the $S H$ wave, the MTRF parameter obtains a minimum value of less than 1 at $25 \mathrm{~km}$. This means that the MTRFs can be replaced by a single time function and moment tensor. We select the inversion run with $S H$ and a depth of $25 \mathrm{~km}$ as the overall best solution, plotted in Figure 2. As seen in Figures 2 and 3, the best double-couple focal mechanism has a fault strike of $317^{\circ}$, fault dip of $14^{\circ}$, and a slip vector angle of $30^{\circ}\left(\mathrm{N} 30^{\circ} \mathrm{E}\right)$ that is nearly pure thrust. This fault strike 


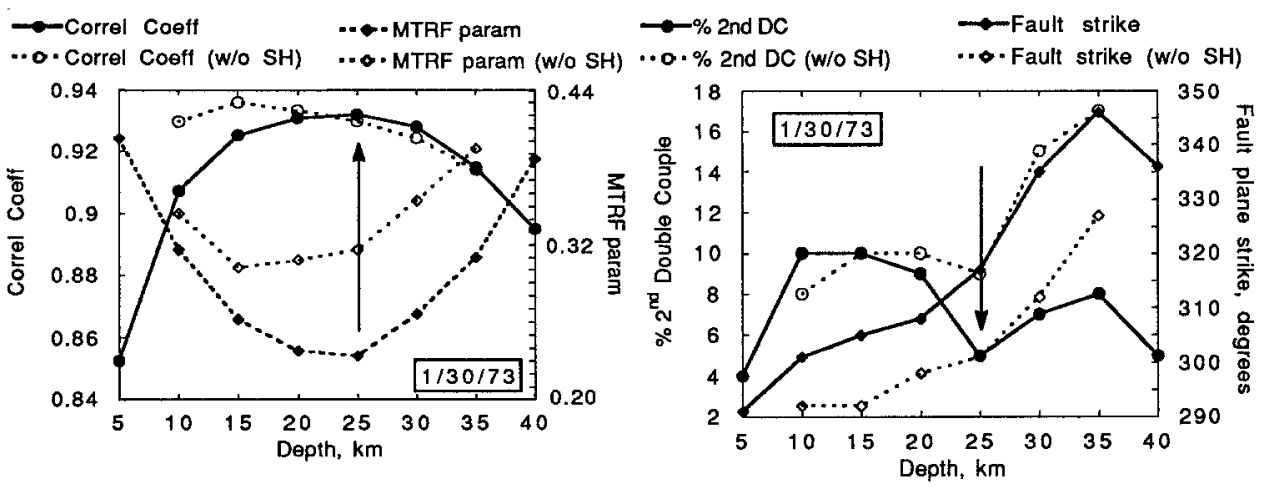

Figure 3

Various MTRF inversion and earthquake parameters as a function of assumed depth for the 1973 Colima earthquake. The match between observed seismograms and the synthetics for one time function and double couple is measured by the correlation coefficient (plotted in the left graph). The MTRF parameter ( $\zeta$ in the Appendix) is also plotted in the left graph. For the Colima event, we show the curves for inversion runs with and without the $S H$ wave. We choose $25 \mathrm{~km}$ as the overall best point-source depth, shown as the arrow. The graph at right shows the fault strike of the major double couple and the percent size of the second double couple for all depths. We use this figure to estimate the allowed range

in fault plane strike.

is close to the estimate of REYES et al. (1979), but our dip of $14^{\circ}$ is shallower than their preferred values. Recall that the fault plane strike of CHAEL and STEWART (1982) is $266^{\circ}$. On the other hand, the auxiliary plane from CHAEL and STEWART has a strike of $122^{\circ}$ and a dip angle of $76^{\circ}$; our auxiliary plane has a strike of $120^{\circ}$ and a dip of $77^{\circ}$. Thus, the auxiliary plane agrees with CHAEL and STEWART, but their fault plane is rotated to an east-west orientation. In the right side of Figure 3, we plot the fault strike of the major double couple extracted at each depth. We see that if we choose a depth less than $25 \mathrm{~km}$, or if we use the $P$ wave-only inversion results, the fault strike is rotated to a more east-west orientation; but is never less than $290^{\circ}$. Thus, the body waves prefer a fault strike between $290^{\circ}$. and $320^{\circ}$, more or less parallel with the local trench orientation; the fault strike of CHAEL and STEWART is not consistent with this result. The auxiliary plane strike is quite stable at the various depths. For the MTRF inversion with $S H$, the auxiliary plane strike is between $120^{\circ}$ and $123^{\circ}$ over the entire 5 to $40 \mathrm{~km}$ depth range. For the MTRF inversion without the $S H$ phase, the auxiliary plane strike only varies from $130^{\circ}$ to $133^{\circ}$ for a depth range of 10 to $25 \mathrm{~km}$. This basic character of a stable auxiliary plane strike hence slip vector strike, is seen for all the Mexico earthquakes.

\subsubsection{Directivity and rupture}

The basic history of moment release is a single pulse of about $30 \mathrm{~s}$ duration, with a small precursor 4 to $8 \mathrm{~s}$ before the main pulse. To test for directivity, we invert for time functions of the station groups indicated in Table 1. We use a depth 
of $20 \mathrm{~km}$, seismogram duration of $80 \mathrm{~s}$, time function duration of $60 \mathrm{~s}$ with $2 \mathrm{~s}$ sampling, triangle filter duration of $3 \mathrm{~s}$. We do a "hand-picked" directivity analysis of two features: (i) the first peak of moment release, and (ii) the termination of moment release, i.e., the zero-crossing of the time functions. An example of these features in the time functions for the North Atlantic stations is shown in Figure 4. We relocate these features with respect to the epicenter, as shown in Figure 5. The peak in moment release is located $32 \mathrm{~km}$ to the northwest along an azimuth of $315^{\circ}$ with a time delay of $14 \mathrm{~s}$; the apparent rupture velocity is $2.2 \mathrm{~km} / \mathrm{s}$. The error ellipse for this location is $\pm 11 \mathrm{~km}$, along a strike of $345^{\circ}$, and $\pm 8 \mathrm{~km}$ along a direction of $75^{\circ}$. The time function zero-crossing is located at a distance of $64 \mathrm{~km}$ along an azimuth of $257^{\circ}$ from the epicenter, with a delay time of $30 \mathrm{~s}$; this gives an apparent rupture velocity of $2.1 \mathrm{~km} / \mathrm{s}$. One interpretation of the azimuthal difference between the peak and termination of moment release is that a rupture front propagated from the southeastern corner of the aftershock both up-dip and along strike to the northwest.

As an additional test, we use the one-dimensional tomographic imaging technique to find the overall average azimuth of rupture propagation and moment

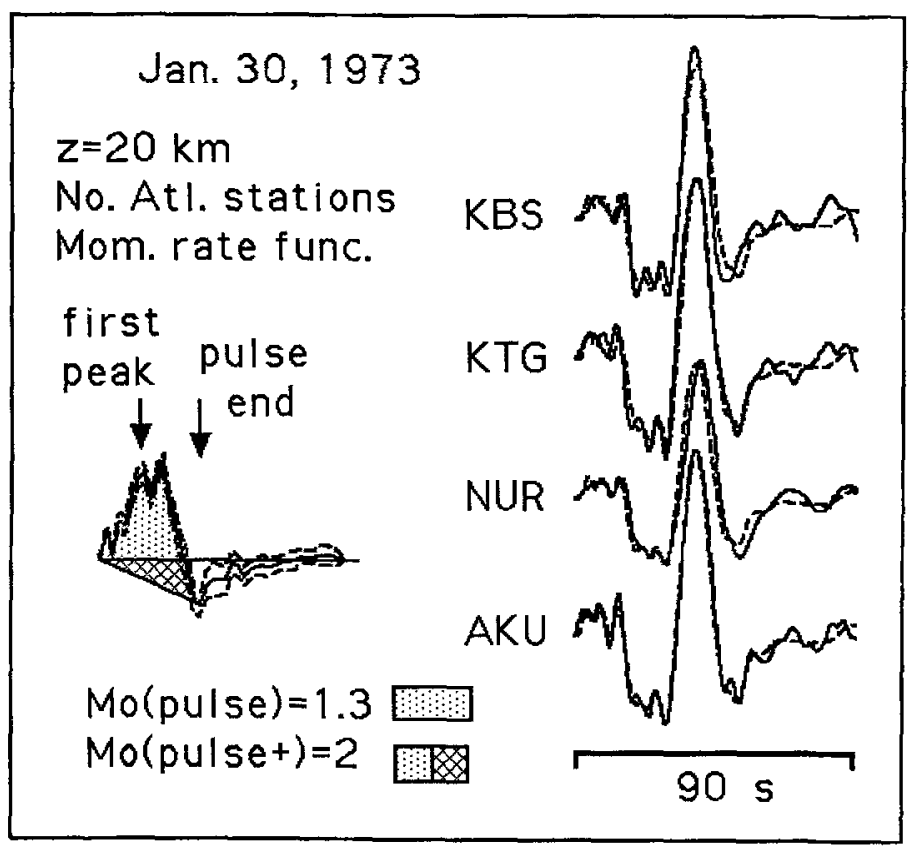

Figure 4

Inversion for the source time function as seen by the "North Atlantic" station group. With a depth of $20 \mathrm{~km}$ and the focal mechanism from Figure 2, the four seismograms are inverted for the time function shown to the left. The dashed traces are the resultant synthetic seismograms. The arrows show the two features that are used in the "hand-picked" directivity analysis. Two different values of seismic moment are shown, the larger value of $2 \times 10^{20} \mathrm{Nm}$ adds a baseline correction to the main pulse. 


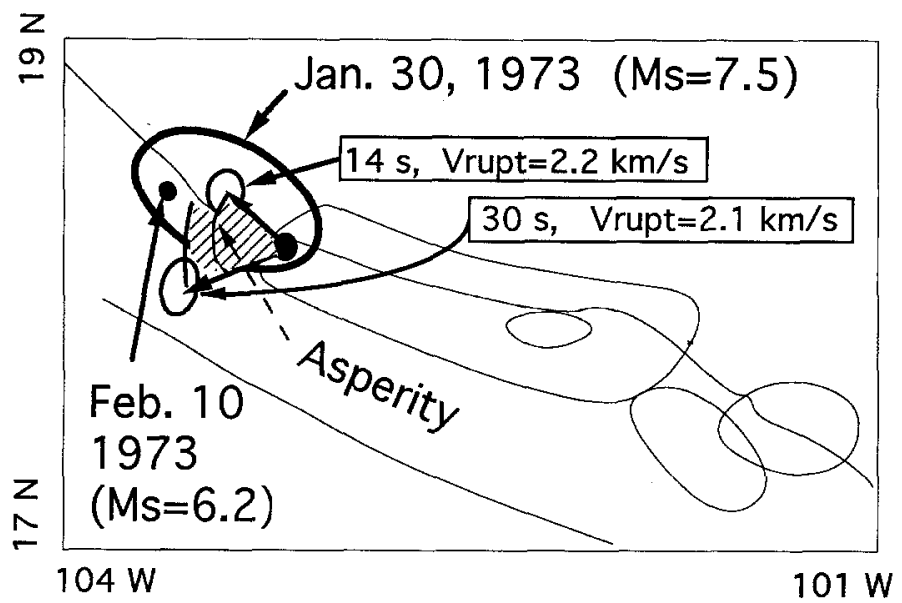

Figure 5

Mexico base map with the rupture process features of the 1973 Colima earthquake. Solid dot in the southeast corner of the 1973 aftershock zone shows our best estimate of the mainshock rupture initiation epicenter. The aftershock epicenter is from ReYes et al. (1979). The arrows and error ellipses show the results from the directivity analysis, which is corroborated by tomographic imaging of the moment release. The hachured region is presumed to be the main pulse asperity.

release. We find that irrespective of rupture velocity, the best average rupture direction is $280^{\circ}$, which is intermediate to the above two directions. The seismic moment contained in this first pulse is about $1.3 \times 10^{20} \mathrm{Nm}$ (Fig. 4). If we assume that the inversion "damps out" a longer period component that would make the first $30 \mathrm{~s}$ entirely positive, then we can boost the seismic moment in Figure 4 to about $2 \times 10^{20} \mathrm{Nm}$. The long-period surface wave estimates of REYES et al. (1979) and CHAEL and STEwART (1982) are about $3 \times 10^{20} \mathrm{Nm}$, where ReYES et al. (1979) also estimate the uncertainty as $3 \pm 2 \times 10^{20} \mathrm{Nm}$. Thus, we can conclude that about half to most of the seismic moment was released in the southeast corner of the aftershock area. Following the interpretations of BECK and RUFF (1985) and SCHWARTZ and RUFF (1987), this southeast corner is identified as the dominant asperity of the 1973 Colima earthquake. If we take the asperity area to be a quarter-circle of radius $50 \mathrm{~km}$, then the average displacement will be $3.4 \mathrm{~m}$. There is only about $1.6 \mathrm{~m}$ of tectonic displacement accumulation between the 1973 Colima earthquake and the previous large earthquake in 1941 (see NISHENKO, 1991). Thus, the asperity of the 1973 earthquake certainly qualifies as an "official" asperity in the context of the asperity model, where the coseismic slip should equal the total accumulated tectonic displacement. This asperity occupies only about half the aftershock area. While the aftershock cluster at the southeastern corner is in the asperity region, the large Feb. 10 aftershock is located just beyond the asperity edge. See Mendoza and Hartzell (1988) for other examples of the relationship between an asperity and aftershocks. 


\subsection{The 1979 Petatlan Earthquake}

\subsubsection{Epicenter and aftershock area}

Due to fortunate circumstances, a temporary local network recorded the foreshocks, mainshock, and aftershocks of the 1979 Petatlan earthquake (GETTRUST et al., 1981; VALDES et al., 1982). While the foreshock sequence is interesting and important, we are mostly concerned with the aftershock area and mainshock hypocenter. We use the mainshock epicenter reported by the above two papers: $17.46^{\circ} \mathrm{N}, 101.46^{\circ} \mathrm{W}$. They also report a hypocentral depth of $15 \mathrm{~km}$ and an origin time of $11 \mathrm{hr} 7 \mathrm{~min} 11.2 \mathrm{~s}$. The above mainshock epicenter is displaced by about $40 \mathrm{~km}$ southwest of the PDE epicenter, similar to the bias seen from the 1973 Colima earthquake. VALDES et al. (1982) show the distribution of 22 aftershocks that occur up to 2.5 days after the mainshock, all with magnitude less than 4 . With the exception of one event, these aftershocks define a narrow zone that is $27 \mathrm{~km}$ wide in the down-dip direction, and extends $60 \mathrm{~km}$ along the coastline. The mainshock epicenter is more or less at the center of this aftershock region. The one exception is an aftershock that is $15 \mathrm{~km}$ further inland than the down-dip edge of the narrow zone; inclusion of this one aftershock greatly increases the aftershock area. As documented in VALDES et al. (1982), the aftershock area expands with time, primarily in the inland, or down-dip, direction. In contrast to most other large subduction earthquakes, it seems that the 1979 rupture initiated in the center of the rupture area, rather than at the down-dip edge. The detailed relocations of Hsu et al. (1985) indicate a fault plane dip angle of about $14^{\circ}$; they also further discuss a possible foreshock migration pattern that they claim is consistent with the model of DMowsKa and LI (1982). The slip front in the DMowsKa and Li (1982) model progresses upward from the down-dip edge; thus the conclusion of Hsu et al. (1985) implies that the entire sequence started at the down-dip edge, though the mainshock epicenter is displaced up-dip.

\subsubsection{Body-wave inversion for MTRFs, depth, and rupture process}

Chael and STewart (1982) modeled the $P$ and surface waves of the Petatlan event, and a Harvard CMT solution is also available. We use a total of 14 WWSSN long-period $P$ waves as listed in Table 2. We first perform the MTRF inversion for seismogram duration of $60 \mathrm{~s}$, filtered with a $10 \mathrm{~s}$ duration triangle, MTRF duration of $60 \mathrm{~s}$ with $4 \mathrm{~s}$ sampling, and damping of 0.1. The MTRF inversion fits the $P$ waves quite well for a point-source depth anywhere between 10 and $25 \mathrm{~km}$ (Fig. 6); again, this lack of depth resolution is expected, given the smooth source time function duration of $20 \mathrm{~s}$. Recall that our depths are determined for a local $P$-wave velocity of $6.7 \mathrm{~km} / \mathrm{s}$, hence our depth would be less than the above values if we used the slightly slower velocity above a depth of $25 \mathrm{~km}$ in the velocity model of VALDES et al. (1982). The MTRF parameter is considerably less than 1 (Fig. 6), thus the MTRFs can be replaced by a single moment tensor and time function, as will be the case for all the Mexico earthquakes. 
Table 2

Station data and some results for the 1979 Petatlan earthquake

\begin{tabular}{|c|c|c|c|c|c|c|c|c|c|c|c|}
\hline \multirow[b]{2}{*}{ Sta } & \multirow[b]{2}{*}{ Net } & \multirow[b]{2}{*}{ Comp } & \multirow[b]{2}{*}{ Phase } & \multicolumn{2}{|c|}{$\begin{array}{l}\text { Epicentral } \\
\text { params }\end{array}$} & \multirow{2}{*}{$\begin{array}{c}\text { Start } \\
\text { time } \\
11 \mathrm{hrs}+\end{array}$} & \multirow{2}{*}{$\begin{array}{l}\text { obs- } \\
\text { pre }\end{array}$} & \multirow{2}{*}{$\begin{array}{c}a \\
\text { factor }\end{array}$} & \multirow{2}{*}{\multicolumn{2}{|c|}{$\begin{array}{c}\text { direct. } \Delta t, \mathrm{~s} \\
\text { peak duration }\end{array}$}} & \multirow[t]{2}{*}{$M_{0}$} \\
\hline & & & & $\Delta,{ }^{\circ}$ & $\mathrm{Az},{ }^{\circ}$ & & & & & & \\
\hline DAG & W & $\mathrm{E}$ & $P$ & 71.4 & 14 & $18: 30.8$ & -2.2 & 0.947 & & & \\
\hline NUR & w & $E$ & $P$ & 91.1 & 24 & $20: 15.3$ & -1.3 & 1.18 & & & \\
\hline $\mathrm{AKU}$ & W & Z & $P$ & 71.5 & 26 & $18: 31.5$ & -1.9 & 0.80 & & & \\
\hline ESK & W & $\mathrm{E}$ & $P$ & 80.4 & 35 & $19: 22.6$ & -1.2 & 0.70 & & & \\
\hline IST & W & Z & $p$ & 105.9 & 37 & $21: 21.3$ & -2.1 & $4.70^{*}$ & 15 & 21 & 0.8 \\
\hline STU & $W$ & $Z$ & $P$ & 89.9 & 38 & $20: 9.4$ & -1.9 & 0.98 & & & \\
\hline VAL & W & $\mathrm{E}$ & $P$ & 77.2 & 39 & 19: 4.2 & -2.0 & 0.58 & & & \\
\hline TRI & W & $\mathrm{E}$ & $P$ & 94.1 & 40 & $20: 28.9$ & -1.7 & 1.28 & & & \\
\hline SJG & W & E & $P$ & 33.6 & 83 & $13: 50.8$ & -2.2 & 0.86 & 16 & 25 & 1.4 \\
\hline LPB & W & $\mathrm{N}$ & $P$ & 47.1 & 134 & $15 ; 43.1$ & -1.6 & $0.79]$ & & & \\
\hline ARE & W & $\mathrm{Z}$ & $P$ & 44.8 & 137 & $15: 25.8$ & -0.6 & 0.52 & 15 & 22 & 0.7 \\
\hline LPA & W & $Z$ & $P$ & 66.5 & 142 & & & $0.58\rfloor$ & & & \\
\hline RAR & W & $Z$ & $P$ & 68.9 & 238 & $18: 16.7$ & -0.6 & 0.70 & 13 & 18 & 1.4 \\
\hline MAT & W & Z & $P$ & 102.2 & 315 & 21: 5.9 & -1.0 & $3.29^{*}$ & 18 & 22 & 0.3 \\
\hline
\end{tabular}

"Net" code: W, WWSSN. "Comp": Z, vertical; N, north; E, east. "Phase": $P$ wave. "Epicentral params": distance and azimuth. "Start time": onset of observed waves, 11 hours plus the listed minutes:seconds. "obs-pre": arrival time residual. " $a$ factor": the seismogram scale factors from omnilinear analysis, based on MTRF inversion at best depth, * diffracted $P$ waves. "direct. $\Delta t$ ": times of features in source time functions, in s, "peak" is the peak moment release just before truncation of pulse, "duration" is duration as measured by baseline-crossing time. " $M_{0}$ ": seismic moment of the source time functions, in $10^{20} \mathrm{Nm}$.
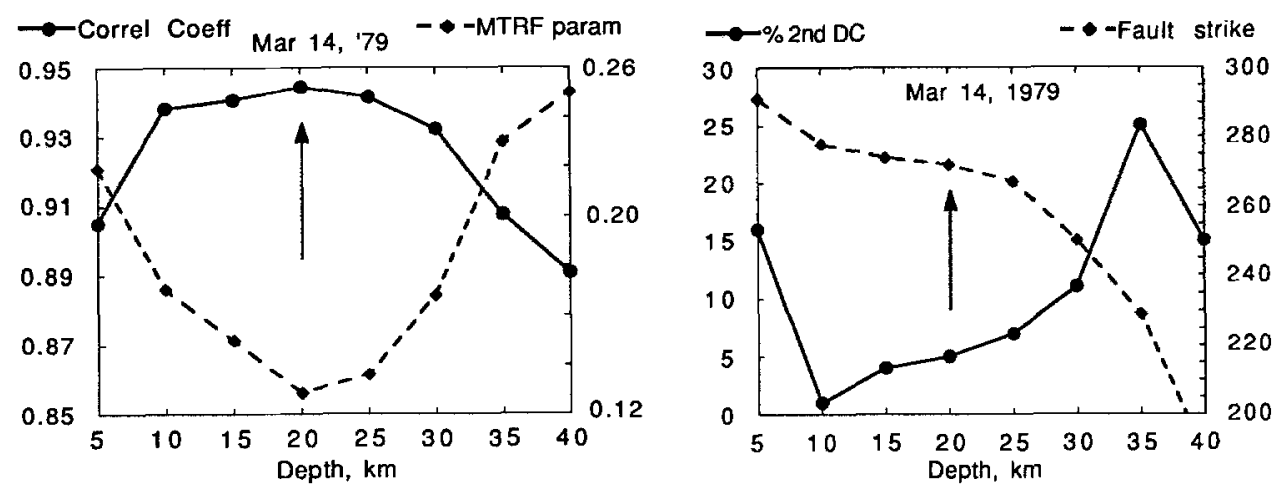

Figure 6

Various MTRF inversion and earthquake parameters as a function of depth for the 1979 Petatlan earthquake. Same as Figure 3. Arrow shows the best point-source depth of $20 \mathrm{~km}$. The MTRF parameter is less than 1, thus a single source time function and single moment tensor is a statistically valid representation of the MTRFs. Fault strike is stable for depths between 10 and $25 \mathrm{~km}$. 
The focal mechanisms that result from the MTRF inversion are quite similar for depths between 10 and $25 \mathrm{~km}$ : the fault plane strike varies from $278^{\circ}$ to $267^{\circ}$ and fault dip varies from $15^{\circ}$ to $16^{\circ}$; the auxiliary plane strike varies from $99^{\circ}$ to $107^{\circ}$. At the best depth of $20 \mathrm{~km}$ - best in the sense of the final fit to the data-the corresponding double couple (Fig. 7) from the MTRF inversion is: strike $104^{\circ}$, dip $74^{\circ}$, slip rake angle of $93^{\circ}$, which gives a fault plane strike and dip of $272^{\circ}$ and $16^{\circ}$. While the Harvard CMT yields a similar auxiliary plane strike of $106^{\circ}$, the CMT fault plane strike is $306^{\circ}$. CHAEL and STEWART (1982) have a fault plane strike of $293^{\circ}$ and an auxiliary plane strike of $116^{\circ}$.

To strive for better depth resolution, we fix the focal mechanism, and then invert for the source time function at different depths: the seismograms are filtered with a $3 \mathrm{~s}$ triangle, time function is sampled at $2 \mathrm{~s}$, and the damping is 0.01 . The best point-source depth is anywhere between 15 to $20 \mathrm{~km}$.

We then invert for individual time functions for the station groups shown in Table 2. An interesting feature of the time functions is that the earthquake starts with a small precursor, followed $6 \mathrm{~s}$ later by a single large pulse that peaks at about $15 \mathrm{~s}$ and ends at about 20 to $25 \mathrm{~s}$ (see MTRFs in Fig. 7). This basic time history is similar to that of the 1973 Colima earthquake. However, for the 1979 Petatlan earthquake, we could not distinguish any coherent directivity in the "hand-picked" features of the time functions. There is no resolvable directivity for the initiation of the main pulse at about $6 \mathrm{~s}$; it is difficult to reliably pick the main pulse initiation

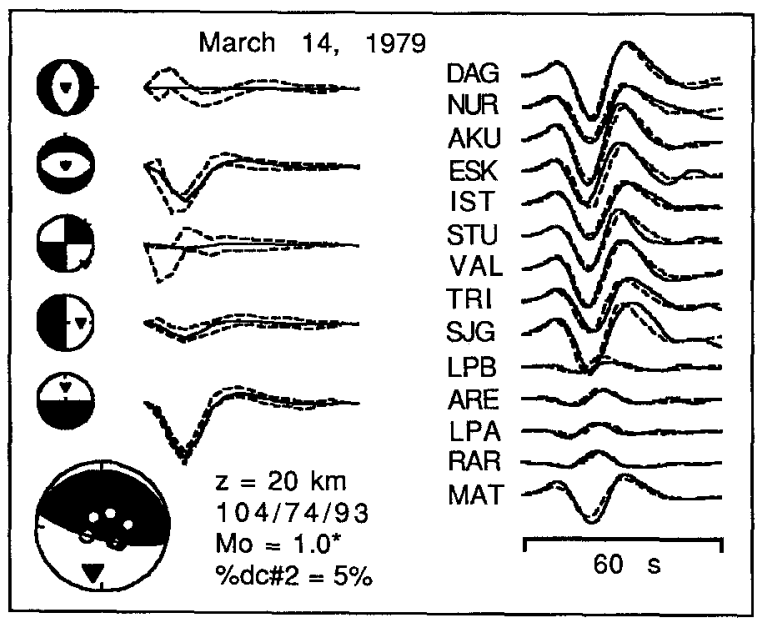

Figure 7

Inversion of seismograms for MTRFs for the 1979 Petatlan earthquake. Same as Figure 2. The inversion is for the best depth of $20 \mathrm{~km}$. Note that for the first moment tensor component at top, the reconstructed MTRF from the time function and double couple (solid trace) falls outside the error bounds of the original MTRF for this component; yet Figure 6 shows that in fact this reconstructed MTRF is statistically acceptable. The MTRF parameter accounts for the full covariance matrix of the MTRFs, while a visual inspection of the above agreement/disagreement does not. 
in the observed seismograms due to interference from the depth phases from the precursor. The overall duration varies from $18 \mathrm{~s}$ at RAR, which is the only station to the south and west, to a range of 21 to $25 \mathrm{~s}$ at all other azimuths. Unfortunately, this difference does not appear to be significant. The lack of apparent directivity is consistent with a rupture front that spreads out in all directions to fill the elliptical aftershock area. The peak in moment release can then be interpreted as the rupture front reaching the edges of the high moment release region. Furthermore, if we associate the moment release peak with a distance of $\pm 30 \mathrm{~km}$, then we have an apparent rupture velocity of about $2 \mathrm{~km} / \mathrm{s}$, but this is all based on assumptions. Chael and Stewart (1982) used a simple trapezoid-shaped time function of $17 \mathrm{~s}$ duration in their forward modeling of the $P$ waves; but they note that there is "... greater complexity" in the onset of this earthquake.

Our overall estimate for the moment in the main pulse from MTRF inversion is about $1 \times 10^{20} \mathrm{Nm}$ (Fig. 7). If we use the maximum value for the first pulse from the individual time functions, then the moment is $1.4 \times 10^{20} \mathrm{Nm}$. From the seismic moment resolved by the body waves, the displacement in the assumed elliptical area around the epicenter is approximately $2.9 \mathrm{~m}$. Since the Harvard CMT moment estimate is $1.7 \times 10^{20} \mathrm{Nm}$ and CHAEL and STEWART (1982) found $2.7 \times 10^{20} \mathrm{Nm}$ in their surface wave analysis, it is likely that additional moment release occurred in the region around the epicentral asperity over a longer time scale. Since the previous large Petalan earthquake occurred in 1943 (NisHenKo, 1991), the accumulated tectonic displacement is only about $2 \mathrm{~m}$; hence we can consider the epicentral elliptical area to be an asperity.

\subsection{The 1981 Playa Azul Earthquake}

\subsubsection{Epicenter and aftershock area}

HASKOv et al. (1983) located the mainshock and aftershocks up to 6 days after the mainshock with local and regional stations. Just as for the other events, their mainshock epicenter is about $35 \mathrm{~km}$ to the southwest of the PDE location. The aftershocks fall into two clusters at the far ends of a $40 \mathrm{~km}$ long region that is oriented nearly east-west. The north-south width is about $20 \mathrm{~km}$, with the mainshock epicenter at the extreme up-dip, i.e. southwestern, edge of the aftershock area. Again, it is unusual to see the epicenter at the up-dip edge of the aftershocks for a large subduction event, though the Playa Azul is a relatively small event.

\subsubsection{Body wave inversion for MTRFs, depth, and rupture process}

A Harvard CMT mechanism is available for this event, and the focal mechanism is nearly pure underthrusting. The fault plane strikes at $287^{\circ}$ with a dip of $20^{\circ}$, the auxiliary plane strike is $115^{\circ}$ with a dip of $70^{\circ}$, and the moment is $0.7 \times 10^{20} \mathrm{Nm}$ at a centroid depth of $32 \mathrm{~km}$. In a later study ASTIZ et al. (1987) find a solution very similar to the Harvard CMT, except that their fault dip is just $11^{\circ}$. TICHELAAR 
Table 3

Station data and some results from the Oct. 25, 1981 Playa Azul earthquake

\begin{tabular}{|c|c|c|c|c|c|c|c|c|c|c|c|c|}
\hline \multirow[b]{2}{*}{ Sta } & \multirow[b]{2}{*}{ Net } & \multirow[b]{2}{*}{ Comp } & \multirow[b]{2}{*}{ Phase } & \multicolumn{2}{|c|}{$\begin{array}{l}\text { Epicentral } \\
\text { params }\end{array}$} & \multirow{2}{*}{$\begin{array}{c}\text { Start } \\
\text { time } \\
3 \mathrm{hrs}+\end{array}$} & \multirow{2}{*}{$\begin{array}{l}\text { obs- } \\
\text { pre }\end{array}$} & \multirow{2}{*}{$\begin{array}{c}a \\
\text { factor }\end{array}$} & \multirow{2}{*}{$\begin{array}{c}\text { main-- } \\
\text { pre }\end{array}$} & \multirow{2}{*}{\multicolumn{2}{|c|}{$\begin{array}{l}\text { direct. } \Delta t, \mathrm{~s} \\
\text { top durat. }\end{array}$}} & \multirow[t]{2}{*}{$M_{0}$} \\
\hline & & & & $\Delta,{ }^{\circ}$ & $\mathrm{Az},{ }^{\circ}$ & & & & & & & \\
\hline NUR & W & $\mathrm{Z}$ & $P$ & 91.1 & 23 & $35: 17.1$ & -0.7 & 1.16 & 4.37 & & & \\
\hline $\mathrm{AKU}$ & W & Z & $P$ & 71.6 & 26 & $33: 33.6$ & -1.2 & 0.88 & 4.3 & 15 & 19 & 0.6 \\
\hline STU & W & Z & $P$ & 90.2 & 38 & $35: 14.3$ & +0.9 & 0.99 & 4.87 & & & \\
\hline VAL & W & Z & $P$ & 77.4 & 39 & $34: 7.5$ & -1.2 & 0.54 & 5.5 & 13 & 15 & 0.7 \\
\hline PTO & W & E & $P$ & 81.2 & 50 & $34: 28.3$ & -0.7 & 0.58 & 5.5 & & & \\
\hline SJG & W & $\mathrm{N}$ & $S H$ & 34.3 & 84 & $34: 22.6$ & -3.1 & 0.27 & & 16 & 20 & 3.6 \\
\hline CAR & W & Z & $P$ & 35.0 & 97 & 29: 5.9 & +0.1 & 1.16 & 5.6 & 15 & 18 & 0.8 \\
\hline ARE & W & Z & $P$ & 45.5 & 137 & $30: 36.9$ & -0.9 & 1.79 & 6.07 & & & \\
\hline NNA & W & $\mathrm{N}$ & $P$ & 38.8 & 138 & $29: 41.5$ & +3.7 & 2.94 & & 13 & 20 & 0.8 \\
\hline LPA & W & $Z$ & $P$ & 67.2 & 142 & $33: 9.7$ & +1.9 & 1.38 & $5.6]$ & & & \\
\hline RAR & W & Z & $P$ & 68.4 & 238 & $33: 20.6$ & +5.3 & 0.91 & 6.07 & & & \\
\hline AFI & W & Z & $P$ & 75.4 & 250 & $34: 1.7$ & +4.3 & 1.56 & 6.8 & 14 & 16 & 0.4 \\
\hline
\end{tabular}

"Net" code: W, WWSSN. "Comp": Z, vertical; N, north; E, east. "Phase": $P$ or $S H$ wave. "Epicentral params": distance and azimuth. "Start time": onset of observed waves, 3 hours plus the listed minutes:seconds. "obs-pre": arrival time residual. "a factor": the seismogram scale factors from omnilinear analysis, based on inversion at best depth and focal mechanism. "main-pre": time difference, in $\mathbf{s}$, between start and main pulse onset as measured on the seismograms. "direct. $\Delta t$ ": times of features in source functions, in s, "top" is peak moment release, "durat." is duration as measured by baseline-crossing time. " $M_{0}$ ": seismic moment of the source time functions, in $10^{20} \mathrm{Nm}$.

and RufF (1993) used the Playa Azul earthquake in their global study of earthquakes at the down-dip edge of the seismogenic zone; they concluded that the best estimate of point-source depth is $18 \mathrm{~km}$, but that the bootstrap uncertainty allowed the depth to be between 16 to $32 \mathrm{~km}$. SiNGH and MORTERA (1991) find a precursor in the source time function derived from single-station deconvolution. MENDOZA (1993) performed a detailed rupture process study of the Playa Azul event, he also notes a precursor to the main rupture process, and concludes that most of the moment release is concentrated just down-dip of the epicenter.

We invert $40 \mathrm{~s}$ of 12 body waves phases, $11 P$ waves and $1 S H$ waves at SJG, for the MTRFs with $30 \mathrm{~s}$ duration and a damping of 0.10 . Given the reduction of the MTRFs to the best double couple and time function, we find that the resultant match between synthetic and observed seismograms allows the depth to be anywhere between 20 and 30 to $35 \mathrm{~km}$. On the other hand, the MTRF parameter shows a fairly sharp minimum at $20 \mathrm{~km}$ depth, consistent with the depth estimate of TIChELAAR and RufF (1993). Since a depth of $20 \mathrm{~km}$ was acceptable in all tests, we use this depth for rupture process inversions. From the right side of Figure 8 , we see that the fault plane strike changes rapidly from $276^{\circ}$ at $20 \mathrm{~km}$ depth to $296^{\circ}$ 

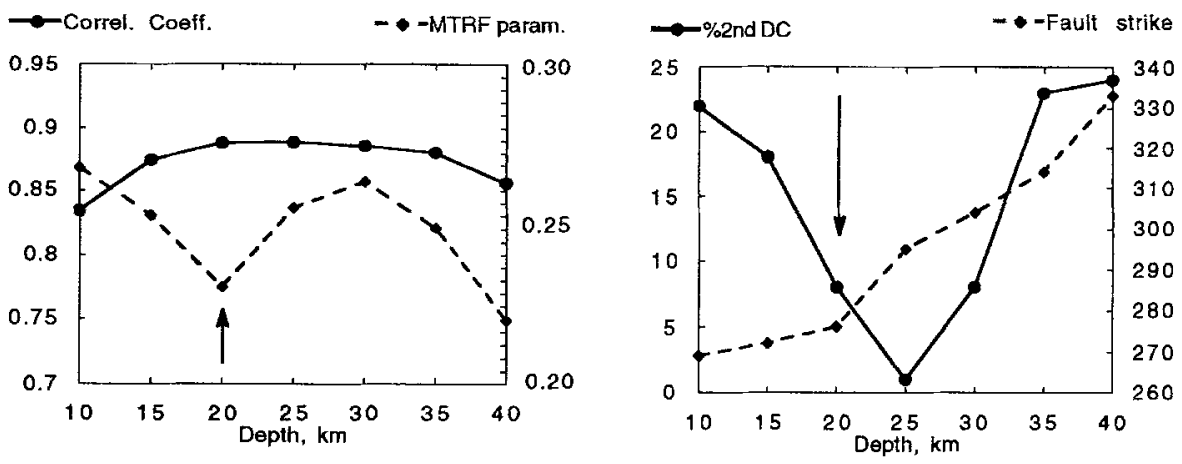

Figure 8

Various MTRF inversion and earthquake parameters as a function of depth for the 1981 Playa Azul earthquake. Same as Figure 3.

at $25 \mathrm{~km}$. We must conclude that the fault plane strike can be anywhere in this range. The auxiliary plane strike has a smaller range of $120^{\circ}$ to $125^{\circ}$, and the dip is between $67^{\circ}$ to $72^{\circ}$.

The basic character of the source time function in Figure 9 is a weak initiation, followed 4 to $6 \mathrm{~s}$ later by the single main pulse of moment release that peaks at about 12 to $15 \mathrm{~s}$ and then has a fairly sharp truncation of moment release centered at 15 to $18 \mathrm{~s}$. Thus, once again we see a time history similar to the 1973 Colima and 1979 Petatlan earthquakes, except that the main pulse is slightly shorter in duration with less seismic moment. As for the 1979 Petatlan event, the time shifts of the

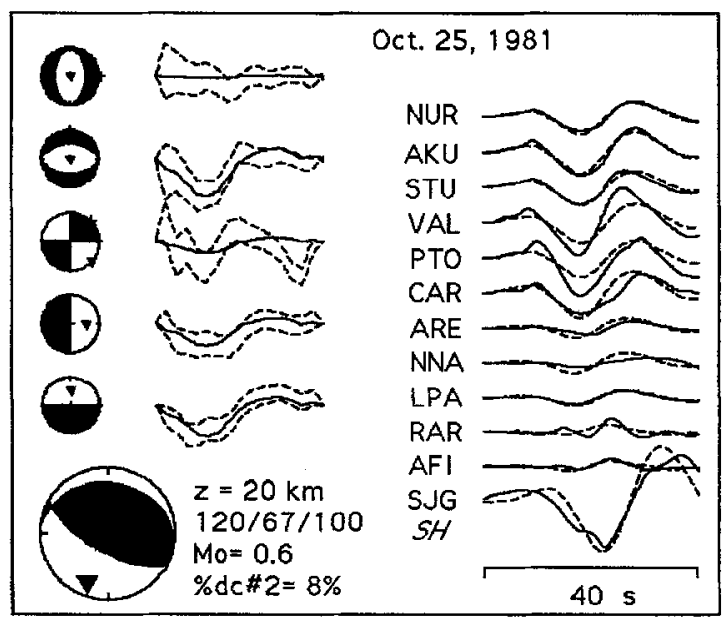

Figure 9

Inversion of seismograms for MTRFs for the 1981 Playa Azul earthquake, at a depth of $20 \mathrm{~km}$. Same as Figure 2. 
"hand-picked" features in the time history show no coherent directivity effects. In fact, the times of the truncation of moment release range over just one sampling interval. Thus, this lack of directivity implies that: (1) the termination of moment release was quite close to epicenter, within about $30 \mathrm{~km}$; and/or (2) the rupture termination occurred close to the same time over several parts of the rupture area. If we assume a rupture velocity of about $2 \mathrm{~km} / \mathrm{s}$, then the pulse duration of about $16 \mathrm{~s}$ allows the rupture front to cover all of the aftershock region of HASKOV et al. (1983). Since we cannot resolve any spatial details, we simply assume that the moment was released uniformly over the aftershock zone. This assumed moment distribution is consistent with the shape and duration of the time history, and is also quite similar to the model presented in MENDOZA (1993).

There is no distinct additional pulse of moment release after this main pulse, which has a seismic moment of $0.6 \times 10^{20} \mathrm{Nm}$ (Fig. 9), essentially the same as the overall moment release. The average displacement in the $20 \times 40 \mathrm{~km}^{2}$ rupture area is then about $2.9 \mathrm{~m}$. The pulse of moment release returns to the baseline at times that range from 15 to $20 \mathrm{~s}$. Thus, the total duration of moment release appears to be no longer than $20 \mathrm{~s}$. If we suppose that the rupture went down-dip for $30 \mathrm{~km}$ (see above), then the depth range of moment release would be $10 \mathrm{~km}$ for a $20^{\circ}$ fault dip (Harvard CMT), or $13 \mathrm{~km}$ for $25^{\circ}$ fault dip (the MTRF results in Fig. 9). This latter number seems consistent with the bootstrap error estimates for depth. Thus, we do not see anything highly unusual in the rupture process of the Playa Azul event; except that it initiated at the up-dip edge of the aftershock area, the fault dip is somewhat steeper, and the time function duration is somewhat long for the earthquake size.

\subsection{The 1985 Michoacan Aftershock}

We discuss the Sept. 21, 1985 aftershock before the Sept. 19, 1985 mainshock. Although this is a departure from the chronological order, we need to use the epicenter of the Sept. 21 event to relocate the Sept. 19 mainshock.

\subsubsection{Epicenter and aftershocks}

The Sept. 21, 1985 event was recorded by a local temporary network that was installed soon after the Sept. 19 mainshock (UNAM, 1986). The Sept. 21 epicentral location should be reliable. Furthermore, since UNAM (1986) used the same crustal structure as VALDES et al. (1982) used for the Petatlan aftershocks, the relative locations of the aftershocks between these two sequences should also be reliable. The UNAM (1986) location of the Sept. 21 event is: $17.62^{\circ} \mathrm{N}, 101.82^{\circ} \mathrm{W}$; this location is about $30 \mathrm{~km}$ southwest of the ISC location.

Seismicity that occurred after the Sept. 21 earthquake fills a region that is southeast of the presumed rupture zone of the Sept. 19 mainshock. UNAM (1986) considers the Sept. 21 earthquake as a separate "mainshock" in the sense that it 
extended the rupture zone beyond the limit of the Sept. 19 earthquake. As a caveat to this interpretation, there is one aftershock that occurred Sept. 20 within the UNAM aftershock zone of the Sept. 21 event.

The aftershock regions of UNAM (1986) show some overlap of the Sept. 21 and 1979 Petatlan regions. In detail, the Sept. 21 aftershocks occur in two main clusters, and the down-dip cluster does overlap with the inner aftershock zone of VALDES $e t$ al. (1982). STOLTE et al. (1986) show aftershocks that occurred from Sept. 22 to Oct. 5; their epicentral maps also show some overlap of the Sept. 21 region with the 1979 Petatlan aftershock zone.

We have picked the $P$-wave arrivals on a total of 33 analog and digital records. The $P$-wave arrival has an emergent character with an initial ramp before the main pulse. Although difficult for some records, we consistently picked the time of the initial ramp. If we use the travel-time residuals between our observed arrivals and the predicted times from the UNAM location, then the globally-derived epicenter is 40 to $50 \mathrm{~km}$ northwest of the UNAM epicenter - the typical bias seen for other Mexico events. We use the UNAM epicenter as the best location for the Sept. 21 event.

\subsubsection{Body-wave inversion for MTRFs, depth, and rupture process}

The Harvard CMT for the Sept. 21 event has a moment of $2.5 \times 10^{20} \mathrm{Nm}$ at a centroid depth of $21 \mathrm{~km}$, and the CMT yields an underthrusting focal mechanism on a fault plane with a strike and a dip of $296^{\circ}$ and $17^{\circ}$. The auxiliary plane strikes at $121^{\circ}$ with a dip of $73^{\circ} . P$-wave first motions at some stations require a steeper dip of the auxiliary plane, perhaps a dip of $78^{\circ}$. We inverted different combinations of stations with several different trial focal mechanisms to find the best point-source depth. The main conclusion is that depth is poorly resolved, and the best pointsource depth is between 10 and $25 \mathrm{~km}$. The MTRF inversion uses a damping of 0.1 , $60 \mathrm{~s}$ of seismogram, filtered with a $10 \mathrm{~s}$ duration triangle, and the MTRFs are sampled at $4 \mathrm{~s}$. WWSSN and digital seismograms are inverted together, the normalization is discussed in the Appendix. The MTRF inversion also produces a good fit to the seismograms over a broad depth range (Fig. 10); note that the MTRF parameter is less than 0.2 for depths between 15 to $35 \mathrm{~km}$. As seen in Figure 10, the fault strike is fairly constant for depths between 10 and $30 \mathrm{~km}$, it varies between $303^{\circ}$ and $294^{\circ}$. The auxiliary plane is even more stable, with a strike of $111^{\circ}$ to $114^{\circ}$. The overall best MTRF inversion, as reduced to a double couple, is for a depth of $25 \mathrm{~km}$, and is shown in Figure 11. The resultant focal mechanism has a fault plane strike and dip of $299^{\circ}$ and $12^{\circ}$, and the auxiliary plane strikes at $114^{\circ}$ with a dip of $78^{\circ}$. Note that the simple time history fits both the WWSSN long period and GDSN intermediate period seismograms in Figure 11. The seismic moment is about $1.1 \times 10^{20} \mathrm{Nm}$, based on the nondiffracted $P$ waves.

Source time functions are determined for the station groups depicted in Table 4. MENDOZA (1993) reports that a short-period precursor is observed 4 to $5 \mathrm{~s}$ before 

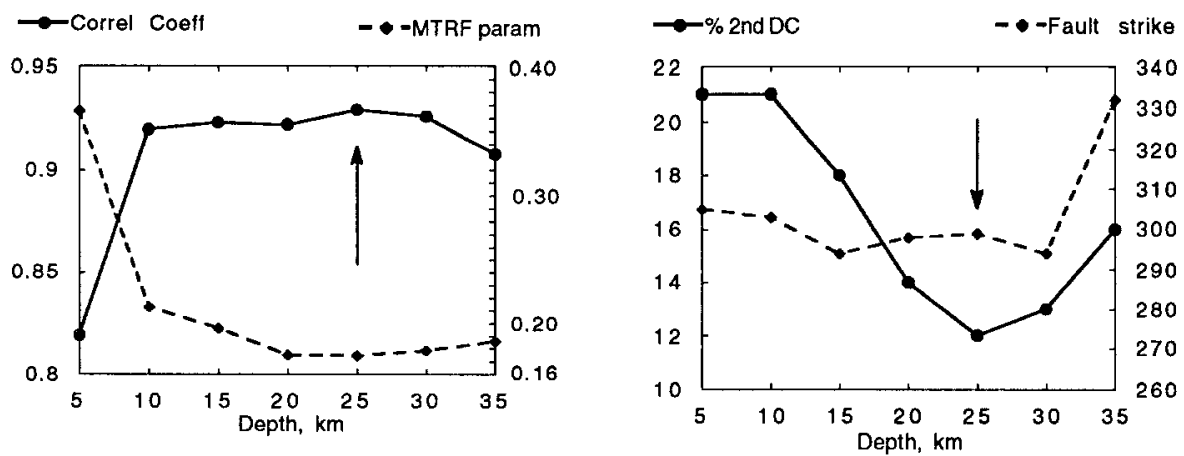

Figure 10

Various MTRF inversion and earthquake parameters as a function of depth for the Sept. 21, 1985 Michoacan aftershock. Same as Figure 3. Note that depth is poorly resolved.

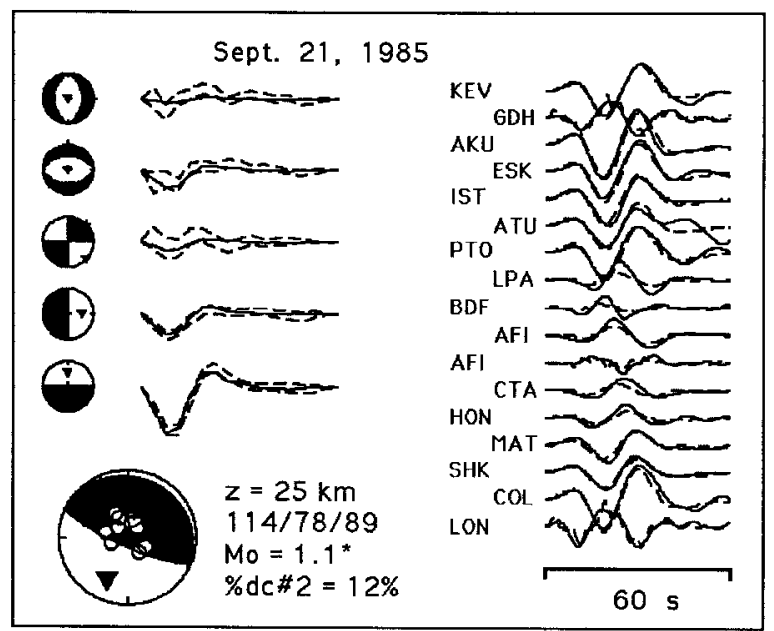

Figure 11

Inversion of seismograms for MTRFs for the Sept. 21, 1985 Michoacan aftershock, at a depth of $25 \mathrm{~km}$. Same as Figure 3.

the main pulse. Indeed, this precursor is responsible for the emergent $P$-wave arrival on long-period records, and it is expressed as an initial ramp in the time functions with a distinct increase in moment release at $4 \mathrm{~s}$ after initiation. This basic character is illustrated in Figure 12 with the time functions from the European and the combined Japan-North America station groups. The seismograms are smoothed with a $3 \mathrm{~s}$ triangle, time functions are sampled at $2 \mathrm{~s}$, with a damping of 0.10 . The impact of adding a digital "broad-band" station is to sharpen the features of the time function, though the basic features are the same as when inverting just the WWSSN seismograms. The moment release peaks at about $10 \mathrm{~s}$, and ends at 
Table 4

Station data and some results for the Sept. 21 Michoacan earthquake

\begin{tabular}{|c|c|c|c|c|c|c|c|c|c|c|}
\hline \multirow[b]{2}{*}{ Sta } & \multirow[b]{2}{*}{ Net } & \multirow[b]{2}{*}{ Comp } & \multirow[b]{2}{*}{ Phase } & \multicolumn{2}{|c|}{$\begin{array}{c}\text { Epicentral } \\
\text { params }\end{array}$} & \multirow{2}{*}{$\begin{array}{c}\text { Start } \\
\text { time } \\
1 \mathrm{hr}+\end{array}$} & \multirow{2}{*}{$\begin{array}{c}\text { obs- } \\
\text { pre }\end{array}$} & \multirow{2}{*}{$\begin{array}{c}a \\
\text { factor }\end{array}$} & \multirow{2}{*}{$\begin{array}{c}\text { direct. } \Delta t, \mathrm{~s} \\
\text { duration }\end{array}$} & \multirow[t]{2}{*}{$M_{0}$} \\
\hline & & & & $\Delta ?^{\circ}$ & $\mathrm{Az},{ }^{\circ}$ & & & & & \\
\hline KEV & W & $\mathrm{N}$ & $P$ & 85.8 & 16 & $49: 50.7$ & -0.3 & 0.427 & & \\
\hline GDH & G & IZ & $P$ & 59.5 & 18 & $47: 13.2$ & -3.1 & 0.44 & 15.6 & 1.1 \\
\hline AKU & $\mathrm{W}$ & $\mathrm{Z}$ & $P$ & 71.5 & 26 & $48: 32.3$ & -1.1 & 0.60 & & \\
\hline ESK & W & $\mathrm{Z}$ & $P$ & 80.5 & 35 & & & $0.51]$ & & \\
\hline IST & W & Z & $P$ & 105.9 & 37 & $51: 22.7$ & -0.9 & $3.38^{*}$ & & \\
\hline ATU & W & $\mathrm{E}$ & $P$ & 104.7 & 42 & $51: 17.4$ & -0.6 & $1.50^{*}$ & 17.4 & 0.4 \\
\hline PTO & W & $\mathrm{E}$ & $P$ & 81.0 & 50 & $49: 25.3$ & -1.4 & 0.31 & & \\
\hline LPA & W & Z & $P$ & $66: 8$ & 142 & 48: 6.6 & +2.1 & $0.78]$ & & \\
\hline BDF & $\mathrm{G}$ & IZ & $P$ & 62.6 & 119 & $47: 36.2$ & -0.9 & 0.54 & 16.2 & 1.8 \\
\hline $\mathrm{AFI}$ & W & $\mathrm{Z}$ & $P$ & 75.8 & 250 & $48: 49.5$ & -8.8 & 1.187 & & \\
\hline $\mathrm{AFI}$ & G & IZ & $P$ & 75.8 & 250 & & & 1.79 & 17.7 & 0.4 \\
\hline CTA & W & $\mathrm{Z}$ & $P$ & 115.9 & 256 & $52: 13.8$ & +5.2 & $6.89^{*}$ & & \\
\hline HON & W & $\mathrm{Z}$ & $P$ & 52.9 & 284 & $46: 30.7$ & +2.0 & 0.78 & 16.4 & \\
\hline MAT & W & Z & $P$ & 101.8 & 315 & $51: 5.4$ & +0.2 & $\left.2.11^{*}\right]$ & & \\
\hline SHK & W & Z & $P$ & 106.7 & 315 & $51: 34.0$ & +6.9 & $3.07^{*}$ & 17.6 & 0.3 \\
\hline $\mathrm{COL}$ & W & $\mathrm{E}$ & $P$ & 56.3 & 338 & $46: 52.0$ & -1.7 & $0.43]$ & & \\
\hline LON & $G$ & IZ & $P$ & 33.4 & 335 & & & 0.85 & 16.9 & 1.1 \\
\hline
\end{tabular}

"Net" code: W, WWSSN. G, GDSN. "Comp": Z, vertical; N, north; E, east; IZ, intermediate-period vertical. "Phase": $P$ wave. "Epicentral params": distance and azimuth. "Start time": onset of observed waves, 1 hour plus the listed minutes:seconds. "obs-pre": arrival time residual. " $a$ factor": the seismogram scale factors from omnilinear analysis, based on MTRF inversion at best depth, ${ }^{*}$ diffracted $P$ waves. "direct. $\Delta t$ ": times of features in source time functions, in $\mathrm{s}$, "duration" is duration as measured by baseline-crossing time. " $M_{0}$ ": seismic moment of the source time functions, in $10^{20} \mathrm{Nm}$.

around $20 \mathrm{~s}$. This basic time history is quite similar to that observed for all four earthquakes discussed above. Clearly, rupture initiation along the Mexico subduction zone is characterized by a low level of moment release for 4 to $6 \mathrm{~s}$, followed by a single simple pulse of moment release. The maximum moment resolved by the body wave inversion is about $1.5 \times 10^{20} \mathrm{Nm}$.

Our directivity study includes "hand-picked" times for the termination of moment release as measured by the baseline-crossing time. This time was distinctly less at the northern European stations. The relocation places this feature only $8 \mathrm{~km}$ to the northeast, but the error ellipse includes the reference epicenter. Thus, there is no resolvable directivity in the "hand-picked" times. Next, we try tomographic imaging to test if there is some overall preferred rupture direction. We tested for all azimuths between $80^{\circ}$ and $240^{\circ}$, and found that a rupture direction of $100^{\circ}$ provides the best fit to the time functions (shown in Fig. 13). The rupture velocity is poorly 


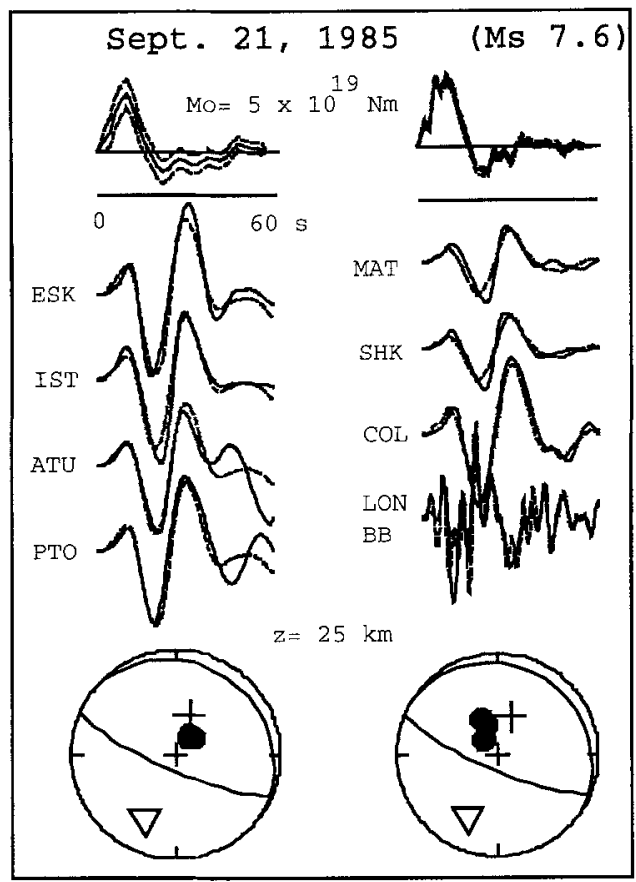

Figure 12

Inversion for source time functions for two different station groups, at a depth of $25 \mathrm{~km}$. Time functions are at top, observed (solid) and synthetic (dashed) seismograms are shown below each time function. Note the distinct precursor before the main pulse. Position of stations on the focal sphere is shown at bottom.

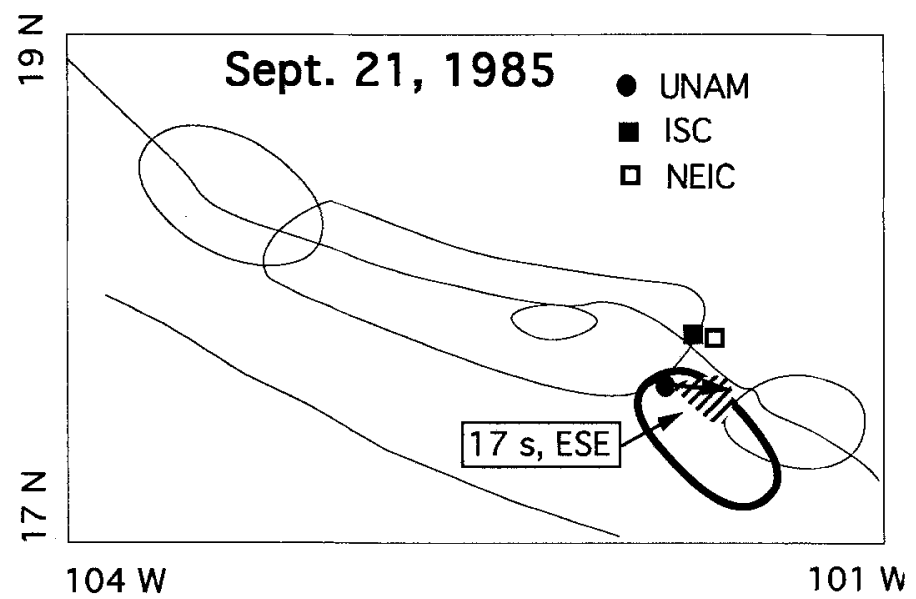

Figure 13

Base map with summary of location information for the Michoacan aftershock. Different epicenters are plotted, as is our best estimate of the region of concentrated moment release (hachured area). 
resolved. Nonetheless, the overall rupture direction of $100^{\circ}$ offers some corroboration of the detailed rupture model of MENDOZA (1993), where he places most of the moment release to the southeast of the epicenter. If we use a seismic moment of $2.5 \times 10^{20} \mathrm{Nm}$ and a rupture area of $30 \times 60 \mathrm{~km}^{2}$ from UNAM (1986), then the average displacement is about $4.5 \mathrm{~m}$; distinctly larger than any of the previous earthquakes. One implication is that the major moment release of the Sept. 21 event does overlap the inner aftershock region of the 1979 Petatlan event.

\subsection{Sept. 19, 1985 Michoacan Mainshock}

\subsubsection{Epicenter and aftershocks}

Determination of the Sept. 19 Michoacan mainshock epicenter is a difficult problem for two reasons: (1) the typical bias for teleseismically-determined epicenters along Mexico; and (2) due to the emergent nature of rupture initiation, it is possible that the arrival data are not all measuring the same feature. The ISC epicenter is clearly too far inland, but it is curious that the PDE epicenter is displaced to the southwest from the ISC location. The most reliable location is from UNAM (1986). They fix the depth at $16 \mathrm{~km}$, and used four arrivals from triggered strong-ground motion stations, including $P$ and $S$ waves from the station CAL that is only about $10 \mathrm{~km}$ from their epicenter. Most recent rupture process studies have used the UNAM (1986) epicenter as the reference point (e.g., EKSTRÖM, 1989).

We examine all possible $P$-wave records from the WWSSN and global digital networks to "pick" the arrival times. We soon discovered that the $P$ wave arrives at different times for the short-period and long-period channels at the same station. There is a relatively small precursor about $5 \mathrm{~s}$ before the sharp onset of major moment release. From our experience with the above-described Mexico earthquakes, we are not surprised to see some type of emergent rupture initiation. Local stations and most teleseismic short-period records see the presursor as the first arrival, but other stations might pick the main pulse onset as the first arrival. Indeed, when we compare our arrival times to those reported in the ISC bulletin, there are many "picks" that are the precursor, a few that are the main pulse onset, and several that are somewhere in between. Thus, we speculate that the poor epicenter estimate from ISC is due to a data set with mixed arrivals. Many WWSSN long-period vertical records are off-scale for the Sept. 19 event, but these records offer reliable identification of both the precursor and main pulse onset arrivals. The overall time difference between the precursor and main onset is about $5 \mathrm{~s}$, the times vary from 4 to $6 \mathrm{~s}$ (Table 5). There was no significant directivity in our measured times, hence the relative location of the precursor and main onset could be the same or differ by up to $20 \mathrm{~km}$, given the scatter in our times. In contrast to our choice of start times for all the above earthquakes, the inversion of the Sept. 19 seismograms will use the main pulse onset as the start time. 
Table 5

Time delay between precursor and main pulse onset for the Sept. 19, 1985 Michoacan event

\begin{tabular}{|c|c|c|c|c|}
\hline \multirow[b]{2}{*}{ Sta } & \multirow[b]{2}{*}{ Net } & \multicolumn{2}{|c|}{$\begin{array}{l}\text { Epicentral } \\
\text { params }\end{array}$} & \multirow[t]{2}{*}{$\begin{array}{l}\text { Delay } \\
\text { time, s }\end{array}$} \\
\hline & & $\Delta,{ }^{\circ}$ & $\mathrm{Az},{ }^{\circ}$ & \\
\hline JAS & G & 25.0 & 324 & 4.2 \\
\hline \multirow[t]{2}{*}{ COL } & W & 55.3 & 338 & 5.1 \\
\hline & $\mathrm{G}$ & 55.3 & 338 & 3.3 \\
\hline RSNT & $T$ & 44.7 & 352 & 4.3 \\
\hline RSON & $\mathrm{T}$ & 33.0 & 10 & 4.5 \\
\hline KEV & W & 85.0 & 16 & 5.5 \\
\hline SSB & Geo & 88.8 & 42 & 6.0 \\
\hline SJG & W & 34.3 & 85 & 4.9 \\
\hline TRN & W & 40.3 & 95 & 5.7 \\
\hline BDF & G & 63.4 & 119 & 5.5 \\
\hline LPB & W & 48.5 & 134 & 5.7 \\
\hline
\end{tabular}

"Net" code: W, WWSSN; G, GDSN; T, regional test network; Geo, GEOSCOPE. "Epicentral params": distance and azimuth. "Delay time", in $s$.

We do not know if the UNAM (1986) epicenter is the location of the precursor or main pulse onset, but we speculate that it is probably the precursor location. Recall that the UNAM (1986) epicenter for the Sept. 21 event is well determined. Thus, we use our time-picks of the Sept. 19 and Sept. 21 events at common stations to locate the main pulse onset of the Sept. 19 event relative to the Sept. 21 epicenter. The relocation is fairly stable with respect to the use of times from either analog or digital stations. The results from the digital readings (Table 6) place the Sept. 19 main pulse onset $124 \mathrm{~km}$ to the northwest of the Sept. 21 event along an azimuth of $288^{\circ}$ (alternatively, $118 \mathrm{~km}$ to the west and $39 \mathrm{~km}$ to the north). The error ellipse is essentially circular with a radius of $10 \mathrm{~km}$. Times read from analog records place the epicenter $103 \mathrm{~km}$ to the northwest aiong an azimuth of $290^{\circ}$. The main pulse onset epicenter is $24 \mathrm{~km}$ southwest of the UNAM (1986) epicenter, or just $12 \mathrm{~km}$ on the oceanward side of station CAL.

Aftershocks of the Sept. 19 event are small and infrequent (UNAM, 1986). The rupture area of the Sept. 19 event is mostly defined by events after Sept. 21. At the northwestern end, the aftershocks abut the presumed epicenter for the 1973 Colima earthquake. There is a cluster of aftershocks just a few $\mathrm{km}$ northwest of the main pulse onset location. Most of the aftershocks in the southeastern end are in the Sept. 21 aftershock zone of UNAM (1986). There are a few scattered aftershocks that are down-dip of the 1981 Playa Azul earthquake. The southeastern down-dip corner of the UNAM (1986) aftershock area is defined by several aftershocks, including one of magnitude greater than 4 that occurred within one day after the Sept. 21 event. 
Table 6

Main pulse $P$ arrival times at broad-band digital stations, used to relocate the Sept. 19, 1985 main pulse onset with respect to the Sept. 21, 1985 epicenter

\begin{tabular}{|c|c|c|c|c|c|}
\hline \multirow[b]{2}{*}{ Sta } & \multirow[b]{2}{*}{ NET } & \multicolumn{2}{|c|}{$\begin{array}{c}\text { Epicentral } \\
\text { params }\end{array}$} & \multirow{2}{*}{$\begin{array}{l}\text { Sept. } 19 \\
\text { arrival time } \\
13 \mathrm{hrs}+\end{array}$} & \multirow{2}{*}{$\begin{array}{c}\text { Sept. } 21 \\
\text { arrival time } \\
1 \mathrm{hr}+\end{array}$} \\
\hline & & $\Delta,{ }^{\circ}$ & $\mathrm{Az},{ }^{\circ}$ & & \\
\hline RSON & $\mathrm{T}$ & 33.0 & 10 & $24: 29.1$ & $43: 57.2$ \\
\hline KEV & $\mathrm{G}$ & 85.0 & 16 & $30: 26.4$ & $49: 54.9$ \\
\hline GDH & $\mathrm{G}$ & 58.8 & 18 & $27: 50.7$ & $47: 18.6$ \\
\hline RSNY & $\mathrm{T}$ & 34.8 & 36 & $24: 45.2$ & 44: 9.6 \\
\hline RSCP & $\mathrm{T}$ & 22.5 & 38 & $22: 55.3$ & $42: 19.1$ \\
\hline SCP & G & 30.5 & 38 & $24: 6.1$ & $43: 30.8$ \\
\hline SSB & Geo & 88.8 & 42 & $30: 43.6$ & $50: 8.0$ \\
\hline NE17 & Nar & 84.4 & 50 & $30: 27.0$ & $49: 50.3$ \\
\hline BDF & $\mathrm{G}$ & 63.4 & 119 & $28: 19.9$ & $47: 37.5$ \\
\hline $\mathrm{AFI}$ & $\mathrm{G}$ & 75.7 & 250 & $29: 36.1$ & 49: 9.8 \\
\hline LON & G & 32.4 & 335 & $24: 23.8$ & $43: 56.3$ \\
\hline COL & $\mathrm{G}$ & 55.3 & 338 & $27: 26.0$ & $46: 57.2$ \\
\hline RSNT & $\mathrm{T}$ & 44.7 & 352 & $26: 7.4$ & $45: 37.2$ \\
\hline RSSD & $\mathrm{T}$ & 25.5 & 357 & $23: 25.3$ & $42: 55.2$ \\
\hline
\end{tabular}

"Net" code: W, WWSSN; G, GDSN; T, regional Test network; Geo, GEOSCOPE; Nar, NARS. "Epicentral params": distance and azimuth. "Sept. 19 arrival time", 13 hours plus the listed minutes:seconds. "Sept. 21 arrival time", I hour plus the listed minutes:seconds.

EкsтRöм (1989) modeled two magnitude 5 aftershocks that are located near the down-dip edge in the Sept. 19 epicentral region. The depth of these two events is 15 to $16 \mathrm{~km}$, for a crustal structure modified from VALDES et al. (1982). These depths place the down-dip edge of the Sept. 19 mainshock within the depth range of TichelaAR and RUFF (1993). For some final comments on the 1985 aftershocks, the largest "aftershock" with $M_{s}$ of 7.0 occurred April 30, 1986, and is located at the northwestern end of the aftershock zone; and an event occurred at the southeastern end on Sept. 28, 1985 with a centroid depth of $41 \mathrm{~km}$ and a strike-slip mechanism.

UNAM (1986) estimates the aftershock area to be $170 \times 50 \mathrm{~km}^{2}$. With a seismic moment of $11 \times 10^{20} \mathrm{Nm}$ (ЕKSTRÖM, 1989), and a crustal rigidity, the average displacement across the aftershock area is $4.3 \mathrm{~m}$. The previous rupture in the central part of the Michoacan zone was in 1911, hence the accumulated tectonic displacement is less than $4 \mathrm{~m}$. Therefore, any concentration of moment release within the aftershock area would qualify as an "official" asperity. The estimates of coseismic displacement can be decreased if we assume a mantle rigidity; but this change is difficult to justify given the shallow depth of the Mexico earthquakes. The convergence rates of 49 to $55 \mathrm{~mm} /$ year are from NUVEL; global constraints make it difficult to change these numbers by a factor of two or so. Overall, it would seem that the coseismic displacement of the recent sequence of earthquakes is greater 
than required to keep up with plate motions. A simple mechanical model of a subduction zone segment with interacting asperities can produce "synthetic earthquake" sequences where the coseismic displacements are greater than tectonic motions for several events, but there must be an occasional "unusual" event that resets the sequence (RUFF, 1992a).

\subsubsection{Body-wave inversion and rupture process}

Due to the large rupture length and strong directivity effects in the body waves, long-period surface waves provide the most reliable average moment tensor and focal mechanism for this event. We found that the focal mechanism of EISSLER et al. (1986), with the fault dip changed to $17^{\circ}$, can provide a good match of the body waves. While the fault strike of EISSLER et al. (1986) is $288^{\circ}$, the Harvard CMT has a fault strike of $301^{\circ}$. As expected, the best equivalent point-source depth is poorly resolved and can be chosen anywhere between 10 to $27 \mathrm{~km}$. The stations are separated into azimuthal groups as indicated in Table 7, and the source time

Table 7

Station used for P-wave inversion and some directivity results for the 1985 Michoacan mainshock

\begin{tabular}{|c|c|c|c|c|c|c|c|c|}
\hline \multirow[b]{3}{*}{ Sta } & \multirow[b]{3}{*}{ Net } & \multirow[b]{3}{*}{ Comp } & \multirow{2}{*}{\multicolumn{2}{|c|}{$\begin{array}{c}\text { Epicentral } \\
\text { params. }\end{array}$}} & \multirow{3}{*}{$\begin{array}{c}\text { Start } \\
\text { time } \\
13 \mathrm{hrs}+\end{array}$} & \multicolumn{3}{|c|}{ Directivity $\Delta t, \mathrm{~s}$} \\
\hline & & & & & & \multirow{2}{*}{$\begin{array}{l}\text { 1st pulse } \\
\text { end }\end{array}$} & \multicolumn{2}{|c|}{ 2nd pulse } \\
\hline & & & $\Delta,,^{\circ}$ & $\mathrm{Az},{ }^{\circ}$ & & & peak & end \\
\hline KEV & G & IZ & 85.0 & 16 & $30: 28.07$ & & & \\
\hline GDH & $G$ & $\mathrm{IZ}$ & 58.8 & 18 & & & & \\
\hline AKU & W & $\mathrm{E}$ & 70.9 & 26 & $29: 12.9$ & & & \\
\hline IST & W & $\mathrm{Z}$ & 105.5 & 36 & 32: 6.4 & 19.6 & 31.0 & 41.0 \\
\hline SCP & $\mathrm{G}$ & IZ & 30.5 & 38 & $24: 36.3$ & & & \\
\hline ATU & W & $\mathrm{E}$ & 104.3 & 41 & 32: 0.0 & & & \\
\hline TOL & G & $I Z$ & 84.4 & 50 & $30: 19.8]$ & & & \\
\hline WIN & W & $\mathrm{Z}$ & 123.5 & 105 & $33: 26.47$ & & & \\
\hline $\mathrm{BDF}$ & G & $\mathrm{IZ}$ & 63.4 & 119 & $28: 20.7$ & 20.4 & 30.7 & 39.3 \\
\hline LPA & W & $\mathrm{Z}$ & 67.8 & 142 & $28: 48.3]$ & & & \\
\hline AFI & $\mathrm{W}$ & $\mathrm{Z}$ & 75.7 & 250 & $29: 37.27$ & & & \\
\hline AFI & $\mathrm{G}$ & IZ & 75.7 & 250 & $29: 36.5$ & & & \\
\hline CTA & W & $Z$ & 115.7 & 256 & $32: 47.3$ & 25.0 & 37.1 & 48.6 \\
\hline HNR & W & $\mathrm{E}$ & 100.2 & 263 & $31: 38.2$ & & & \\
\hline PMG & W & $\mathrm{Z}$ & 112.3 & 267 & $32: 34.0]$ & & & \\
\hline GUA & W & $\mathrm{Z}$ & 106.5 & 291 & $32: 5.17$ & 25.5 & 38.7 & 50.5 \\
\hline ANP & W & $\mathrm{Z}$ & I19.1 & 314 & $33: 6.5$ & & & \\
\hline MAT & W & $\mathrm{E}$ & 100.9 & 314 & $31: 43.0$ & & & \\
\hline SHK & W & $\mathrm{Z}$ & 105.7 & 315 & $32: 8.2$ & 23.2 & 35.5 & 47.1 \\
\hline HKC & W & $\mathrm{Z}$ & 126.0 & 317 & $33: 35.7$ & & & \\
\hline LON & G & $\mathrm{IZ}$ & 32.4 & 335 & $24: 23.4$ & & & \\
\hline $\mathrm{COL}$ & G & IZ & 55.3 & 338 & $27: 25.4$ & & & \\
\hline
\end{tabular}

"Net" code: W, WWSSN; G, GDSN. "Comp": Z, vertical; N, north; E, east; IZ intermediate-period vertical. "Epicentral params": distance and azimuth. "Start time": onset of observed waves, 13 hours plus the listed minutes:seconds. "directivity $\Delta t$ ": times of features in source time functions, in $\mathrm{s}$. 
functions are determined. As described by many previous investigators, the basic time history is a double event with strong directivity placing the second event to the southeast (see Fig. 14). For example, the "hand-picked" peak of the second pulse of moment release follows the main pulse onset by $31 \mathrm{~s}$ to the southeast azimuth, and by 37 to $39 \mathrm{~s}$ for western azimuths. We could consistently identify three features for the "hand-picked" directivity analysis: end of the first pulse of moment release; peak of the second pulse; and end of the second pulse. Examples of our "handpicked" times for the ends of the first and second pulses are shown in Figure 14. The locations of these features are shown in Figure 15, all relative to our epicenter for main pulse onset ("LP rupture initiation"). The peak of moment release of the second pulse is always located half-way between the truncations of the two pulses. All three features are located at the extreme down-dip edge in the eastern part of the aftershock area. Tomographic imaging of the source time functions finds the overall best rupture direction to be $100^{\circ}$, with a preferred rupture velocity of $2.0 \mathrm{~km} / \mathrm{s}$. The "hand-picked" directivity of the end of the second pulse gives a rupture direction that is the same as the tomographic imaging, but with an apparent rupture velocity of $2.9 \mathrm{~km} / \mathrm{s}$. EKSTRÖM (1989; also see EKSTRÖM and DzIEWONSKI, 1986) also obtains an overall rupture velocity direction and velocity for his body-

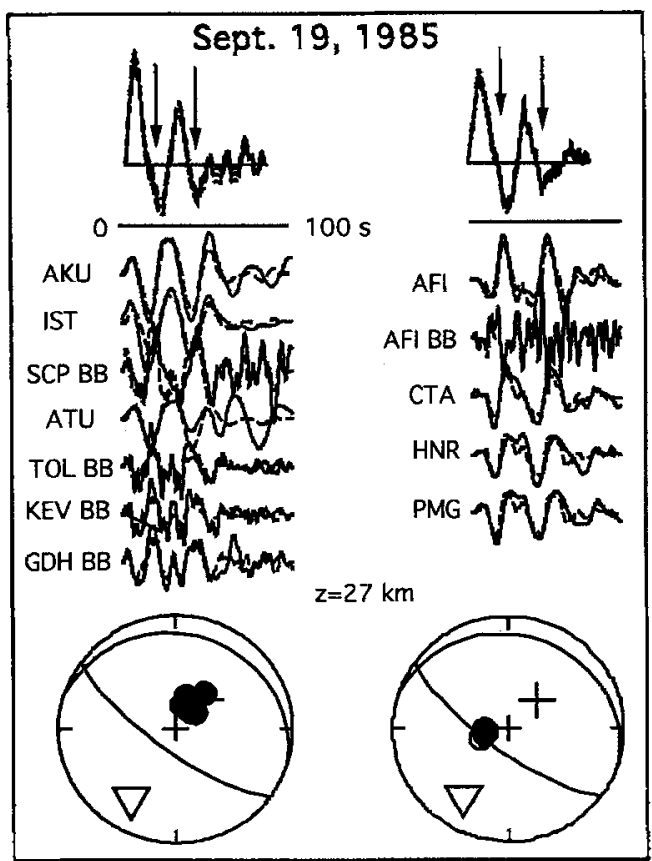

Figure 14

Inversion for source time functions for two different station groups, at a depth of $27 \mathrm{~km}$, for the Michoacan mainshock. Same as Figure 12. The double event nature is clearly seen, and the arrows show our directivity time picks. 


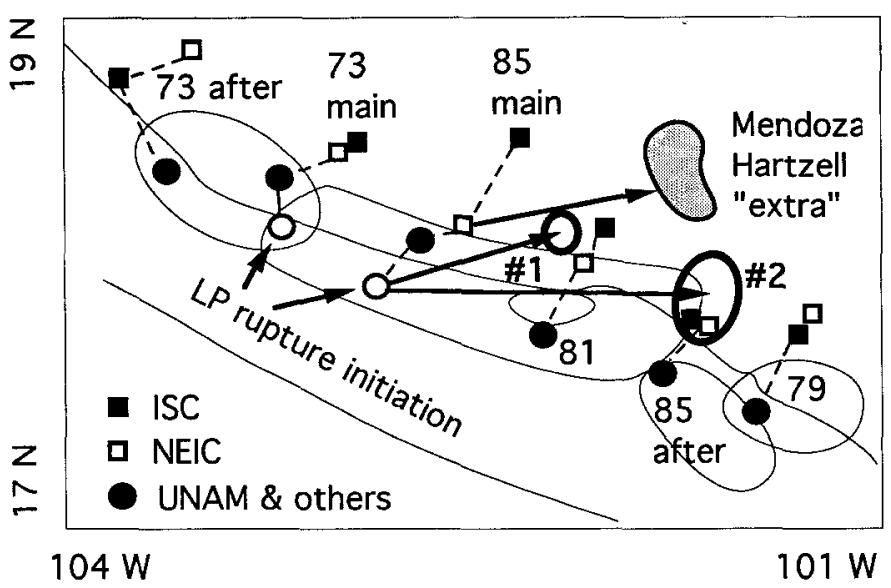

Figure 15

Map of Mexico that summarizes directivity results for the Michoacan mainshock and epicentral bias for all earthquakes. We use the epicenters labeled "LP rupture initiation" for the 1973 Colima and 1985 mainshock events, and we use the regional determinations of epicenter for the other events (solid dots, labeled as "UNAM \& others"). The ISC and NEIC epicenters generally agree with each other, but are systematically biased with respect to the regional epicenters. There is an additional problem for the 1985 mainshock (see text). The arrows and error ellipses for features \#1 and \#2 show our directivity results for the 1985 mainshock; we place the moment release of the second event along the down-dip edge of the aftershock zone between \#1 and \#2. MENDOZA and HARTZELL (1989) found an "extra" asperity; if we moved our epicenter down-dip to the NEIC epicenter, then we would move the second event down-dip close to the "extra" asperity. Conversely, perhaps the "extra" asperity can be moved up-dip to our location of the second event.

wave inversion; he finds a rupture direction of $97^{\circ}$ and rupture velocity of $2.4 \mathrm{~km} / \mathrm{s}$. Thus, although the details of the techniques used by EKSTRÖM (1989) and ourselves are quite different, and we used a total of 22 analog and digital stations while EKSTRÖM (1989) used 12 "broad-band" digital records, the two teleseismic bodywave studies give essentially the same result for moment release projected onto a one-dimensional "rupture ray." As concluded by nearly all the previous teleseismic studies, the temporal gap in moment release between the double events corresponds spatially to the 1981 Playa Azul event, and moment release is concentrated in the southeastern corner of the UNAM aftershock region. Our results do not make a clear statement as to whether there was no significant moment release in the 1981 Playa Azul zone, but we do locate the moment release of the second event in the southeastern corner. We see no evidence to continue the rupture process beyond the southeastern limit of the UNAM (1986) aftershock zone. Figure 15 also shows a summary of the epicentral location bias for all earthquakes. We show the epicenters used in our analysis, and related information is listed in Table 8.

The remaining key aspect of the rupture process of the Sept. 19 event is the additional "extra" asperity (Fig. 15) of MendOZA and HARTZELl (1989; also see HOUSTON and KANAMORI, 1986 for a somewhat different interpretation). The 
Table 8

Summary of origin times, epicenters, and depths for the five earthquakes. These parameters are used to calculate the theoretical arrival times in the previous tables

\begin{tabular}{lcccccc}
\hline Earthquake & Date & $M_{s}$ & $\begin{array}{c}\text { Origin Time } \\
\text { hr:min:sec }\end{array}$ & Lat. & Lon. & km \\
\hline Colima & Jan. 30, 1973 & 7.5 & $21: 01: 13.8$ & 18.20 & -103.18 & 20 \\
Petatlan & Mar 14, 1979 & 7.6 & $11: 07: 11.2$ & 17.46 & -101.46 & 15 \\
Playa Azul & Oct. 25, 1981 & 7.3 & $03: 22: 13.0$ & 17.75 & -102.25 & 20 \\
Michoacan & Sept. 19, 1985 & 8.1 & $13: 17: 53.7$ & 17.97 & -102.85 & 27 \\
Michoacan & Sept. 21, 1985 & 7.5 & $01: 37: 12.7$ & 17.62 & -101.82 & 25 \\
\hline
\end{tabular}

All hypocentral parameters for the Petatlan event are from GeTtrust et al. (1981). All hypocentral parameters for the Playa Azul events are from Haskov et al. (1983). Michoacan aftershock epicenter is from UNAM (1986). Other parameters are described in text.

MENDOZA and HARTZELL study used the local strong-ground motion records with a few SRO-type long-period records to invert for the two-dimensional spatial distribution of slip across a specified fault plane. They argue that the deep extra asperity is resolved by the data. The local records presumably provide the resolution to split the second event into two separate locations along the dip direction. Our tomographic imaging method woud find the average location between their shallow and deep high-slip regions. We wish to point out that MENDOZA and HARTZELL used the PDE epicenter as the reference point to start the rupture front in their model (see Fig. 15). Although one might suppose that the local records could constrain the absolute location of moment release, we offer the possibility that their spatial locations may depend on the choice of a reference point. Now note that if we were to shift our reference epicenter down-dip to the UNAM or PDE location in Figure 15, our spatial location of the second pulse would be about $20 \mathrm{~km}$ down-dip of the aftershock zone edge, and approximately halfway between the separate high-slip zones of MENDOZA and HARTZELL (1989). Hence, we would have to conclude that our teleseismic results were compatible with the model of MENDOZA and HARTZELL (1989). If we are allowed to shift their pattern toward the trench by about $30 \mathrm{~km}$, then the center of their down-dip extra asperity is at the down-dip edge of the UNAM (1986) aftershock region. We speculate that this trenchward shift of their slip pattern would reconcile their high-slip regions with all the other indications that seismic coupling goes no further down-dip than the UNAM (1986) aftershock zone.

\section{Discussion of Results}

Our discussion starts with some detailed seismological aspects of these earthquakes, and we end with some seismological and tectonic generalizations. 


\subsection{Radiated Wave Energy}

Recall from the earlier discussion the question of whether radiated wave energy estimates are systematically less than expected from the energy-moment formula of KANAMORI (1977). Since we have determined some aspects of the space-time history of moment release for three earthquakes, we can also determine the radiated wave energy of the 1973 Colima event, and the 1985 Michoacan mainshock and aftershock. The source time function duration for these earthquakes is at least $20 \mathrm{~s}$, thus the teleseismic body waves with periods of a few seconds and greater should contain most of the radiated wave energy (see KIKUCHI and FUKAO, 1988, for more discussion of this point). As KIKUCHI and FUKAO (1988) give an energy estimate for the 1985 Michoacan mainshock, we provide an independent estimate based on: a different teleseismic data set; a different inversion procedure; and different assumed fault finiteness. In addition, we will add energy estimates for two additional earthquakes. The radiated wave energy is presented as the ratio of energy to the seismic moment.

For the 1985 Michoacan mainshock, we can see from Figure 16 that our upper bound on radiated wave energy is the same as the KIKUCHI and FuKaO (1988) estimate, while our lower bound is a factor of four less. Our independent calculation supports the result of KIKUCHI and FUKAO (1988). The wave energy estimates for the 1973 Colima and the 1985 Michoacan aftershock are 0.1 to $0.2 \times 10^{-5}$, similar to the 1985 mainshock. Thus, these earthquakes add two more examples to the list in KIKUCHI and FUKAO (1988) of large subduction earthquakes with a $E / M_{0}$ ratio less than one-tenth the "expected" value of $5 \times 10^{-5}$. As discussed in KANAMORI (1977) and KIKUCHI and FUKAO (1988), the "expected" energy/moment ratio is

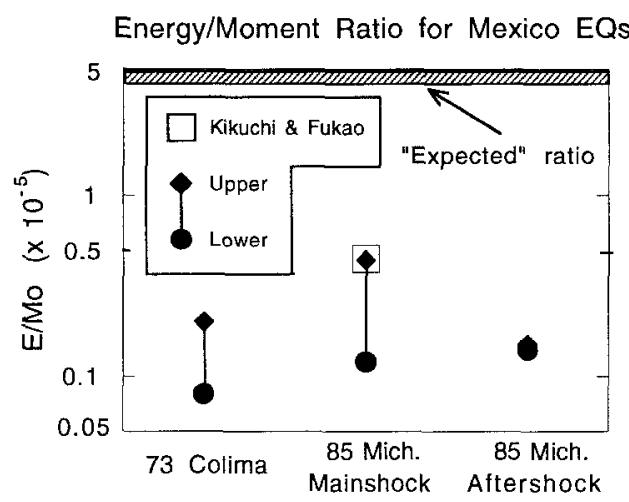

Figure 16

The energy/seismic moment ratio for the Colima and Michoacan earthquakes. Given the uncertainty in some of the rupture parameters, we calculate upper and lower bounds on the radiated wave energy. The value of this ratio calculated by KIKUCHI and FUKAO (1988) for the Michoacan mainshock is also plotted. The "expected" value of the ratio is $5 \times 10^{-5}$. Our calculations show that the radiated wave energy is only about $2 \%$ to $10 \%$ of the expected value. 
based on two assumptions: (1) the stress drop is a typical value of about 30 bars; and (2) the seismic efficiency is $100 \%$. Hence, the $E / M_{0}$ ratio can be lower if the stress drop is lower, the seismic efficiency is lower, or a combination of these two. Seismic efficiency is a measure of the frictional properties during the rupture process, and an efficiency of $100 \%$ results from the dynamic frictional stress equal to the final stress on the fault. If the average dynamic frictional stress is greater than the final stress, then the efficiency is less than 100\%. KIKUCHI and FuKaO (1988) and KIKUCHI (1990) argue that the observed values of the energy/moment ratio are explained by a seismic efficiency of only $1 \%$ to $10 \%$. Since our estimates of the static stress drop of the 1973 Colima and 1985 Michoacan aftershock are in the range of 30 to 40 bars, then we are also compelled to argue that the seismic efficiency of the large Mexico earthquakes is only about $2 \%$ to $10 \%$. However, other evidence exists that the above conclusions may not be correct. KANAMORI et al. (1993) have used the "direct" method, described as method \#1 in Section 2.4, to estimate energy of California earthquakes, and they find that the observed energy agrees with the "expected" value. Even more relevant to our study are the results of SINGH and ORDAZ (1993), who apply the "direct" method to Mexico earthquakes, including the 1985 Michoacan earthquakes. They find far more energy in the radiated waves than we do-their results are roughly compatible with the "expected" value. How to reconcile these results? As one possibility, some recent numerical experiments that we have performed indicate that inversion for the rupture process of large earthquakes may "lose" much of the wave energy (see, e.g., RUFF, 1992b). This important question must be resolved in future studies.

\subsection{Fault Geometry, Slip Vectors, and Plate Motions}

Figure 17 shows estimates of the strike and dip of the fault plane and the slip vector direction for the five earthquakes. For our results, we have indicated the acceptable ranges in these parameters by the boxes. Given the scatter in the results, it seems that a fault strike of $290^{\circ}$ to $295^{\circ}$ would be acceptable for all five events. If we focus on fault strike determinations by the same investigator, the Harvard CMT fault strikes are between $287^{\circ}$ and $306^{\circ}$, while our preferred MTRF fault strikes range from $272^{\circ}$ to $317^{\circ}$. The only earthquake for which the range in MTRF results do not include the overall value of $290^{\circ}-295^{\circ}$ is the 1979 Petatlan earthquake, with a preferred strike of $272^{\circ}$. However, since two other investigators found a fault strike of $290^{\circ}$ or greater, we should conclude that all five events allow the same fault strike.

Fault dip angles from the Harvard CMT solution and our study are shown in the middle part of Figure 17. The MTRF results give a fault dip of $12^{\circ}$ to $16^{\circ}$, except for the 1981 Playa Azul event which has a distinctly steeper dip of $25^{\circ}$. The Harvard CMT solution for the Playa Azul event yields a dip angle of $20^{\circ}$. Thus, it appears that the Playa Azul event does have a steeper fault plane dip as compared 


\section{Fault Plane \& Slip Vector Geometry}

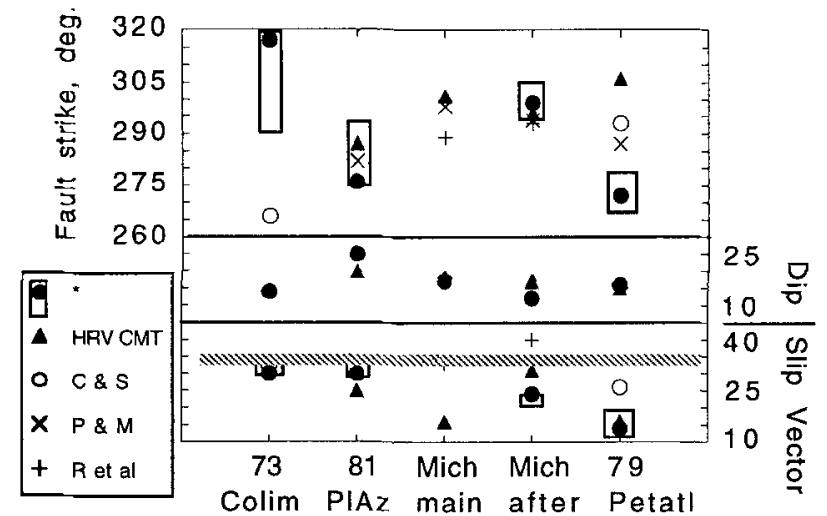

Figure 17

Summary of different estimates of focal mechanism geometry for the five earthquakes. The legend shows the symbols for different investigators: *, our results; HRV CMT, Harvard CMT results; C \& S, CHAEL and Stewart (1982); P \& M, Priestley and Masters (1986); R et al, Riedesel et al. (1986). The open bars show the allowed range from our MTRF study. The upper panel shows the fault plane strike, the middle panel shows fault plane dip, and the lower panel shows slip vector direction. The hachured line through the lower panel is the predicted direction from NUVEL (DEMETs et al., 1990).

to the other larger Mexico earthquakes. Since the Playa Azul rupture area is located at the down-dip edge of the coupled zone, this steeper dip could reflect a general steepening in fault dip across the seismogenic plate interface. Alternatively, the specific plate interface area ruptured by the Playa Azul event is geometrically anomalous as compared to the adjacent segments along the down-dip edge. Perhaps future detailed studies of microseismicity can discriminate between these two possibilities.

The lower part of Figure 17 shows the slip vector strike for the five events from different investigators. As previousiy discussed, the slip vector strikes from the Harvard CMTs are less (i.e., more northerly) than the predicted NUVEL strike of $33^{\circ}$ to $34^{\circ}$ across the subduction zone segment (the horizontal bar in Fig. 17), However, the results from RiEDESEL et al. (1986) for the 1985 mainshock and aftershock are consistent with the NUVEL direction. Our results for the 1973 Colima and 1981 Playa Azul events agree quite closely with the NUVEL direction. On the other hand, all three values plotted in Figure 17 for the 1979 Petatlan earthquake are less than the NUVEL direction. Either the seismological results are biased, or the slip vector for the Petatlan earthquake is rotated to a more northerly direction with respect to NUVEL. The Harvard CMTs in northern Mexico for smaller events (see compilation in DEMETs et al., 1990) show that the overall preferred slip vector strike is in the range of $20^{\circ}$ to $25^{\circ}$. The Harvard CMTs from earthquakes further south are consistent with the NUVEL direction. To accommodate this difference of $8^{\circ}$ in slip vector direction, between $25^{\circ}$ to $33^{\circ}$, requires a 
significant change in the location of the Cocos-North America rotation pole, and this change would not be compatible with the global constraints on the location of the rotation pole. At this time, the most parsimonious solution is to accept the NUVEL rotation pole, and ascribe the slip vector bias to seismological "noise."

\subsection{Time Functions and Rupture Initiation}

One common characteristic of all earthquakes is the emergent rupture initiation. All five earthquakes show a precursor, followed 4 to $8 \mathrm{~s}$ later by the main pulse of moment release. After identification in the time functions, the precursor timing can be seen in the seismograms. Figure 18 shows simplified versions of the basic time functions for all five earthquakes. These time functions are all plotted at the same amplitude and time scales. In detail, the precursor is seen either as a small ramp, or as some "glitches" superimposed on a ramp-these details have been simplified in Figure 18. The precursor duration varies from 4 to $8 \mathrm{~s}$, while total time function duration varies from $20 \mathrm{~s}$ to $65 \mathrm{~s}$. The precursor duration is $4 \mathrm{~s}$ for the Michoacan aftershock and Playa Azul event, which both have a total duration of about $20 \mathrm{~s}$. The Petatlan event has a $6 \mathrm{~s}$ precursor and a total duration of about $25 \mathrm{~s}$, and the precursor duration is $8 \mathrm{~s}$ for the Colima earthquake with a total duration of $30 \mathrm{~s}$. The Michoacan mainshock has a precursor duration of $5 \mathrm{~s}$. Although the overall duration of this event is at least $65 \mathrm{~s}$, the duration of the two individual pulses is

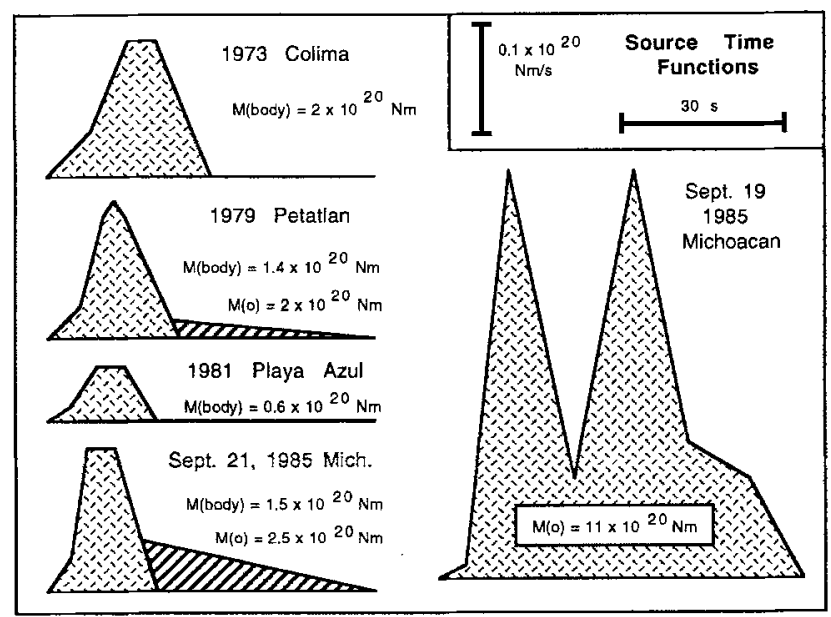

Figure 18

Schematic summary of the source time functions for each earthquake. The stylized time functions retain the duration and amplitude information; amplitude and time scales are at top. The resolved body-wave moment is listed. If additional moment release is required to match the long-period surface wave moment, it is added as a later ramp for the Petatlan event and Michoacan aftershock, and as an overall baseline correction for the Michoacan mainshock (also see EkSTRÖM, 1989). An important feature is the small precursor for all earthquakes. 
about $20-25 \mathrm{~s}$. Thus, it is possible that the precursor duration is linked to the duration of the main pulse that follows, though there are too few examples to convincingly prove this idea. If we accept some linkage between precursor and main pulse duration, then the precursor duration would be related to the size of the "asperities" since longer pulse duration is usually related to a larger region of higher moment release. At this point, we move into the realm of speculation by suggesting that the precursors are an intrinsic part of the rupture process of Mexico earthquakes, and that the time delay between precursor and main pulse onset is determined by the size of the asperity that is about to break. There are at least two theoretical models for rupture initiation that might explain this speculative interpretation of the precursors. One model is presented in OHNAKA (1992), where the rupture process is characterized by a slow precursory growth of the rupture front until the crack obtains a critical size, then a typical earthquake rupture occurs. The characteristics of this precursory phase depend on the unknown frictional properties of fault zones. Another model is that of Kostrov and DAS (1988), who show the results of a theoretical study of how an isolated asperity would fail. They discuss a curious geometric effect in which the rupture front initially propagates around the edge of the asperity, and then eventually a rupture front can sweep across the entire asperity. They use the term: "double encircling pincer," to describe this geometric effect. This style of rupture produces a source time function with a precursory ramp, followed by a main pulse as the rupture front breaks the interior of the asperity. Note that the duration of the precursor should be linked to the overall size of the asperity. Thus, the KOSTROV and DAS (1988) model for asperity failure appears to offer a good explanation of our interpretation of the Mexico earthquakes rupture process. This explanation has the appealing feature that the linkage between the precursor and the main pulse is a purely geometric effect. Precursors have been noted by many previous investigators for many subduction zone earthquakes. The results from Mexico certainly stimulate the desire to study these precursors in a more systematic fashion.

\subsection{Asperity Distribution and Subduction of the Orozco Fracture Zone}

One goal of this study is to determine the asperity distribution along the northern Mexico subduction zone. Our overall conclusion is that the rupture process studies do not give us a clear picture of distinct asperities separated by extensive "weak" regions. We were able to resolve a distinct subregion of higher moment release for the 1973 Colima earthquake, shown by the triangular region in Figure 19. Also, there is a concentration of moment release in the epicentral area of the 1979 Petatlan earthquake, shown as the oval region in Figure 19. There is also a concentration of moment release in the epicentral area of the Sept. 21 Michoacan aftershock, but it is poorly defined and is represented in Figure 19 by the open triangular area. Our results for the Sept. 19 Michoacan mainshock place bounds on 


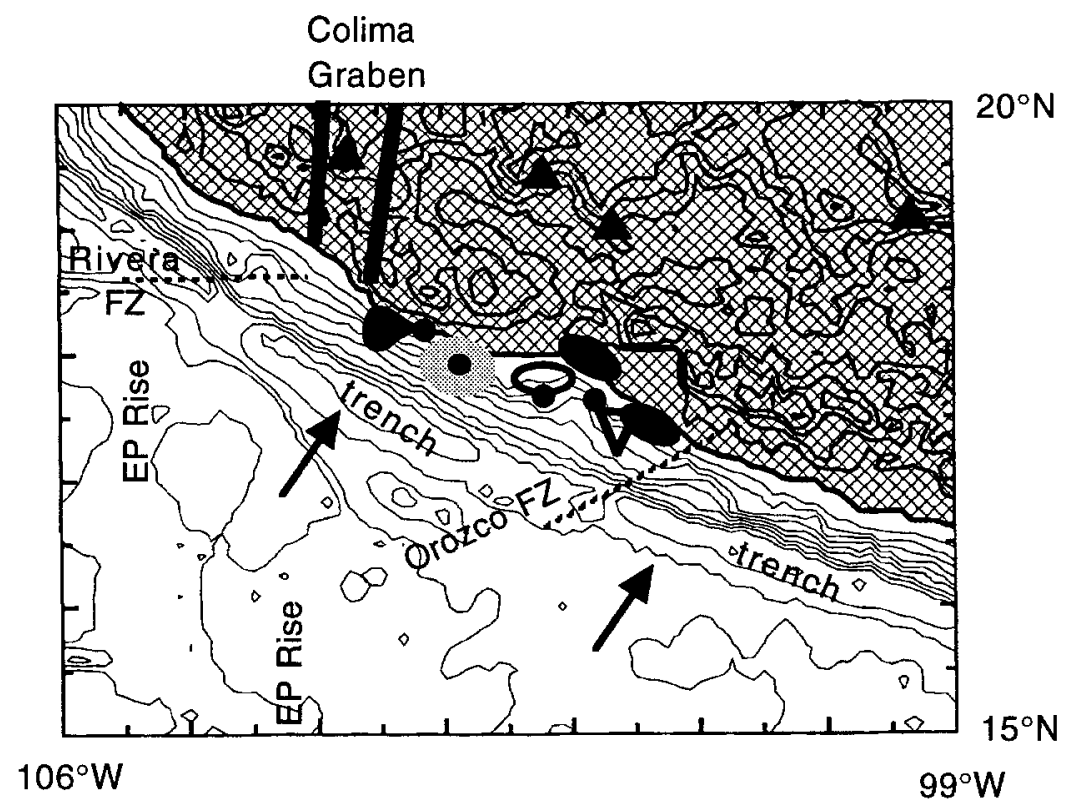

Figure 19

Detailed map of the northern Mexico subduction zone segment with the results from the rupture process studies. Contour interval is $500 \mathrm{~m}$. Land is indicated by the cross-hatching. Oceanic features include the East Pacific Rise, the Orozco and Rivera fracture zones, and the Mexico trench. Arrows show the convergence direction of the Cocos plate with respect to North America; the convergence rate varies from 49 to $55 \mathrm{~mm} /$ year from Colima to Petatlan. Triangles are active volcanos, and the Colima graben is bordered by bold lines. Dots are large earthquake epicenters. Asperity candidates are shown as regions in the seismogenic zone; more confidence is attached to the solid regions. The asperity distribution along this segment can be characterized as "indistinct," and it is possible that the asperities overlap each other (see text). Most of the moment release is closely associated with the subducting Orozco Fracture Zone.

Note the physiographic effects in the upper plate above the Orozco Fracture Zone.

the along-strike location of the second pulse of moment release; this "asperity" is shown as the oval region down-dip of the Sept. 21 aftershock. In detail, the moment release of this pulse could be distributed both up-dip and down-dip from the oval "asperity." Recall the work of MendozA and HARTZell (1989) who do split this asperity into two distinct regions of higher slip. Our study does not place useful bounds on the moment release of the first pulse of the Michoacan mainshock; this fact is indicated by the dotted region about the mainshock epicenter in Figure 19. Finally, the moment release of the 1981 Playa Azul event is probably contained within the open oval attached to the epicenter in Figure 19, but recall that the common interpretation of this region is a "weak" area between the two dominant asperities of the 1985 Michoacan mainshock. The 1981 Playa Azul rupture area could be an intervening "weak" region, but it is also possible that significant moment release occurred in this area during the 1985 Michoacan mainshock. The collection of results in Figure 19 would allow us to postulate a nearly continuous 
distribution of "asperities" along the subduction zone segment. This map of "asperities" looks quite different from the asperity map for the Kuriles Islands (SCHWARTZ and RUFF, 1987) with clear distinct asperities separated by distances of 50 or more $\mathrm{km}$. Given the relatively smaller size of the Mexico earthquakes, one explanation could be that the asperity lengths and separations are so small that our teleseismic rupture process techniques may not resolve the distinct asperities. Use of acceleragrams, such as in the study of MENDOzA and HARTzeLl (1989), might provide better spatial resolution. However, since acceleragrams are not available to study the adjacent 1973 Colima and 1979 Petatlan earthquakes, we still cannot conclude that there are distinct asperities along the subduction segment. To summarize, our rupture process studies are consistent with a continuous chain of "asperities" from the 1979 Petatlan earthquake to the 1973 Colima asperity. Given some evidence from the other studies, we speculate that in fact there is heterogeneity in moment release along the subduction segment.

Subduction of the Orozco Fracture Zone causes a shallow trench to the southwest of the Petatlan, Playa Azul, and Sept. 21, 1985 earthquakes. Although the Orozco Fracture Zone is a complex bathymetric feature (see SINGH and MORTERA, 1991), its overall trend is clearly rotated to a more easterly azimuth than the convergence direction of the Cocos plate with North America (see Fig. 19). The southern edge of the Orozco Fracture Zone projected down the seismogenic zone would follow a trend similar to the dashed line in Figure 19. The "width" of the Orozco Fracture Zone is conveniently determined at the trench axis by shallowing of the trench to less than $4500 \mathrm{~m}$. Thus, the 1979 Petatlan earthquake and the 1985 Michoacan aftershock are located more or less in the middle of the Orozco Fracture Zone. Also, the southern part of the Michoacan mainshock is located over the Orozco Fracture Zone. On a global basis, the subduction of bathymetric features like the Orozco Fracture Zone is usually associated with reduced seismic coupling (see MCCANN and HabermanN, 1989). However, for the case of the Orozco Fracture Zone in Mexico, we see earthquakes that are typical in size for Mexico occurring on the crest of the subducted feature. It appears that the Playa Azul earthquake initiated at the northern edge of the Orozco Fracture Zone. Furthermore, the slip associated with the second pulse of moment release of the Michoacan mainshock is located somewhere along the extension of the Orozco Fracture Zone. Thus, a significant portion of the moment release in the northern Mexico subduction is associated with the Orozco Fracture Zone.

It is interesting to note the topographic effects in the North America plate that may be associated with the subduction of the Orozco Fracture Zone. The trend of the mountain front, i.e., the $500 \mathrm{~m}$ contour, north of the Orozco Fracture Zone is nearly east-west (Fig. 19). Along the projection of the Orozco Fracture Zone there is a sharp embayment with a steep mountain front. The trend of the mountain front south of the Orozco Fracture Zone more nearly parallels the trend of the trench axis. MCCANN and HABERMANN (1989) present a model in which the subduction 
of bathymetric features such as the Orozco Fracture Zone has a profound effect on the physiography and geology of the upper plate. Two predictions of their model are that: (i) there will be coastal uplift and terraces over the subducting features; and (ii) the volcanic arc will be displaced inland behind the feature (also see NUR and BEN-AVRAHAM, 1983). In Mexico, there is clearly a topographic anomaly over the ridge, with possible uplift at the southern, i.e., trailing, edge of the fracture zone. Also, a simple extension of the Orozco Fracture Zone inland shows that it corresponds with a change in the trench-volcano distance, and possibly with a gap in the most recent volcanic activity (see Fig. 19).

Given the difference in azimuths between the Orozco Fracture Zone and the Cocos-North America plate motion, the intersection of the Orozco Fracture Zone with the Mexico trench migrates north as plate motions proceed. The Guererro seismic gap (SINGH and MorTERA, 1991) is in the region just behind the passage of the Orozco Fracture Zone, though we note that it takes several million years for the Orozco Fracture Zone to traverse the seismic gap region. Would this tectonic interaction change the character of the plate interface in the Guererro region for a few million years? It is important to know the answer to this question.

The northern limit of the 1973 Colima earthquake appears to coincide with the extensions of the Rivera Fracture Zone and the Colima graben (Fig. 19). This northern limit of the seismogenic plate interface could be defined by the subducted boundary between the Cocos and Rivera plates, or the fragmentation of the upper plate, or both. The small seismic gap between the 1973 Colima and 1932 Jalisco earthquake (see NisHeNKO, 1991) would appear to coincide with the Colima graben, and hence may not be capable of generating a large underthrusting earthquake.

In the spirit of "comparative subductology" (UYEDA and KANAMORI, 1979; JARRARD, 1986), we propose that there are seismotectonic similarities between northern Mexico and two other subduction zone segments: the Santa Cruz Islands segment (see TAJIMA et al., 1990); and the central Peru segment (BECK and RUFF, 1989). As fully described in TAJIMA et al. (1990), the Santa Cruz Islands segment is characterized by overlapping aftershock areas of two large earthquakes in 1966 $\left(M_{s} 7.9\right)$ and $1980\left(M_{s} 7.7\right)$. This is similar to the overlapping rupture areas of the 1979 Petatlan event and 1985 Michoacan aftershock. In the Santa Cruz Islands segment, it is also difficult to identify distinct asperities (see Fig. 20). The central Peru segment also offers an interesting comparison. As presented in BECK and RuFF (1989), the central Peru subduction segment extends for about $500 \mathrm{~km}$ between the Mendana Fracture Zone to the north and the Nazca Ridge to the south (segment shown in Fig. 20). This segment was ruptured by three large earthquakes in 1940,1966, and 1974; however it seems that the entire segment was ruptured by a single great earthquake in 1746 . The 1974 Peru earthquake $\left(M_{s} 7.8\right)$ shares many similarities with the 1985 Michoacan mainshock: (1) seismic moment is the same; (2) it was a double event; (3) the first event in the northern part displayed some 


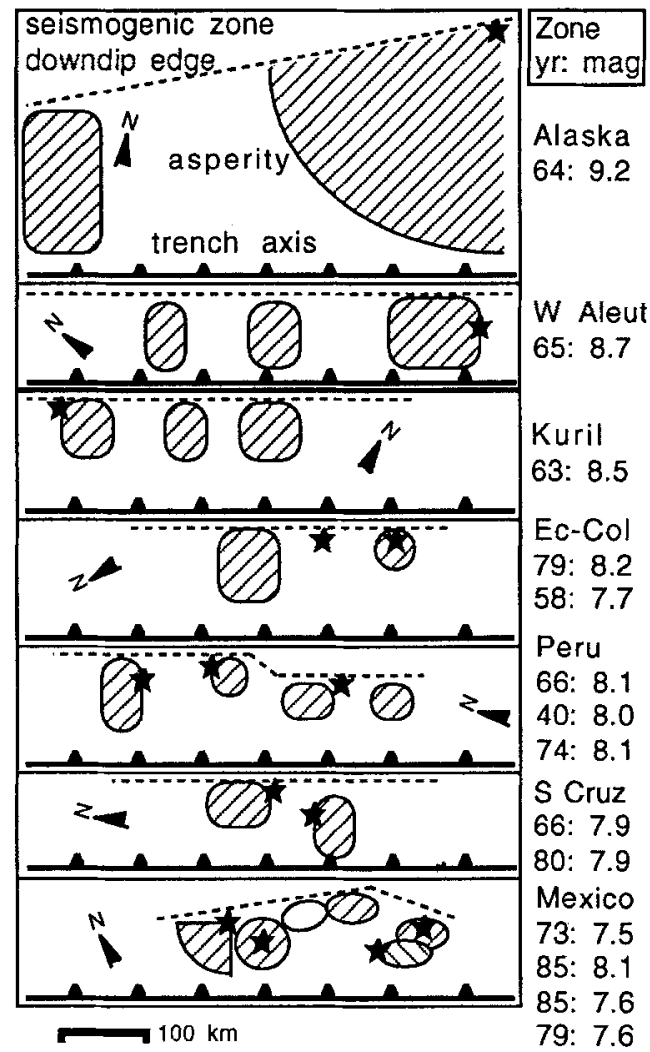

Figure 20

Schematic map views of asperity distributions determined for several subduction zones from rupture process studies of great earthquakes. For each subduction zone segment: asperities are the hachured regions; trench axis and down-dip edge of the seismogenic zone are plotted as the bold and dashed lines, respectively; north arrow is given for approximate orientation; stars plot the great earthquake epicenters; for more than one star, the list corresponds to left-to-right ordering of epicenters. Earthquake list to the right of each zone gives the year, e.g., "64" is the March 28, 1964 Alaska earthquake, and magnitude is either $M_{w}$ or or $M_{s}$. Abbreviations and references are: Alaska, CHRISTENSEN and BECK (1994), this issue; W Aleut (Western Aleutians), BECK and CHRISTENSEN (1991); Kuril (Kurile Islands), Ec-Col (Ecuador-Colombia), and Peru, BECK and RufF, (1989); S Cruz (Santa Cruz Islands), TAJIMA et al. (1990); and Mexico, results from this paper. Same scale is used for all plots, $100 \mathrm{~km}$ is shown at bottom. Asperity size varies from large in the subduction zones plotted at top of figure, to small (yet close together) in the zones plotted at bottom

component of bilateral rupture; (4) the second event ruptured to the southern edge of the segment, more or less near the crest of the Nazca Ridge; (5) there is a precursory rupture before the first main pulse onset; and, (6) there is even a strange cluster of aftershocks located significantly down-dip of the main rupture area of the 1974 Peru event (DEWEY and SPENCE, 1979). While there are many similarities between the rupture process of the 1974 Peru and 1985 Michoacan earthquake, the overall asperity distribution in central Peru appears to be more distinct than 
Mexico. One speculative aspect to consider is whether the entire northern Mexico segment could rupture in a single great earthquake, just as central Peru has in previous earthquake cycles. The combined moments of all five earthquakes in Mexico would be about twice as large as the 1985 Michoacan mainshock. An event of this size is contrary to the known earthquake history along the Mexico subduction zone (SINGH et al., 1984). On the other hand, a simple mechanical model of asperity interaction can produce synthetic earthquake sequences with a long succession of smaller "single" events, punctuated by an occasional larger "multiple" event (RUFF, 1992a). We emphasize that it is pure speculation to suggest that this type of variable rupture mode, as observed in central Peru, is relevant to the northern Mexico subduction segment. The facts of earthquake history in Mexico offer a stronger suggestion that "indistinct" asperity distributions cause a spatially-overlapping sequence of large earthquakes, as opposed to great earthquakes that rupture the entire segment.

\section{Conclusions}

We have studied the focal mechanism and rupture process of five large earthquakes in the northern Mexico subduction zone. The rupture process of all five earthquakes shares a common feature: rupture begins with a low-level of moment release for the first 4 to $8 \mathrm{~s}$, followed by the main pulse onset with a duration of about $20 \mathrm{~s}$. In the case of the 1985 Michoacan mainshock, the rupture continued with a second main pulse of $20 \mathrm{~s}$ duration, with a total duration of $70 \mathrm{~s}$ or more. Rupture directivity and an epicentral region asperity are resolved for the 1973 Colima earthquake. There are various difficulties in resolving the spatial extent of rupture for all other events. As found by previous investigators, there is a strong directivity for the second pulse of the 1985 Michoacan mainshock. Our results for the Michoacan mainshock are most similar to those of EKSTRÖM (1989); he also used a one-dimensional rupture model. Our results are also consistent with the MENDOZA and HARTzELl (1989) model where the second pulse is split into a shallow asperity and an "extra" deep asperity — as long as we are able to shift their entire slip pattern trenchward. One unusual feature is the overlap in rupture areas of the 1979 Petatlan event and the 1985 Michoacan aftershock. Moment release for the 1981 Playa Azul earthquake can be contained within the aftershock area.

Detailed considerations of the focal mechanisms allow us to choose an acceptable overall fault strike of $290^{\circ}$ to $295^{\circ}$ for all events. The fault dip angle can be chosen as $16^{\circ}$ for all events, except for the 1981 Playa Azul earthquake which has a dip angle of $20^{\circ}$ to $25^{\circ}$. Given the freedom to combine results from different investigators, the slip vector directions of four earthquakes are consistent with the NUVEL (DE METs et al., 1990) direction of $33^{\circ}$ for Cocos-North America convergence. The slip vectors of the 1979 Petatlan earthquake are more northerly 
than the NUVEL direction. The Harvard CMT solutions for large and small earthquakes in northern Mexico prefer an overall slip vector direction of $20^{\circ}$ to $25^{\circ}$.

The northern boundary of this subduction segment is defined by significant features in both the subducting and upper plates. The southern boundary of this segment coincides with the southern edge of the subducting Orozco Fracture Zone. Most of the seismic moment release in this segment is associated with the Orozco Fracture Zone. We speculate that the subducting Orozco Fracture Zone influences the physiography and volcanism in the upper plate. The Guererro seismic gap is located just to the south of the Orozco Fracture Zone. We cannot speculate as to what effect the geologically recent passage of the Orozco Fracture Zone has had on the plate interface in the Guererro region.

There are several seismotectonic similarities between the northern Mexico segment and the subduction zone segments in central Peru and the Santa Cruz Islands. The small separation of asperities is a common feature for all three segments, with the northern Mexico and Santa Cruz Islands characterized by nearly continuous "asperities" and overlapping rupture areas. This asperity distribution and earthquake behavior is in contrast to that of Alaska, where the very large and distinct epicentral asperity generates "truly great" earthquakes when it breaks (see Fig. 20). The 1985 Michoacan mainshock and the 1974 Peru earthquake appear to have quite similar rupture processes and tectonic environments. The central Peru segment is characterized by a variable rupture mode, where the previous earthquake cycle consisted of a single great event that ruptured the entire segment. Significant differences between central Peru and northern Mexico include the age of subducting lithosphere and the fact that the known earthquake history of Mexico does not include the occasional great earthquakes that occur in Peru.

\section{Acknowledgments}

Thanks to C. Mendoza, S. K. Singh, S. Hartzell, and J. Anderson for materials and preprints. Thanks to Bart Tichelaar and Roland LaForge for stimulating discussions, and to the reviewers for their helpful comments. Yuichiro Tanioka assisted with the preparation of Figure 19. Also, special thanks to those "Harvard CMT" people! These research efforts are supported by the National Science Foundation (NSF90-19003 to LJR).

\section{Appendix: MTRF Inversion and Extraction of Source Time Function and Moment Tensor}

This section presents a thorough and detailed discussion of inversion for the MTRFs. The first subsection covers the forward problem and "standard" linear 
inversion. The second subsection covers omnilinear inversion for MTRFs. The final section addresses the inverse problem for reduction to the best source time function and moment tensor together with a statistical measure of the adequacy of this reduction.

\section{A1. MTRF Notation and Linear Inversion for MTRFs}

We can write the MTRFs explicitly as:

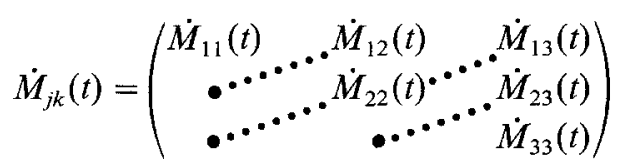

where the moment tensor is required to be symmetric. $M_{11}$ represents a source dipole along the $x_{1}$ direction of a Cartesian coordinate system; positive $M_{11}$ corresponds to a "dilatational" dipole. The orientation of the Cartesian system used here is: $+x_{1}$ points "East"; $+x_{2}$ points "North"; and $+x_{3}$ points "Up"; at the source location.

An isotropic seismic source, i.e., an explosion or implosion, is represented by the trace of the moment tensor. Since we shall be focused on earthquake studies, the isotropic source component will be eliminated by setting the trace to zero. This constraint is linear, hence the inverse problem for the five independent moment tensor components is linear. There are several different choices that can be made to define the five independent moment tensor components from the six components of Eq. (A1). Recall that a double-couple source corresponds to a moment tensor for which one eigenvalue is zero, and hence the other two are equal and opposite . Following the formulation in RUFF and TICHELAAR (1990), the moment tensor is constructed from five double-couple sources as follows:

$$
\begin{aligned}
\dot{M}_{j k}(t)= & \left(\begin{array}{rrr}
1 & 0 & 0 \\
0 & 0 & 0 \\
0 & 0 & -1
\end{array}\right) \dot{M}_{1}(t)+\left(\begin{array}{rrr}
0 & 0 & 0 \\
0 & 1 & 0 \\
0 & 0 & -1
\end{array}\right) \dot{M}_{2}(t)+\left(\begin{array}{lll}
0 & 1 & 0 \\
1 & 0 & 0 \\
0 & 0 & 0
\end{array}\right) \dot{M}_{3}(t) \\
& +\left(\begin{array}{lll}
0 & 0 & 1 \\
0 & 0 & 0 \\
1 & 0 & 0
\end{array}\right) \dot{M}_{4}(t)+\left(\begin{array}{lll}
0 & 0 & 0 \\
0 & 0 & 1 \\
0 & 1 & 0
\end{array}\right) \dot{M}_{5}(t) .
\end{aligned}
$$

For a given seismogram, the Green's functions for each of the above five components are synthetic seismograms calculated for the five pure double couples with a delta function time history and unit moment. The MTRFs are identified by their focal mechanisms (e.g., Fig. 2 in main text). Substitution of Eq. (A2) into Eq. (5) in the main text then yields

$$
s_{i}(t, \Omega)=g_{f m 1} * \dot{M}_{1}(t)+g_{f m 2} * \dot{M}_{2}(t)+\cdots+g_{f m 5} * \dot{M}_{5}(t)
$$


where $g_{f m 1}$ through $g_{f m 5}$ are the Green's functions for the first through fifth focal mechanisms in Eq. (A2) (written in full, they are: $g_{i, f m 1}\left(t, \Omega, V_{0}\right)$ ). To streamline the notation of Eq. (A3), let $s_{i}(t, \Omega)$ simply be the $n$th seismogram, $s_{n}(t)$; and $g_{f m 1}$, becomes $g_{n m}$, the Green's function for the $n$th seismogram from the $m$ th focal mechanism and MTRF. Then, Eq. (A3) is written as the contraction of a row vector with the Green's functions and convolution and a column vector with the MTRFs:

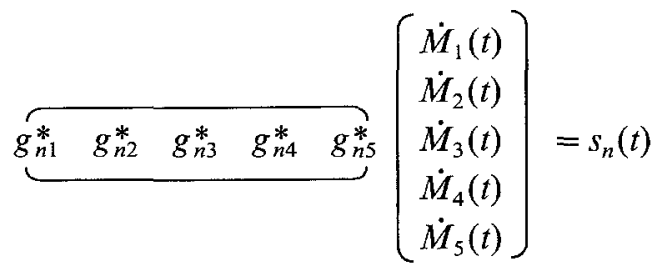

where * represents the convolution operation. We cannot expect to determine the five unknown functions from one observed seismogram. We now write down in symbolic form the simultaneous equations for $N$ seismograms:

$$
\left[\begin{array}{cccc}
g_{11}^{*} & g_{12}^{*} & \cdots & g_{15}^{*} \\
g_{21}^{*} & g_{22}^{*} & \cdots & g_{25}^{*} \\
\vdots & \vdots & & \vdots \\
g_{N 1}^{*} & g_{N 2}^{*} & \cdots & g_{N 5}^{*}
\end{array}\right] \quad\left(\begin{array}{c}
\dot{M}_{1}(t) \\
\dot{M}_{2}(t) \\
\vdots \\
\dot{M}_{5}(t)
\end{array}\right)=\left(\begin{array}{c}
s_{1}(t) \\
s_{2}(t) \\
\vdots \\
s_{N}(t)
\end{array}\right) .
$$

The above system corresponds to the equation in RUFF and TICHELAAR (1990).

We must now discretize the above system. The unknown MTRFs are stacked into the model column vector, and the observed seismograms are stacked into the data vector. It is not necessary for the duration or averaging intervals of the seismograms and time functions to be the same. The $g^{*}$ operation becomes a submatrix (see RUFF and KANAMORI, 1983b for details).

Our preference is to invert the seismograms as recorded, rather than preprocess the seismograms to equalize instrument responses. Digital seismograms are rescaled from digitial counts to ground displacement or velocity. Amplitudes are normalized by dividing both the Green's functions and seismograms by the average spectral level of the instrument response in the pass-band of 10 to $30 \mathrm{~s}$. This procedure allows us to simultaneously invert WWSSN seismograms with digital seismograms from various instruments and networks. The relative amplitudes as plotted are meaningful in the sense that nodal seismograms will have smaller amplitudes, etc. The discretized version of Eq. (A5) is then written as

$$
A m=? d
$$

where "=?" indicates that Eq. (A6) is a statistical estimation "equation." As in RufF and Kanamori (1983b) and RUfF and TichelaAR (1990), we use the damped least squares inverse to obtain the model estimate

$$
m=\left(A^{T} A+\delta J\right)^{-1} A^{T} d=A^{*} d
$$


where the $A^{T}$ matrix is the transpose of the $A$ matrix, $\delta$ is the model damping parameter, which is specified by the user as a fraction of the average value of the diagonal elements of $A^{T} A ; J$ is a "sawtooth" diagonal matrix that increases from zero to the average diagonal value of $A^{T} A$ for each MTRF (see RUFF and KANAMORI, 1983b, for statistical explanation of this choice). $A^{*}$ is commonly referred to as the generalized inverse.

At this point, we can invert seismograms for the MTRFs. However, a problem appears due to the scatter in the amplitudes of long-period body waves. This scatter introduces unwanted noise into the model results. We now discuss a method that eliminates this problem.

\section{A2. Omnilinear Inversion of Seismograms for MTRFs}

The underlying reasons, numerical experiments, and some philosophical notions of body-wave amplitude scatter and omnilinear inversion are discussed in RUFF (1989b) and TichelaAr and RufF (1991). Here we shall simply discuss the technical details of seismogram scaling factors and omnilinear analysis. The data vector in Eq. (A6) contains the $N$ seismograms. An explicit representation of this is

$$
A m=?\left(\begin{array}{c}
s_{1} \\
s_{2} \\
\hdashline \vdots \\
\vdots s_{N}
\end{array}\right)
$$

where the horizontal lines within the data vector separate the subvectors for each seismogram. We now modify this equation by explicitly including the unknown scale factors $a_{1}, \ldots, a_{N}$, one for each seismogram:

$$
A m=?\left(\begin{array}{c}
s_{1} \\
-s_{2} \\
\hdashline \vdots \\
\vdots \\
\hline s_{N}
\end{array}\right) \begin{gathered}
a_{1} \\
a_{2} \\
\vdots \\
a_{N}
\end{gathered}
$$

where $a_{i}$ multiplies every component of seismogram $s_{i}$. We want to determine the set of scale factors that will make the data vector most compatible with the model description. Assemble the $a$ factors into the vector $a$ by placing the seismograms in a matrix:

$$
A m=?\left(\begin{array}{c}
s_{1} \cdot a_{1} \\
-s_{2} \cdot a_{2} \\
\hdashline \vdots--- \\
\hdashline s_{N}: a_{N}
\end{array}\right)=\left(\begin{array}{cccc}
{\left[s_{1}\right]} & & & 0 \\
& {\left[s_{2}\right]} & & \\
& & \ddots & \\
0 & & & {\left[s_{N}\right]}
\end{array}\right]\left(\begin{array}{c}
a_{1} \\
a_{2} \\
\vdots \\
a_{N}
\end{array}\right)=S a
$$

The $S$ matrix has $N$ columns; the $i$ th column vector contins the $i$ th seismogram shifted to the $i$ th position, and all other elements are zero. The above formulation 
shows that the simultaneous estimation of $m$ and $a$ can be treated as a linear problem, but it is a different problem than the simple linear form of Eq. (A8). First, notice that Eq. (A10) is now always exactly solved by all $a$ 's and all $m$ 's equal to zero. This trivial solution must be eliminated. As discussed in RUFF (1989b), the physical problem provides the constraint equation for $a$ : the product of scale factors is one, i.e., $\prod_{i} a_{i}=1$. Other constraint equations on $a$ for different physical problems could be $\sum_{i} a_{i}=N$, for example.

We shall briefly outline the solution of the above described problem. First, rewrite Eq. (A10) as:

$$
e=\left[\begin{array}{l:l}
A & -S
\end{array}\right]\left(\begin{array}{c}
m \\
\hdashline a
\end{array}\right)
$$

where $e$ is the error vector; the difference between the rescaled observed seismograms, $S a$, and the synthetic seismograms, $A m$. We now minimize the squared length of the error vector with respect to both $m$ and $a$ to find the normal equations

$$
\left[\begin{array}{c:c}
A^{T} A & -A^{T} S \\
\hdashline-S^{T} \bar{A} & -\bar{S}^{\bar{T}} \bar{S}
\end{array}\right]\left(\begin{array}{c}
m \\
\hdashline a
\end{array}\right)=?\left(\begin{array}{c}
0 \\
\hdashline 0
\end{array}\right)
$$

where 0 is a vector with all zeros, and "=?" symbolizes the fact that this equation might not be exactly solved due to constraints that may be placed on $m$ or $a$. The goal is to find some acceptable nontrivial solution of the above system. Note that the upper-half of Eq. (A12) is

$$
A^{T} A m=A^{T} S a
$$

which represents the normal equations to find the least-squares estimate for $m$, while the lower-half of Eq. (A12) are the normal equations to find the least-squares estimate for $a$. One style of solution of the above problem is known as canonical correlation analysis, as invented by HoTELLING (1936); however, this solution has undesirable properties for the model constraints and the rescaling of the data. The new solution adopted by RUFF (1989b) is to solve the upper-half of the system in Eq. (A12) exactly (making allowances for the damped least-squares solution, i.e., $\left(A^{T} A+\delta J\right)^{-1}$ replaces $\left.\left(A^{T} A\right)^{-1}\right)$, and then seek the best solution of the lower-half system subject to the constraint equation on $a$. For the case of no damping, the solution for $m$ is then

$$
m=\left(A^{T} A\right)^{-1} A^{T} S a .
$$

This solution can be substituted for $m$ in the lower-half system of Eq. (A12) to obtain

$$
\left[S^{T} S-S^{T} A\left(A^{T} A\right)^{-1} A^{T} S\right] a=? 0
$$

which can be rewritten as

$$
L a=? 0 .
$$


The $L$ matrix has some interesting properties. First and most important, $L$ is a positive definite matrix, though it can have zero eigenvalues. We now try to find $a$ that satisfies the constraint equation and minimizes the squared length of $L a$, i.e., tries to achieve zero length as requested by Eq. (A16). If we adopt the constraint equation of $a^{T} a=1$, where $a^{T}$ is the transpose of the column vector $a$, then the solution to Eq. (A16) is given by $a$ that is the eigenvector associated with the smallest eigenvalue of $L$. Other constraint equations require slightly more analysis. First, define a residual vector as: $k=L^{1 / 2} a$. Then, the scalar residual is $\rho=k^{r} k=$ $a^{T} L a$; and $\rho$ is a quadratic surface as a function of $a$. The gradient vector of this surface is given by $v=L a$; and $v$ is orthogonal to the contours of constant $\rho$. These contours are a generalized elliptical shape in higher dimensional spaces. The existence of an exact solution corresponds to a singular $L$ matrix and would be represented by an ellipse in which one of the axes extends to infinity. For this case, a solution is the eigenvector associated with the zero eigenvalue. Exact solutions are not encountered when inverting real data. We now seek to minimize $\rho$ given various constraints on $a$. In geometric terms, we seek the inner-most elliptical contour that just touches the constraint curve for $a$, that is, the two surfaces share the same tangent direction at this point. In this geometric view, we seek the $a$ vector that produces $v=L a$ that is orthogonal to the constraint surface. If the constraint surface is linear-for example, $c^{T} a=1$-then the vector normal to the constraint surface points in the same direction everywhere in the space. Let this normal vector be $u$. Then, the direction of the solution vector is $\alpha$, where: $L \alpha=u$. With $L$ a positive definite nonsingular matrix, $\alpha=L^{-1} u$; then $a$ is the rescaled $\alpha$ : $a=\left(1 / c^{T} \alpha\right) \alpha$.

The constraint surface for $\prod_{i} a_{i}=1$ is "nonlinear" in the sense that the normal vector points in different directions as a function of $a$. For an $a$ vector that satisfies this "nonlinear" constraint, the normal vector to this surface can be written as: $\left(1 / a_{1}, 1 / a_{2}, \ldots, 1 / a_{N}\right)$. The solution is then the $a$ vector that minimizes $\rho$ and also produces $v=L a$ such that $v_{i}=c\left(1 / a_{i}\right)$, where $c$ is some constant. Hence, we have a nonlinear equation for $a$

$$
L a=c\left[1 / a_{i}\right] .
$$

Although this equation is nonlinear as it cannot be solved in an explicit one-step operation, it is easily solved by iteration or geometric manipulation in the linear space of the $a$ vector. The key is to notice that the solution vector will lie in the sector between the $u$ and $\alpha=L^{-1} u$ vectors, as previously defined. Thus, provided with this good guess of the solution, we use Eq. (A17) to quickly converge on the solution.

We finish this discussion with a critical review of the constraint equations that might be used for omnilinear analysis. The constraint of $a^{T} a=1$ is perhaps the simplest case to analyze because the solution is given by the eigenvector for the smallest eigenvalue of $L$. However, this constraint is difficult to justify from a 
statistical point of view. Furthermore, if two or more eigenvalues of $L$ share the same mimimum value, then there is no unique solution. Even for this situation, minimizing $\rho$ with $\sum a_{i}=1$ or $\prod a_{i}=1$ will produce a unique solution. Given the symmetry of the error surface and the constraint surface of $\prod a_{i}= \pm 1$, an alternative solution to the "correct" $a$ is to multiply all $a_{i}$ 's by -1 ; of course this would also reverse the sign of $m$ in Eq. (A14). For the present application, we imagine that the polarities of most seismograms are correct, thus we choose the $a$ vector that mostly points toward positive values of the individual components. Omnilinear analysis has the capability to find reversed polarity seismograms and automatically "flip" them to the correct polarity, but this option should be carefully monitored.

Once the scale factors are determined, the best model is calculated from Eq. (A14). We define the a posteriori data variance as: $\sigma^{2}=e^{T} e / N$, where $e$ is the error vector $S a-A m$, and $N$ is the total number of data vector elements. The model covariance matrix is then

$$
[\mathrm{Cov}]=A^{*}\left[\sigma^{2} I\right] A^{* T}
$$

where $I$ is the identity matrix, and $A^{*}$ is the generalized inverse. A single value of the overall data variance is used to be compatible with the construction of $A^{*}$. We can easily represent the diagonal elements of the model covariance matrix by plotting the plus and minus standard deviation about each time function point by dashed lines, as in Figure 2 in the main text. A clear graphical representation of the full covariance matrix is more diffcult. In the section below, we shall use the covariance matrix as part of the numerical calculations to extract the best time function and moment tensor.

\section{A3. Extraction of Moment Tensor and Time Function from MTRFs}

This lengthy section covers both theoretical and practical aspects of the quasinonlinear inversion problem to extract the best moment tensor and time function from the MTRFs. The first subsection sets up the forward problem; subsection A3.2 develops the inverse equations for the "bouncing" method; A3.3 shows the omnilinear formulation; A3.4 shows how to obtain a global solution; A3.5 generalizes A3.4 to include a data covariance matrix; A3.6 then returns to the statistical question of whether the earthquake can be represented by a single moment tensor and time function, or not; and A3.7 finishes with a practical discussion of several issues including error propagation to the faulting parameters.

\section{A3.1 Statement of the problem}

If an earthquake has a constant moment tensor during rupture, then the individual MTRFs will all have exactly the same shape. If we normalize the waveshape to have positive unit area, then the scale factors $\left(m_{1}, m_{2}, \ldots, m_{5}\right)$ that 
multiply this waveshape to produce the MTRFs will have units of seismic moment, and these scale factors are components of the moment tensor:

$$
m_{1} f(t)=\dot{M}_{1}(t), \quad m_{2} f(t)=\dot{M}_{2}(t), \ldots, \quad m_{5} f(t)=\dot{M}_{5}(t)
$$

Since the MTRFs are organized into a column vector for the data inversion, the above relations can also be written as

$$
\left(\begin{array}{c}
\frac{m_{1} f}{-}-\bar{f} \\
\overline{m_{2}}-\bar{\vdots} \\
-\bar{m}_{5} f
\end{array}\right)=\left(\begin{array}{c}
\dot{M}_{1} \\
-\overline{\dot{M}}_{2}^{-} \\
-\frac{\vdots}{\vdots} \\
-\dot{\bar{M}}_{5}
\end{array}\right)
$$

where the horizontal lines within the column vectors separate the MTRFs. The moment tensor is then given by

$$
M_{j k}=\left(\begin{array}{ccc}
m_{1} & m_{3} & m_{4} \\
m_{3} & m_{2} & m_{5} \\
m_{4} & m_{5} & -m_{1}-m_{2}
\end{array}\right) .
$$

The moment tensor can be further analyzed to see whether or not it represents a single double couple. Let the eigenvalues of $M_{j k}$ be $\lambda_{1}$, the largest positive one, $\lambda_{2}$, the intermediate one, and $\lambda_{3}$ the minimum one. Also, designate the eigenvectors associated with the $\lambda_{1}, \lambda_{2}$, and $\lambda_{3}$ eigenvalues as: $t, n$, and $p$. Then, a pure double couple is represented by a moment tensor with $\lambda_{2}=0$, and consequently $\lambda_{3}=-\lambda_{1}$. Then the $t, n$, and $p$ unit vectors are the tension, nodal, and pressure axes of the focal mechanism. The seismic moment of the earthquake is $M_{0}=\lambda_{1}=-\lambda_{3}$. If $\lambda_{2} \neq 0$, the moment tensor can be separated into either major or minor double couples, or a major double couple and a compensated linear vector dipole. The geometry of the major double couple is the same for either choice, only $M_{0}$ differs slightly. We us the former option, where the seismic moment is given by the larger of $\lambda_{1}$ or $\left|\lambda_{3}\right|$. The "size" of the secondary source is given by the ratio of $\left|\lambda_{2}\right| \mid M_{0}$, and is expressed as "percent second double couple."

When we invert real data to find the MTRFs, we do not expect to see the same identical shapes for each MTRF. The shapes will be different due to "noise", i.e., inadequate Green's functions, combined with low resolution, or possibly because the earthquake actually did rupture with time-varying moment tensor. The scientific challenge is: How can we assess if the variations between MTRFs are significant? We must make use of the estimates of data and model variance in answering this question. The procedure of RUFF and TicheLAAR (1990) is to first find the "best" single time function and moment tensor, and then see if the "synthetic" MTRFs obtained from recombining the time function and moment tensor fall within the error bounds of the MTRFs. This basic procedure is graphically displayed in several figures in the main text, Figure 2 for example. If the synthetic MTRFs fall within the error bounds of the MTRFs, then we conclude that the earthquake can 
be represented by a single time function and moment tensor. RUFF and TICHELAAR (1990) prefer to use two standard deviations as the error bounds. We would then expect about $95 \%$ of the samples of the synthetic MTRFs to fall within these error bounds, and a few points that lie outside are not cause for concern. If the synthetic MTRFs fall significantly outside the error bounds of the MTRFs, then we must retain some aspects of the more complicated description of the earthquake rupture process.

\section{A3.2 How to find the best $f(t)$ and $M_{j k}$}

We must now find the best time function and moment tensor components given the MTRFs and their covariance. This is another problem in statistical estimation. This inverse problem requires some discussion because of the apparent nonlinearity of our model parameters, i.e., the product of the unknown $f(t)$ and $m_{i}$ 's. It seems intuitively clear that the "best" time function should be some average of the individual MTRFs. As one example of a quantitative application of this idea, VAsco (1988) assembled the MTRFs into individual column vectors of a matrix, and then used the "principal components" technique to find a single time function shape that best represents the MTRFs. Another example is the technique used by RUFF and TICHELAAR (1990), where a weighted average of the MTRFs produces the overall time function shape, and the weights are based on the average standard deviation of each MTRF, with positive and negative signs determined by whether an individual MTRF is mostly positive or negative. Here, we shall develop the details of the statistical inverse problem that allows for rigorous definition of the "best" time function and moment tensor with respect to the best-fit of the MTRFs; and we shall see how this formal development unites the above two ad hoc techniques as part of the overall best solution.

There is a special structure to the nonlinear inverse problem for $f(t)$ and $m_{i}$ that allows a global analysis of this problem. Also, it is possible to pose this problem as one in omnilinear analysis, albeit an ill-posed problem that is not recommended. We first develop the inverse problem with no statistical information on the MTRFs, and then go back to add in the MTRF covariance matrix.

We now define the error vector, $e$, as the difference between the MTRFs and the "synthetic" MTRFs based on a single time function, $f(t)$, and moment tensor components, $m_{1}$ through $m_{5}$ :

$$
e=\left(\begin{array}{c}
\dot{M}_{1} \\
\hline \dot{M}_{2} \\
-\frac{\vdots}{\vdots}- \\
\hline \dot{M}_{5}
\end{array}\right)-\left(\begin{array}{c}
m_{1} f \\
\overline{m_{2}} \bar{f} \\
-\frac{\vdots}{m_{5} f}
\end{array}\right)=d-(m f)
$$

The discretized time function vector is $f$, and the five $m_{i}$ 's are collected into a vector, $m$. We seek the $f$ and $m$ that minimize the squared length of the error vector, 
$\varepsilon=e^{T} e$. More generally, we can explicitly include the MTRF covariance matrix, Cov, by minimizing: $e^{T}\left[\operatorname{Cov}^{-1}\right] e$.

To focus on the synthetic MTRF vector, note that the $m$ and $f$ vectors can be extracted in the following fashion:

$$
\begin{aligned}
& (m f)=\left(\begin{array}{llll}
m_{1} & & & 0 \\
& m_{2} & & \\
& & \ddots & \\
0 & & m_{5}
\end{array}\right]\left[\begin{array}{c}
I \\
\hline I \\
\hdashline \\
\hdashline I
\end{array}\right] f=A_{m} f \\
& (m f)=\left(\begin{array}{llll}
{[f]} & & & 0 \\
& {[f]} & & \\
0 & & \ddots & \\
0 & & {[f]}
\end{array}\right] m=A_{f} m
\end{aligned}
$$

where " $I$ " is the identity matrix. Thus, we can extract either $f$ or $m$ as the unknown model parameters, but the resultant $A$ matrices will then depend on $m$ or $f$, respectively. Keeping $f$ and $m$ together in the $(m f)$ vector, and with the MTRFs in the $d$ vector, the error function is

$$
\varepsilon=e^{T} e=d^{T} d+(m f)^{T}(m f)-2(m f)^{T} d .
$$

Regardless of whether we use Eq. (A23a) or (A23b) for ( $m f)$, we find that

$$
(m f)^{T}(m f)=\left(m^{T} m\right)\left(f^{T} f\right)
$$

that is, the product of the squared lengths of the $m$ and $f$ vectors. Define the $D$ matrix as below:

$$
D=\left[\left(\dot{M}_{1}\right)\left(\dot{M}_{2}\right)\left(\dot{M}_{3}\right)\left(\dot{M}_{4}\right)\left(\dot{M}_{5}\right)\right] .
$$

If we use Eq. (A23a) to extract the $f$ vector from (mf), then Eq. (A24) becomes

$$
\varepsilon=d^{T} d+\left(m^{T} m\right)\left(f^{T} f\right)-2 f^{T} D m
$$

and a similar development based on Eq. (A23b) results in

$$
\varepsilon=d^{T} d+\left(m^{T} m\right)\left(f^{T} f\right)-2 m^{T} D^{T} f .
$$

Equations (A27) and (A28) are virtually identical because: $m^{T} D^{T} f=f^{r} D m$.

The least squares normal equations are obtained by finding the minimum in the error surface with respect to the model parameters. If the error surface is quadratic with respect to the model parameters, then setting the equations of the partial derivatives of $\varepsilon$ (with respect to each model parameter) equal to zero results in linear equations for the model parameters. Equation (A28) represents a quadratic surface for $m$, keeping $f$ fixed, and it is also a quadratic surface for $f$, keeping $m$ fixed. However, if we form a model vector that combines both $f$ and $m$, i.e., 
$h^{T}=\left(f^{T}, m^{T}\right)$, we encounter the problem that $\left(m^{T} m\right)\left(f^{T} f\right)$ term in the above equation displays a fourth-order dependence on components of the model vector. On the other hand, the last term in the above equations presents no problems. We shall return to analyze this nonlinear character, but first let us write down the separate normal equations for $f$ and $m$ :

$$
\begin{gathered}
\left(m^{T} m\right) I_{f} f=D m \\
\left(f^{T} f\right) I_{m} m=D^{T} f
\end{gathered}
$$

where $I_{f}$ is the identity matrix with dimension that corresponds to the number of elements in $f$, and $I_{m}$ is the same for $m$. The above two systems of equations cannot be solved simultaneously as a linear system due to the scalar factors on the LHS. However, if we consider (A29a) and (A29b) as two distinct systems, we have as solutions for $f$ and $m$ :

$$
\begin{aligned}
f & =\left(1 / m^{T} m\right) D m \\
m & =\left(1 / f^{T} f\right) D^{T} f .
\end{aligned}
$$

Thus, Eq. (A30a) gives the best $f$, for a given specified $m$; while Eq. (A30b) gives the best $m$, for a given specified $f$. This pair of equations can be used to find $f$ and $m$ by the "bouncing" method of alternating back and forth with the updated $f$ and $m$ vectors. To start this procedure, one must provide some initial estimate for $m$, or $f$, that is nonzero. We need to know whether this procedure converges, and if a unique solution exists.

\section{A3.3 Omnilinear formulation}

The special structure of this nonlinear inverse problem allows an omnilinear formulation of the problem, with certain restrictions. Using Eqs. (A20) and (A23a), we can write the statistical estimation problem

$$
\left[\begin{array}{llll}
m_{1}, & & & 0 \\
\hdashline & m_{2} & & \\
& \ddots & \\
0 & & & m_{5}
\end{array}\right]\left[\begin{array}{c}
I \\
\hdashline I \\
\hdashline \vdots \\
\hdashline I
\end{array}\right] f=\left(\begin{array}{c}
\dot{M}_{1} \\
\hdashline \dot{M}_{2} \\
\hdashline \vdots \\
\hdashline \dot{M}_{5}
\end{array}\right] .
$$

The purely diagonal matrix of $m_{i}$ 's can be inverted, but ONLY if none of the $m_{i}$ 's are equal to zero. If we proceed with this assumption, we can extract the $\left(1 / m_{i}\right)$ components as a vector on the RHS as

$$
\left[\begin{array}{c}
I \\
\hdashline I \\
\hdashline \vdots \\
\hdashline I
\end{array}\right] f=\left(\begin{array}{cccc}
{\left[\dot{M}_{1}\right]} & & & 0 \\
& {\left[\dot{M}_{2}\right]} & & \\
& & \ddots & \\
0 & & & {\left[\dot{M}_{5}\right]}
\end{array}\right]\left[\begin{array}{c}
1 / m_{1} \\
1 / m_{2} \\
\vdots \\
1 / m_{5}
\end{array}\right) \text {. }
$$


Thus, we have an omnilinear problem for the estimation of $f$ and $\left(1 / m_{1}, \ldots, 1 / m_{5}\right)$, which could be solved for an unconstrained $\left(1 / m_{1}, \ldots, 1 / m_{5}\right)$ vector and a $f$ vector with the unit area constraint of: $\sum_{i} f_{i}=1$. However, examination of this solution shows that the moment tensor components $\left(m_{1}, \ldots, m_{5}\right)$ derived from the $\left(1 / m_{1}, \ldots, 1 / m_{5}\right)$ vector have the undesirable property that the $m_{i}$ are larger for a smaller correlation between $f$ and the individual MTRFs. Thus, the omnilinear formulation of this problem is NOT recommended for two reasons: (1) it presumes that none of the moment tensor components are zero-this condition is artificially restrictive; (2) the resultant solution for $m$ has undesirable statistical properties.

\section{A3.4 Global solution}

The basic fact that we reparameterize the MTRFs into the product of two model components forces us to eventually prescribe additional information. The reason for this requirement is that: if we find an $f$ and $m$ that equals $M$, i.e. $(m f)=M$, we can always multiply all components of $m$ by an arbitrary nonzero number $c$, and divide all components of $f$ by that same number, and the resultant $(m f)$ is exactly the same. Thus, the reparameterization of the model description from the MTRFs to $f$ and $m$ must be accompanied by some constraint equation on either $f$ or $m$. Perhaps the most common choice for a constraint equation is to assign unit area to $f$ : i.e. $\Delta t_{f} \sum_{i} f_{i}=1$, where $\Delta t_{f}$ is the sampling interval of the time function. An example of a constraint equation for $m$ is: $m^{T} m=1$.

Note that we must also assign units to $f$ and $m$. Their product must have the units of moment rate, but there is no unique choice for dividing the units between $f$ and $m$. A common choice is to split the units such that $f$ has units of ( $1 /$ time), and then $m$ has units of (seismic moment). This choice motivates the above constraint equation of $\Delta t_{f} \sum_{i} f_{i}=1$. In other applications, $m$ is chosen to be dimensionless, and $f$ carries the units of (moment rate). For the following applications, we let $m$ have units of (moment).

Recalling Eq. (A28), we see that choosing the constraint equation to be either $\left(m^{T} m\right)=1$ or $\left(f^{T} f\right)=1$ is a judicious choice because it removes the nonliner coupling between $f$ and $m$. For example, choose $m^{T} m=1$, and then the least squares solution for $f$, Eq. (A30a), becomes

$$
f=D m \text {. }
$$

Equation (A30b) is no longer valid because it was derived for an unconstrained $m$. But we can substitute the above solution for $f$ into the error function, Eq. (A28), to obtain

$$
\xi=d^{T} d-m^{T} D^{T} D m .
$$

We can now minimize $\xi$ with respect to $m$ by analysis of the above scalar equation. To proceed, first recognize that $D^{T} D$ is a positive definite matrix with dimensions of $5 \times 5$, and the $i$ th diagonal component is the squared length of the $i$ th MTRF. 
Now notice that $d^{T} d$ can be written as: $d^{T} d=\left|\dot{M}_{1}\right|^{2}+\cdots+\left|\dot{M}_{5}\right|^{2}$. Thus, $d^{T} d$ equals the trace of the $D^{T} D$ matrix. Now note that the maximum value of the eigenvalues of $D^{T} D$ is trace $\left(D^{T} D\right)=d^{T} d$, and this maximum value is only obtained if all other eigenvalues are zero. With the constraint of $m^{T} m=1$, we thus have the upper bound on the second term of Eq. (A34):

$$
m^{T} D^{T} D m \leq d^{T} d .
$$

Thus the overall minimum value of $\xi$ is achieved by the maximum value of $\left(m^{T} D^{T} D m\right.$ ), which is achieved by choosing $m$ as the eigenvector associated with the largest eigenvalue of $D^{T} D$. Zero error is only achieved when there is only one linearly-independent column vector of $D$, or in other words, when all MTRFs share the same shape.

The above analysis provides a unique solution for $m$ and $f$ with the following exceptions: (1) in all situations, all components of $f$ and $m$ can be multiplied by -1 ; (2) in special pathological circumstances, there may be two or more eigenvalues of $D^{T} D$ that have the same maximum value. The ambiguity presented by the first exception is easily resolved by choosing the sign of $f$ to make it mostly positive. If the second exception is encountered in applications, then it probably means that the earthquake cannot be represented by a single $f$ and $m$.

The basic idea of analyzing the $D$ matrix to find a solution for $m$ associated with the largest eigenvalue was advocated by VASCO (1988). We now see that there is a statistical basis for this approach in that it minimizes the least squares error between the synthetic and "observed" MTRFs, when combined with Eq. (A23) for the determination of $f$, plus the original constraint condition of $m^{T} m=1$. Are there other solutions associated with other constraint conditions that further minimize $\xi$ ? Another option that can be easily analyzed would be to choose $\left(f^{T} f\right)=1$. Then, we have $m=D^{T} f$ and substitution of this solution for $m$ into Eq. (A28) produces

$$
\xi=d^{T} d-f^{T} D D^{T} f .
$$

This scalar equation is complementary to Eq. (A34) for $m$. While the $\left(D D^{T}\right)$ matrix has the dimensions of $f$, it is still easily seen that $\operatorname{Trace}\left(D D^{T}\right)=d^{T} d$. Therefore, the minimum of the error function is the same number as above, and is found by choosing $f$ as the eigenvector for the largest eigenvalue of $\left(D D^{T}\right)$. Does this complementary solution produce the same $f$ and $m$ as above, possibly scaled by a constant? We let the readers ponder this question.

Given the above assurances that a global solution can be found, does the "bouncing" method of Eqs. (A30a,b) also find this globally best solution? Let's write our initial guess of the $m$ vector as: $m_{\text {init }}=\alpha \mu_{1}+\beta \mu_{2}+\ldots$, where $\mu_{1}$ is the eigenvector associated with the largest eigenvalue of $D^{T} D, \lambda_{1}$, and $\mu_{2}$ is the eigenvector for the next largest eigenvalue, $\lambda_{2}$, etc. Then Eq. (A30a) gives: $f_{\text {init }}=$ $\left(1 / m_{\text {init }}^{T} m_{\text {init }}\right) D m_{\text {init }}$. Substitution of this expression back into the least squares 
PAGEOPH,

equation for $m$, Eq. (A30b), provides the "Ith" estimate for $m$

$$
m_{I}=\left(1 / f_{\text {init }}^{T} f_{\text {init }}\right)\left[\lambda_{1} \alpha \mu_{1}+\lambda_{2} \beta \mu_{2}+\ldots\right] .
$$

Thus the first iteration for $m$ changes the direction of the $m_{\text {init }}$ vector by emphasizing the contribution of $\mu_{1}$ since each eigenvector contribution is multiplied by its eigenvalue. It is easy to generalize the "bouncing" method to show that the $N$ th estimate for $m$ will be

$$
m_{N}=\left(1 / f_{N-1}^{T} f_{N-1}\right)\left[\lambda_{1}^{N} \alpha \mu_{1}+\lambda_{2}^{N} \beta \mu_{2}+\ldots\right] .
$$

We see that as $N$ obtains a large value, the first eigenvector will dominate the $m$ vector, though of course we must renormalize the length of the $m$ vector in the end. Thus, as long as there is a distinct maximum eigenvalue of $D^{T} D$, then the "bouncing" method will converge to the overall globally best solution, unless our initial choice for $m$ is exactly orthogonal to $\mu_{1}$. If the only nonzero eigenvalue if $\lambda_{1}$, then the "bouncing" method will find the exact answer in one iteration. In practice, if $\lambda_{1}$ is about one hundred times larger than $\lambda_{2}$, then we find the solution in one iteration or so.

\section{A3.5 Extraction analysis with covariance}

The error function normalized by the inverse of the MTRF covariance matrix is

$$
\xi=e^{T}\left[\mathrm{Cov}^{-1}\right] e .
$$

Similar to above, we can derive two systems of equations by separately seeking the minimum of $\xi$ with respect to $f$ and $m$

$$
\begin{gathered}
f=\left[m_{i} m_{j} \operatorname{Sub}_{i j}\right]^{-1}[I|I| \cdots \mid I] \hat{M} \hat{d} \\
m=\left[\hat{F}^{T} \hat{F}\right]^{-1} \hat{F}^{T} \hat{d}
\end{gathered}
$$

with the definitions,

$$
\begin{aligned}
& \hat{d}=\left[\operatorname{Cov}^{-1 / 2}\right] d \\
& \hat{\mathscr{H}}=\left[\begin{array}{cccc}
m_{1} & & & 0 \\
& m_{2} & & \\
0 & \ddots & m_{5}
\end{array}\right]\left[\mathrm{Cov}^{-1 / 2}\right] \\
& \hat{F}=\left[\operatorname{Cov}^{-1 / 2}\right]\left[\begin{array}{cccc}
{[f]} & & & 0 \\
& {[f]} & & \\
0 & & \ddots & \\
0 & & & {[f]}
\end{array}\right]
\end{aligned}
$$

and where $\operatorname{Sub}_{i j}$ is a submatrix of the $\left[\mathrm{Cov}^{-1}\right]$, where $\left[\mathrm{Cov}^{-1}\right]$ is divided into 
twenty-five submatrices, the divisions corresponding to the five MTRFs. The pair of equations (A40a,b) allows us to find $f$ and $m$ by the "bouncing" method. Can we also perform a global analysis of the error function, similar to above? If we substitute the least squares solution for $f$ back into Eq. (A39), we find

$$
e^{T}\left[\mathrm{Cov}^{-1}\right] e=d^{T}\left[\mathrm{Cov}^{-1}\right] d-m^{T} \hat{D}^{T}\left[m_{i} m_{j} \operatorname{Sub}_{i j}\right]^{-1} \hat{D} m
$$

where

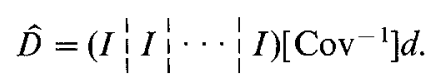

To find $m$ from this equation, we must extract an $m$ vector from the middle matrix of the second term:

$$
\left(m_{i} m_{j} \operatorname{Sub}_{i j}\right)^{-1} .
$$

Equation (A44) indicates that we must sum together the 25 submatrices of [ $\left.\mathrm{Cov}^{-1}\right]$, each submatrix multiplied by $m_{i} m_{j}$, and then invert the resultant matrix. If we allow $\left[\mathrm{Cov}^{-1}\right]$ to have nonzero off-diagonal values, then we cannot extract $m$ from the above matrix.

If the $\left[\mathrm{Cov}^{-1}\right]$ matrix is diagonal, then the problem is tractable, and it becomes quite straightforward if we assign a single value of covariance to each MTRF. Then all submatrices are zero except for $i=j$, where the five diagonal submatrices are: $\operatorname{Sub}_{i i}=\left(1 / s d_{i}^{2}\right) I_{f}$. We can then write Eq. (A44) as

$$
\left(m_{i} m_{j} \mathrm{Sub}_{i j}\right)^{-1}=\left(1 /\left(m_{1}^{2} / s d_{1}^{2}+m_{2}^{2} / s d_{2}^{2}+\cdots+m_{5}^{2} / s d_{5}^{2}\right)\right) I_{f} .
$$

Equations (A42) then becomes

$$
\begin{aligned}
& e^{T}\left[\mathrm{Cov}^{-1}\right] e=\hat{d}^{T} \hat{d}-\hat{n}^{T} \hat{D}^{T} \hat{D} \hat{n}
\end{aligned}
$$

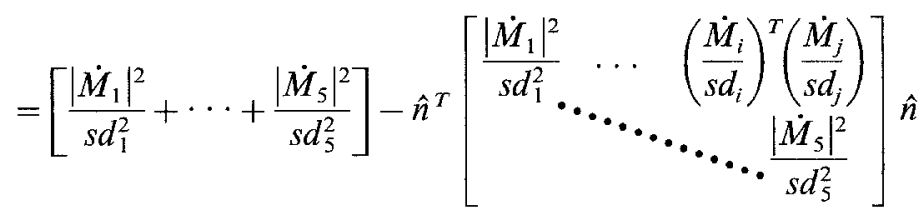

with the modified $m$ vector,

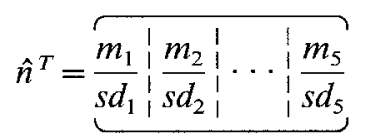

and explicit use of the constraint relation,

$$
\hat{n}^{T} \hat{n}=1 .
$$

We also have the reduced form of the covariance-weighted least squares solution for $f$

$$
f=\hat{D} \hat{n} .
$$


The error function in Eq. (A46) has the same structure as the one analyzed in the problem with no covariance estimates. As a consequence, we are again guaranteed of finding the overall best solution with the following prescription:

(1) Normalize the MTRFs by dividing each MTRF by the average standard deviation for that MTRF.

(2) Assemble the MTRFs into the $\hat{D}$ matrix.

(3) Find the eigenvalues and eigenvectors of the $\hat{D}^{T} \hat{D}$ matrix.

(4) The best $\hat{n}$ is the eigenvector for the largest eigenvalue, and $m$ is found by multiplying $\hat{n}$ by the standard deviations for each MTRF, i.e., $m_{i}=s d_{i} \hat{n}_{i}$.

(5) The best $f$ is found from the relation: $f=\hat{D} \hat{n}$.

(6) Change the scaling for $f$ and $m$ such that $\Delta t_{f} \sum_{i} f_{i}=1$, and then the $m_{i}$ 's will be in units of seismic moment.

As before, we also know that the "bouncing" method will arrive at the same globally best solution. RUFF and TICHELAAR (1990) used the above simplification of the covariance matrix and the "bouncing" method to find the best $f$ and $m$ for the 1989 Loma Prieta earthquake. The advantage of using the simplified covariance matrix is that we know a global solution exists and that we will find that solution. On the other hand, we would like to use the full covariance matrix as there might be significant trade-offs between components of the MTRFs. At this point, we can only use the full covariance matrix with the "bouncing" method. In the applications in the main text, we will show results for use of the full covariance matrix.

\section{A3.6 Formal analysis of the adequacy of a single $f$ and $m$ with the full covariance matrix}

The above analysis shows that the best $f$ and $m$ exist and can be found under certain conditions. We now return to the central scientific question as to whether the earthquake is adequately represented by the best $f$ and $m$. For the case where we consider the covariance matrix to be diagonal, we can use the same arguments and graphical display as in Figure 2 of the main text. If we allow a covariance matrix with significant off-diagonal values, then it is possible that the synthetic MTRFs will fall outside the error bounds based on the diagonal elements, but in fact the synthetic MTRFs are within the higher-dimension error ellipsoid of the full covariance matrix. While a full graphical picture of the situation is not practical, it is possible to reduce this scientific test to a single number. Recall that the error function is given by

$$
\xi=e^{T}\left[\mathrm{Cov}^{-1}\right] e .
$$

We see that the above scalar function is nondimensional. We can attach significance to the numerical value of $\xi$ by considering a diagonal covariance matrix, then let each component of $e$ equal the standard deviation of that component

$$
\zeta=\sum_{i=1, N}\left(s d_{i}^{2} / s d_{i}^{2}\right)=N
$$


where $N$ is the total number of components of the $e$ vector. We could choose $\xi \leq N$ as our condition for an acceptable error vector, hence acceptance of a single $f$ and $m$ to represent the earthquake. Of course, an error vector that has all zeros except for one value that was a factor of $N$ greater than its standard deviation would produce the same number for $\xi$; and this would also be considered as acceptable with the above criterion. To find the most suitable choice for the numerical value of $\xi$, write the components of the error vector as the ratio of the error to the standard deviation

$$
e_{i}=r_{i} s d_{i}
$$

Since the covariance matrix can be diagonalized, we can use a diagonal matrix for $\left[\mathrm{Cov}^{-1}\right]$ in this discussion without loss of generality. Then for the case of a diagonal covariance matrix, but with different diagonal values, we have

$$
\xi=e^{T}\left[\operatorname{Cov}^{-1}\right] e=\sum_{i=1, N} r_{i}^{2} .
$$

If the $e_{i}$ are in fact normally distributed, then the expected values of $r_{i}$ should follow the normal distribution with zero mean and unit variance. If we assign an occurrence frequency to values of $r_{i}$ based on the normal distribution, we find that for a sufficient number of components, the summation in Eq. (A51) equals $N$. This expectation is well-satisfied for $N=100$ or more; clearly it may not be satisfied for small values of $N$ less than 10. A typical size for $N$ in our applications is about 50 to 100 . Thus, we can characterize the overall consistency of a single time function and moment tensor with the MTRFs and their covariance by calculating the normalized scalar error, $\zeta$ (see Fig. Al for simplified view):

$$
\zeta=\xi / N=e^{T}\left[\mathrm{Cov}^{-1}\right] e / N .
$$

If $\zeta \leq 1$, then the synthetic MTRF vector falls within the contour of the multidimensional error ellipse expected from the covariance matrix and normal distribution of errors. In applications, we will show the graphical representation of the

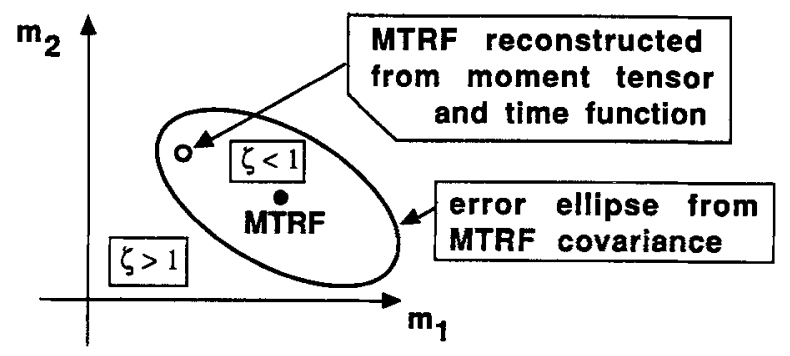

Figure Al

Pictorial representation of the MTRF parameter, $\zeta$. Basic concept is illustrated for MTRFs with only two components, $m_{1}$ and $m_{2}$. Solid dot shows the MTRF solution, error ellipse is centered on MTRF. After finding the best moment tensor and time function, the reconstructed MTRF is shown as open dot. If this reconstructed MTRF is within the error ellipse, $\zeta<1$; if it is outside, then $\zeta>1$. 
error bounds from the diagonal elements of the covariance matrix, i.e., Figure 2 in the main text, in addition to quoting a value of $\zeta$, which is referred to as the "MTRF parameter" in the plots (see Fig. 3 in text).

\section{A3.7 Error estimates of $f_{\text {best }}$ and $m_{\text {best }}$ and overall match to data}

We are still not finished in our statistical analysis of the MTRF inverse problem. Let us suppose now we have $f_{\text {best }}$ and $m_{\text {best }}$, and we find them to be an adequate representation of the earthquake from the above error analysis. We should provide error estimates for $f_{\text {best }}$, and especially for $m_{\text {best }}$ since we must perform further analysis of the moment tensor to find $M_{0}$ and the faulting geometry of the major double couple. We use linear error estimation by choosing Eq. (A40b) for the basic least squares solution of $m$ given $f_{\text {best }}$. Thus, the covariance matrix for $m_{\text {best }}$ is then

$$
\left[\operatorname{Cov} m_{\text {best }}\right]=\left[\hat{F}^{T} \hat{F}\right]^{-1} \hat{F}^{T}\left[\operatorname{Cov}^{-1}\right] \hat{F}\left[\hat{F}^{T} \hat{F}\right]^{-1} .
$$

Of course, we can simply quote individual standard deviations of each $m_{i}$ by taking the square root of the diagonal elements of the above covariance matrix. This is easily accomplished, and previous investigators do give error estimates of the $m_{i}$, e.g., the Harvard CMT solutions. At this point it is not clear how to use these error estimates since the eigenvalue analysis of the moment tensor displays a nonlinear dependence on the original components of the moment tensor, and further nonlinear relationships are introduced when converting the $t$ and $p$ eigenvectors into fault strike, dip, and slip rake angles. Fortunately, new computer-intensive methods in statistics are now being used that circumvent these analytical difficulties (see TICHELAAR and RUFF, 1991). Resampling methods such as bootstrapping and jackknifing can find error estimates on final model parameters even if the connection is nonlinear and the error distribution is unknown. Our problem is a nonlinear mapping from the five components of $m_{i}$ to five other parameters: (1) $M_{0} ;(2) \%$ second double; (3) fault strike; (4) fault dip; and (5) slip vector rake angle. We use a somewhat primitive form of resampling where $m_{\text {test }}$ is systematically varied about $m_{\text {best }}$ by the standard deviations; the resultant determinations of the above five variables are then analyzed to determine the mean and standard deviation of each variable. It is more complicated to display the covariance between the five derived parameters. The best way to show covariance between the focal mechanism parameters is to simply plot all the focal mechanisms. Another simple approach is to plot four of the parameters versus the one parameter that shows the most variation. Since the resampling scheme is not exhaustive, we consider these error estimates of $M_{0}$ and faulting geometry to be lower bounds on the true errors. Indeed, for the Mexico earthquakes, errors in the focal mechanism geometry due to depth uncertainty are greater than the above formal errors.

The MTRF inversion method also tests the match between synthetic and observed seismograms at every step of the reduction from MTRFs to a single time function and double couple. For any estimate of the MTRFs in $m$, the discretized 
synthetic seismograms are: $d_{\mathrm{syn}}=A m$. The match between $d_{\mathrm{syn}}$ and $d$ is measured by the correlation coefficient

$$
c c=\left(1 /\left|d_{\mathrm{syn}}\right||d|\right) d_{\mathrm{syn}}^{T} d
$$

where $c c$ is 1 for a perfect match, and 0 if $d_{\mathrm{syn}}$ is orthogonal to $d$. The correlation coefficient measures the match to data without regard to any slight scaling mismatches that might arise as the MTRFs are reduced to $f$ and a focal mechanism. With the standard usage of MTRF inversion, there are three values of $c c$ that are calculated:

(1) when $m$ consists of the full MTRFs from the initial linear inversion;

(2) when $m$ is composed of a single $f$ and moment tensor extracted from the MTRFs; and

(3) when $m$ is composed of a single $f$ and the major double couple from the moment tensor.

Our experience with MTRF inversion shows that $c c$ for above cases \#2 and \#3 is much more sensitive to variations in the key parameters that are used to construct the Green's functions. The one key seismological parameter is earthquake depth. For most earthquake studies, the best depth is determined by repeating the MTRF inversion at several trial depths, we then choose the depth that produces the best overall match to the seismograms, as measured by $c c$. The peak in $c c$ versus depth is typically better defined by $c c \# 2$ and \#3. It seems that omnilinear inversion for the MTRFs is quite good at matching seismograms, even if the MTRFs are "garbage" that vary widely. These "garbage" MTRFs present a "wild story" for the earthquake rupture, and hence the match to the data declines rapidly as we reduce the MTRFs to the simplest description of the earthquake with a single $f$ and $m$. Given the sensitivity of body wave Green's functions to depth for shallow earthquakes, proper use of MTRF inversion should always include analysis for the best depth.

There is one further option of the MTRF inversion method. This option uses $f_{\text {best }}$, but then determines the moment tensor by reinverting the seismograms for just the five components of $m$. In other words, the seismograms are inverted twice: (1) full MTRF inversion, followed by extraction of $f_{\text {best }}$; and then (2) $f_{\text {best }}$ is convolved with the Green's functions, and Eq. (7) in the main text is used to invert for the five independent components of the moment tensor. The reason for this complicated dual-inversion is to avoid the use of damping when inverting for the moment tensor. The $A$ matrix for the full MTRF inversion is poorly conditioned and the damped least squares inversion must be used, i.e., Eq. (A7). One problem with this damped inversion is that it preferentially eliminates the poorly resolved components of the model. While this consequence of damping on time functions is well-understood and acceptable, it potentially has the undesirable effect of reducing the contribution of some moment tensor elements. This effect could bias the resultant focal mechanism. Thus, the complex dual-inversion performs the second inversion 
for the moment tensor with zero damping. Use of this special option is reserved for final tests of the robustness of the MTRF results. After several tests, we found no scientifically significant results from applying the reinversion scheme to large Mexico earthquakes, but it might be useful for other earthquakes.

The technical details of the MTRF inversion methodology have now been covered in sufficient detail such that any investigator should be able to reproduce the technique and results shown here. In this paper, we have applied this methodology to large Mexican earthquakes. We anticipate many other exciting applications in future studies.

\section{REFERENCES}

AKI, K. (1979), Characterization of Barriers on an Earthquake Fault, J. Geophys. Res. 84, 6140-6148. AKI, K., and Richards, P. G., Quantitative Seismology (Freeman, San Francisco 1980) 932 pp.

Astiz, L., Kanamori, H., and EIssler, H. (1987), Source Characteristics of the Earthquakes in the Michoacan Seismic Gap in Mexico, Bull. Seismol. Soc. Am. 77, 1326-1346.

BARKER, J., and LANGSTON, C. (1981), Inversion of Teleseismic Body Waves for the Moment Tensor of the 1978 Thessaloniki, Greece Earthquake, Bull. Seismol. Soc. Am. 71, 1423-1444.

BeCK, S. L., and Christensen, D. H. (1991), Rupture Process of the February 4, 1965, Rat Islands Earthquake, J. Geophys. Res. 96, 2205-2221.

BECK, S., and RuFF, L. (1985), The Rupture Process of the 1976 Mindanao Earthquake, J. Geophys. Res. 90, 6773-6782.

BECK, S., and Ruff, L. (1987), Rupture Process of the Great 1963 Kurile Islands Earthquake Sequence: Asperity Interaction and Multiple Event Rupture, J. Geophys. Res. 92, 14123-14138.

BECK, S., and RUFF, L. (1989), Great Earthquakes and Subduction along the Peru Trench, Phys. Earth Planet. Int. 57, 199-224.

Byrne, D. E., DAvies, D. M., and Sykes, L. R. (1988), Loci and Maximum Size of Thrust Earthquakes and the Mechanics of the Shallow Region of Subduction Zones, Tectonics 7, 833-857.

Chael, E. P., and StewART, G. S. (1982), Recent Large Earthquakes along the Middle America Trench and their Implications for the Subduction Process, J. Geophys. Res. 87, 329-338.

DAS, S., and AKı, K. (1977), Fault Planes with Barriers: A Versatile Earthquake Model, J. Geophys. Res. $82,5658-5670$.

DeMets, C., Gordon, R. G., Argus, D. F., and Stein, S. (1990), Current Plate Motions, Geophys. J. Int. 101, 425-478.

Dewey, J. W., and SPENCE, W. (1979), Seismic Gaps and Source Zones of Recent Large Earthquakes in Coastal Peru, Pure and Appl. Geophys. 117, 1148-1171.

DMowskA, R., and LI, V. C. (1982), A Mechanical Model of Precursory Source Processes for Some Large Earthquakes, Geophys. Res. Lett. 9, 393-396.

Dziewonski, A. M., and Woodhouse, J. H. (1983), An Experiment in Systematic Study of Global Seismicity: Centroid Moment Tensor Solutions for 201 Moderate and Large Earthquakes of 1981, J. Geophys. Res. 88, 3247-3271.

Eissler, H., Astiz, L., and Kanamori, H. (1986), Tectonic Setting and Source Parameters of the September 19, 1985 Michoacan, Mexico Earthquake, Geophys. Res. Lett. 13, 569-572.

Ekström, G. (1989), A Very Broad Band Inversion Method for the Recovery of Earthquake Source Parameters, Tectonophysics $166,73-100$.

Ekström, G., and Dziewonski, A. M. (1986), A Very Broad Band Analysis of the Michoacan, Mexico Earthquake of September 13, 1985, Geophys. Res. Lett. 13, 605-608.

Gettrust, J. F., Hsu, V., Helsley, C. E., Herrero, E., and Jordan, T. (1981), Pattern of Seismicity Preceding the Petatlan Earthquake of 14 March 1979, Bull. Seismol. Soc. Am. 71, 761770 . 
GutenberG, B., and Richter, C. F. (1956), Magnitude and Energy of Earthquakes, Ann. Geofis. Rome $9,1-15$.

Haskell, N. A. (1964), Total Energy and Energy Spectral Density of Elastic Wave Radiation from Propagating Faults, Bull. Seismol. Soc. Am. 54, 1811-1842.

Haskov, J., Singh, S. K., Nava, E., Dominguez, T., and Rodriguez, M. (1983), Playa Azul, Michoacan, Mexico Earthquake of 25 October $1981\left(M_{s}=7.3\right)$, Bull. Seismol. Soc. Am. 73, 449-457.

Hotelling, H. (1936), Relation between Two Sets of Variates, Biometrika 28, 321-377.

Houston, H., and Kanamori, H. (1986), Source Characteristics of the 1985 Michoacan, Mexico Earthquake at Periods of 1 to 30 Seconds, Geophys. Res. Lett. 13, 597-600.

Hsu, V., Helsley, C. E., Berg, E., and Novelo-Casanova, D. A. (1985), Correlation of Foreshocks and Aftershocks and Asperities, Pure and Appl. Geophys. 122, 878-893.

JARrard, R. D. (1986), Relation among Subduction Parameters, Rev. Geophysics 24, 217-284.

Kanamori, H. (1977), The Energy Release in Great Earthquakes, J. Geophys. Res. 82, 2981-2987.

KANAMORI, H., The nature of seismicity patterns before large earthquakes. In Earthquake PredictionAn International Review (D. Simpson and P. Richards, eds.) (AGU, Washington D.C. 1981) pp. 1-19.

Kanamori, H., Mori, J., Hauksson, E., Heaton, T., Hutton, L., and Jones, L. (1993), Determination of Earthquake Energy Release and $M_{L}$ Using TERRAscope, Bull. Seismol. Soc. Am. 83, $330-346$.

KIKuCHI, M., Strength and stickiness of earthquake source. In Proceedings of Internat. Sympos. Earthquake Source Physics and Earthquake Precursors (University of Tokyo, 1990) pp. 163-166.

KikUChI, M., and FUKaO, Y. (1988), Seismic Wave Energy Inferred from Long-period Body Wave Inversion, Bull. Seismol. Soc. Am. 78, 1707-1724.

Kostrov, B. V., and DAS, S., Principles of Earthquake Source Mechanics (Cambridge University Press, Cambridge 1988) $286 \mathrm{pp}$.

Lay, T., Kanamori, H., and RuFf, L. (1982), The Asperity Model and the Nature of Large Subduction Zone Earthquakes, Earthquake Pred. Res. 1, 3-71.

MADARIAGA, R. (1977), High-frequency Radiation from Crack (Stress Drop) Models of Earthquake Faulting, Geophys. J. Roy. Astron. Soc. 51, 625-651.

MCCAnn, W. R., and Habermann, R. E. (1989), Morphologic and Geologic Effects of the Subduction of Bathymetric Highs, Pure and Appl. Geophys. 129, 41-69.

MCNAlly, K. C., and Minster, J. B. (1981), Non-uniform Seismicity Rates along the Middle America Trench, J. Geophys. Res. 86, 4949-4959.

Mendez, A. J., and Anderson, J. G. (1991), The Temporal and Spatial Evolution of the 19 September 1985 Michoacan Earthquake as Inferred from Near-source Ground Motion Records, Bull. Seismol. Soc. Am. $81,844-861$.

MendozA, C. (1993), Coseismic Slip of Two Large Mexican Earthquakes from Teleseismic Body Waveforms: Implications for Asperity Distribution in the Michoacan Plate-boundary Segment, J. Geophys. Res. submitted.

Mendoza, C., and Hartzell, S. H. (1988), Aftershock Patterns and Mainshock Faulting, Bull. Seismol. Soc. Am. 78, 1438-1449.

Mendoza, C., and Hartzell, S. H. (1989), Slip Distribution of the 19 September 1985 Michoacan, Mexico Earthquake: Near-source and Teleseismic Constraints, Bull. Seismol. Soc. Am. 79, 655-669.

NABELEK, J., Determination of Earthquake Source Parameters from Inversion of Body Waves, Ph.D. Thesis (Mass. Inst. of Technol. Cambridge, 1984) $346 \mathrm{pp}$.

Nishenko, S. P. (1991), Circum-Pacific Seismic Potential: 1989-1999, Pure and Appl. Geophys. 135, $169-259$.

Nur, A., and Ben-Avraham, Z. (1983), Volcanic Gaps due to Oblique Consumption of Aseismic Ridges, Tectonophysics $99,355-362$.

OhNaKA, M. (1992), Earthquake Source Nucleation: A Physical Model for Short-term Precursors, Tectonophysics $211,149-178$.

Priestley, K. F., and MAsters, T. G. (1986), Source Mechanism of the September 19, 1985 Michoacan Earthquake and its Implications, Geophys. Res. Lett. 13, 601-604.

Reyes, A., Brune, J. N., and Lomnitz, C. (1979), Source Mechanism and Aftershock Study of the Colima, Mexico Earthquake of January 20, 1973, Bull. Seismol. Soc. Am. 69, 1819-1840. 
Riedesel, M. A., Jordan, T. H., Sheehan, A. F., and Silver, P. G. (1986), Moment-tensor Spectra of the 19 Sept. 85 and 21 Sept. 1985 Michoacan, Mexico Earthquakes, Geophys. Res. Lett. 13, $609-612$.

Rikitake, T. (1976), Recurrence of Great Earthquakes at Subduction Zones, Tectonophysics 35, $335-362$.

RUFF, L., Fault asperities inferred from seismic body waves. In Earthquakes: Observation, Theory, and Interpretation (Kanamori, H. and Boschi, E., eds.) (North-Holland, Amsterdam 1983) pp. 251276.

Ruff, L. (1984), Tomographic Imaging of the Earthquake Rupture Process, Geophys. Res. Lett. 11, $629-632$.

Ruff, L., Tomographic imaging of seismic sources. In Seismic Tomography (Nolet, G., ed.) (Reidel, Dordrecht, Holland 1987) $386 \mathrm{pp}$.

RUFF, L. (1989a), Do trench sediments affect great earthquake occurrence in subduction zones? In Subduction Zones, Part II (Ruff, L. and Kanamori, H., eds.), Pure and Appl. Geophys. 129, 263-282.

RuFF, L. J. (1989b), Multi-trace Deconvolution with Unknown Trace Scale Factors: Omnilinear Inversion of $P$ and $S$ Waves for Source Time Functions, Geophys. Res. Lett. 16, 1043-1046.

RuFf, L. J. (1992a), Asperity Distributions and Large Earthquake Occurrence in Subduction Zones, Tectonophysics $211,61-83$.

RUFF, L. J., Seismic energy release of great subduction earthquakes: Can irregular rupture models explain the "missing" energy? Extended Abstract in Wadati Conference on Great Subduction Earthquakes (Christensen, D., Wyss, M., Habermann, R., and Davies, J., eds.) (University of Alaska, Fairbanks 1992b) pp. 12-14.

Ruff, L., and Kanamori, H. (1983a), Seismic Coupling and Uncoupling at Subduction Zones, Tectonophysics 99, 99-117.

Ruff, L., and Kanamori, H. (1983b), The Rupture Process and Asperity Distribution of Three Great Earthquakes from Long-period Diffracted P Waves, Phys. Earth Planet. Int. 31, 202-230.

RufF, L., and TichelaAR, B. (1990), Moment Tensor Rate Functions for the 1989 Loma Prieta Earthquake, Geophys. Res. Lett. 17, 1187-1190.

SCHELl, M., and RUFF, L. (1989), Rupture of a Seismic Gap in Southeastern Alaska: The 1972 Sitka Earthquake $\left(M_{s}\right.$ 7.6), Phys. Earth Planet. Int. 54, 241-257.

SCHOLZ, C. H., The Mechanics of Earthquakes and Faulting (Cambridge University Press, New York 1990) 439 pp.

SCHWARTZ, S., and RufF, L. (1987), Asperity Distribution and Earthquake Occurrence in the Southern Kurile Islands Arc, Phys. Earth Planet. Int. 49, 54-77.

SingH, S. K., and LeRmo, J. (1985), Mislocation of Mexico Earthquakes as Reported in International Bulletins, Geof. Int. 24 (2), 333-351.

SinGH, S. K., and MorterA, F. (1991), Source Time Functions of Large Mexican Subduction Earthquakes, Morphology of the Benioff Zone, Age of the Plate, and their Tectonic Implications, J. Geophys. Res. 96, 21,487-21,502.

Singh, S. K., and Ordaz, M. (1993), Seismic Energy Release in Mexican Subduction Zone Earthquakes, preprint.

SingH, S. K., Rodriguez, M., and Espindola, J. M. (1984), A Catalog of Shallow Earthquakes of Mexico from 1900-1981, Bull. Seismol. Soc. Am. 74, 267-279.

SIPKIN, S. (1986a), Estimation of Earthquake Source Parameters by the Inversion of Waveform Data: Global Seismicity 1981-1983, Bull. Seismol. Soc. Am. 76, 1515-1541.

SIPKIN, S. (1986b), Interpretation of Non-double-couple Earthquake Mechanisms Derived from Moment Tensor Inversion, J. Geophys. Res. 91, 531-549.

Stolte, C., McNally, K. C., Gonzalez-Ruiz, J., Simila, G. W., Reyes, A., Rebollar, C., Munguia, L., and MendozA, L. (1986), Fine Structure of a Postfailure Wadati-Benioff Zone, Geophys. Res. Lett. 13, 577-580.

Stump, B. W., and Johnson, L. R. (1977), The Determination of Source Properties by the Linear Inversion of Seismograms, Bull. Seismol. Soc. Am. 67, 1489-1502.

Tajima, F., Ruff, L., Kanamori, H., Zhang, Z., and Mogi, K. (1990), Earthquake Source Processes and Subduction Regime in the Santa Cruz Islands Region, Phys. Earth Planet. Int. 61, 269-290. 
TichelaAr, B. W., Christensen, D. H, and RufF, L. J. (1992), Depth Extent of Rupture of the 1981 Chilean Outer-rise Earthquake as Inferred from Long-period Body Waves, Bull. Seismol. Soc. Am. 82, $1236-1252$.

TichelaAR, B. W., and Ruff, L. J. (1991), Seismic Coupling along the Chilean Subduction Zone, J. Geophys. Res. 96, 11,997-12,022.

TichelaAR, B. W., and RufF, L. J. (1993), Depth of Seismic Coupling along Subduction Zones, J. Geophys. Res. 98, 2017-2037.

UNAM SEISMology Group (1986), The September 1985 Michoacan Earthquakes: Aftershock Distribution and History of Rupture, Geophys. Res. Lett. 13, 573-576.

Uyeda, S., and Kanamori, H. (1979), Back-arc Opening and the Mode of Subduction, J. Geophys. Res. $84,1049-1061$.

Valdes, C., Meyer, R. P., Zuniga, R., Haskov, J., and Singh, S. K. (1982), Analysis of the Petatlan Aftershocks: Numbers, Energy Release, and Asperities, J. Geophys. Res. 87, 8519-8527.

VASCO, D. W. (1989), Deriving Source-time Functions Using Principal Component Analysis, Bull. Seismol. Soc. Am. 79, $711-730$.

Yomogida, K. (1988), Crack-like Rupture Processes Observed in Near-fault Strong Motion Data, Geophys. Res. Lett. 15, 1223-1226.

(Received April 27, 1993, revised/accepted January 11, 1994) 